\title{
Antibody-Conjugated Nanoparticles for Therapeutic Applications
}

\author{
M.M. Cardoso*, I.N. Peça and A. C. A. Roque \\ REQUIMTE, Departamento de Química, Faculdade de Ciências e Tecnologia, Universidade Nova de Lisboa, 2829 - 516 Caparica, \\ Portugal
}

\begin{abstract}
A great challenge to clinical development is the delivery of chemotherapeutic agents, known to cause severe toxic effects, directly to diseased sites which increase the therapeutic index whilst minimizing off-target side effects. Antibody-conjugated nanoparticles offer great opportunities to overcome these limitations in therapeutics. They combine the advantages given by the nanoparticles with the ability to bind to their target with high affinity and improve cell penetration given by the antibodies. This specialized vehicle, that can encapsulate several chemotherapeutic agents, can be engineered to possess the desirable properties, allowing overcoming the successive physiological conditions and to cross biological barriers and reach a specific tissue or cell. Moreover, antibody-conjugated nanoparticles have shown the ability to be internalized through receptor-mediated endocytosis and accumulate in cells without being recognized by the P-glycoprotein, one of the main mediators of multi-drug resistance, resulting in an increase in the intracellular concentration of drugs. Also, progress in antibody engineering has allowed the manipulation of the basic antibody structure for raising and tailoring specificity and functionality. This review explores recent developments on active drug targeting by nanoparticles functionalized with monoclonal antibodies (polymeric micelles, liposomes and polymeric nanoparticles) and summarizes the opportunities of these targeting strategies in the therapy of serious diseases (cancer, inflammatory diseases, infectious diseases, and thrombosis).
\end{abstract}

Keywords: Active targeting, antibody-conjugated nanoparticles, infectious diseases therapy, inflammatory diseases therapy, surface modification, targeted drug delivery, tumour therapy.

\section{INTRODUCTION}

Many new classes of drugs are being discovered and rational designed to treat severe diseases. However, they are often restricted by dose-limiting toxicity and exhibit poor specificity in reaching the desired organ/tissue/cell. A great challenge to clinical development is delivering these drugs precisely and safely to the sites they are needed at the proper dose for the required amount of time, therefore achieving the maximum therapeutic effect. The recent advances in nanotechnology have a great potential to improve the prevention, diagnosis, and treatment of human diseases. Cell targeting therapeutics conjugating specific recognizing units such as antibodies will allow to increase therapeutic efficacy and to decrease systemic adverse effects. This approach is of great interest in oncology, pharmacology, and nanomedicine.

\section{TARGETED DRUG DELIVERY}

The combination of targeted delivery and controlled drug release technology offer numerous advantages in chemotherapy: greater efficacy, because optimal concentration of active drug can be maintained on the desired local site thus decreasing the toxic side effects, and greater convenience because fewer applications or treatments are needed [1]. Nanoparticles (NPs) offer enormous advantages to be used as drug carriers due to their dimension and physical-chemical properties. A schematic presentation of a NP is shown in Fig. (1a). Their size ranging from $20 \mathrm{~nm}$ to $200 \mathrm{~nm}$ allows them to circulate in the blood or stay in the body for long periods, to pass through cell membranes and be internalized. Their high surface/volume ratio allows the incorporation of large amounts of two or more drugs for combination therapy, or for the simultaneously delivery of two or more therapeutic modalities such as radiation and drugs causing lower systemic toxicity when compared with drugs in solution, since drugs are encapsulated and biologically unavailable during transit in systemic circulation [2]. They can also improve the solubility of hydrophobic compounds, which has significant implications because more than $40 \%$ of active substances being identified through combinatorial screening

*Address correspondence to this author at the Requimte, Departamento de Química, Faculdade de Ciências e Tecnologia, Universidade Nova de Lisboa, 2825 Monte de Caparica, Portugal; Tel: 0035121 2948385; Fax: 0035121 2948550;

E-mail: mmcmac@fct.unl.pt programs are poorly soluble in water [3], and offer a protection against drug degradation and an enhancement in the stability of drugs such as peptides, oligonucleotides, DNA and RNA molecules, and so forth. Another advantage is the facilitation of drug delivery across various barriers, the most important of which is the blood brain barrier (BBB). NPs currently used include liposomes (L), polymeric nanoparticles (PNP), polymeric micelles (PM), dendrimers, gold NPs, quantum dots, carbon nanotubes, and nanofibers [4-8].

For an efficient treatment, the ideal drug carrier would have the ability to deliver the drug in the desired cell/tissue/organ - target. Targeted of therapeutic NPs in a cell-, tissue-, or disease-specific manner represents a potentially powerful technology $[9,10]$. Systemic delivery of targeted NPs presents great multidisciplinary challenges where for developing an effective drug delivery vehicle NPs must be engineered to possess the desirable properties capable of overcoming the successive physiological barriers/conditions they will encounter in their way to reach the target, and the ability to recognize the target cell, deliver the drug, or be internalized. This recognition capacity can be achieved by exploring the altered physiology of the diseased cells and tissues. Using smart materials, drug release can be triggered by the environment or other external events such as changes in $\mathrm{pH}$ and temperature that generally occurred in tumour tissues, the presence of an analyte such as glucose that occurred in diabetes or the increase in temperature that accompanies the inflammatory process. A more specific recognition can be obtained through molecules that are uniquely expressed or overexpressed by disease cells such as specific antigens, a carbohydrate or surface receptors. NPs may be functionalized by conjugating specific units such as antibody, lectins, peptides, proteins, DNA or RNA aptamers, and small molecules able to recognize those entities therefore delivering the drug to the desired target cells [9, 11] - active targeting - further increasing their specificity and efficacy. There has been an intensive research in the development of NPs as effective drug delivery systems for medical practice, especially for chemotherapy and gene delivery to which progresses in NP technology, material science, and cellular and molecular physiology and pathology have contributed [1, 12-19].

Monoclonal antibodies (MAbs) were the first class of targeting molecules and have been preferentially used due to their high affinity, specificity, and versatility. The development of chimeric, humanized and more recently the fully human antibodies or 


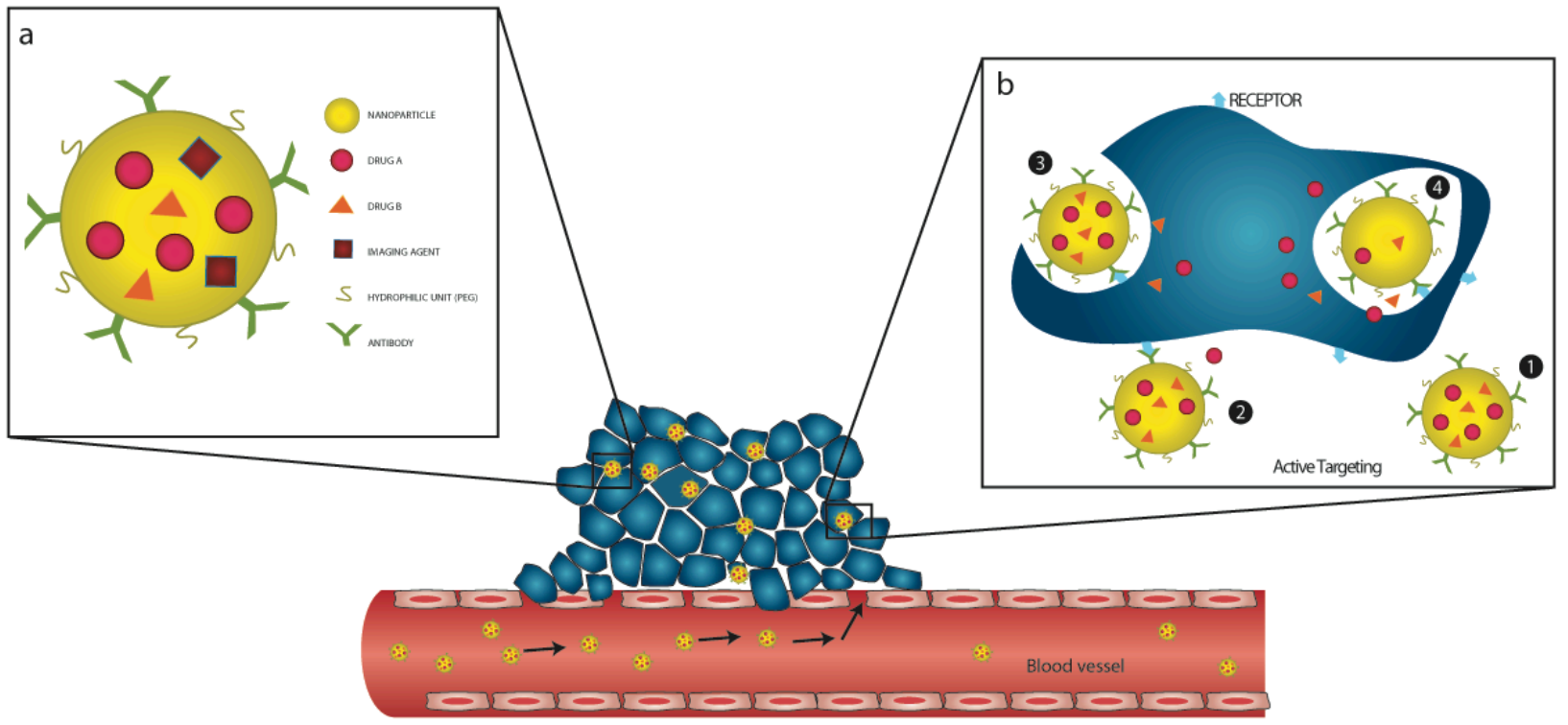

Fig. (1). (a) Schematic illustration of a multi-functional NPs. (b) NP drug delivery and internalization via RME. Specific antibodies on the NP surface bind to cell-surface receptors, which trigger internalization of the NPs into the cell. The drug will be released intracellulary on exposure to lysosomal enzymes or lower $\mathrm{pH}$. Drug-loaded NPs bypass the P-glycoprotein efflux pump leading to high intracellular drug concentration.

fragments produced in transgenic animals or through phage display technique $[20,21]$ has partially solved the rapid opsonization and immunogenicity caused with the first mouse MAbs used.

Due to the complexity of the body and its barriers, the efficiency of targeting NP accumulation to a specific cell/tissue/ organ is still a challenge. Effective targeting would require a dual focus strategy, a better understanding of the target/receptor and a simultaneous development of the targeting system.

Some therapeutic conjugates are now under clinical development or in clinical practice. However, the success has been largely limited to ligand-drug conjugates and attempts have been made to enhance these systems by encapsulating the therapeutic agents in NPs.

This review will focus on drug targeting strategies to treat severe diseases based on NPs surface functionalized with MAbs with potential clinical relevance. Different therapeutic applications and possibilities regarding PNP, L, and PM which have been conjugated with antibodies for the purpose of targeting therapy will be analyzed. The current statues of development will be reviewed and the challenges for developing improved drug delivery systems will be highlighted.

\section{MONOCLONAL ANTIBODIES AS TARGETING MOLE- CULES}

MAbs were first shown to be able to bind to specific tumour antigens in 1975 [22] but their use in cancer treatment took many years. The emergence of recombinant technologies has revolutionized the selection and production of MAbs, allowing the design of fully human antibodies of any specificity and for diverse purposes. Recombinant antibodies can be engineered with optimized properties, such as antigen-binding affinity, molecular architecture, and dimerization state, and fused with a vast array of effector moieties to enhance their cell-targeting ability and potency $[20,22]$.

\subsection{Antibody Engineering}

Antibodies or immunoglobulins occur naturally as part of the immune system of mammals by recognizing antigens and are produced by plasma B-cells [23]. The development of antibody engineering systems started in 1975 with the production of MAbs by the mouse hybridoma technology [22]. Since then, and with the need for antibodies with unique specificity and biopharmaceuticalgrade, antibodies and derived structures have been produced at large scale for various biomedical applications. The mouse hybridoma technology represents an almost universal method to produce antibodies against any desired antigen. This technology relies on the fusion of spleen cells from an immunized animal with myeloma cells to obtain hybridoma cells. Clones producing the desired MAbs are then further selected and screened. The majority of MAbs produced by hybridoma technology are murine monoclonal antibodies (MuMAbs), which are immunogenic when used as therapeutics in humans [24]. The induced human antimouse antibody (HAMA) response quickly reduces the effectiveness of therapy by clearing the murine antibody from the bloodstream. The generation of human monoclonal antibodies (HuMAbs) may be performed either by immortalization of human B-lymphocytes and subsequent fusion with neoplastic cells (fusion partners), or by transformation with Epstein-Barr virus. However, human hybridoma technology has been restricted by inefficient immortalization procedures and the ethically unacceptable immunization of humans [24]. The combination of hybridoma technology [22] with recombinant DNA technology and valuable display techniques $[25,26]$ made possible, in the $80 \mathrm{~s}$, the construction of humanized antibodies [27] with desirable affinity/specificity and low immunogenicity [28]. Over the last years, resources were therefore directed towards genetically engineering the basic immunoglobulin structure in order to produce new and versatile therapeutic agents.

\subsection{Structure of Antibodies}

Antibodies possess a similar basic structure in a Y form (Fig. 2a) of bifunctional molecules with two identical domains for antigen recognition ( $\mathrm{Fab}$ fragment), and two identical domains ( $\mathrm{Fc}$ fragment) [29] involved in effector functions and biodistribution of the antibody, linked via the flexible hinge region. These regions are part of two pairs of polypeptide chains folded into compact globular domains. Each heavy and light chain has a similar structure with 


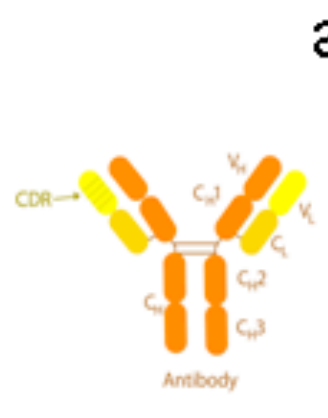

a

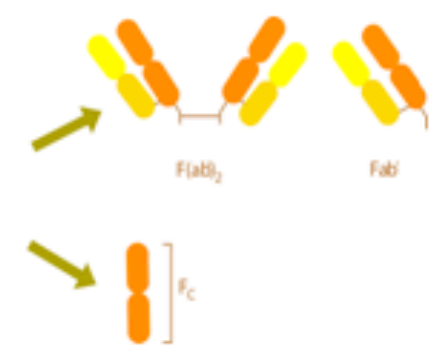

b
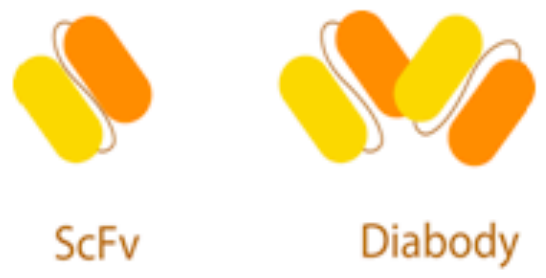

Fig. (2). (a) Structure of an IgG molecule. (b) Genetic construction of different antibody fragments.

constant and variable regions. The main differences observed in the variable regions are located in three small hypervariable sequences, responsible for antigen binding, the so-called complementary determining regions (CDR), and corresponding to the $N$-terminal regions of the light and heavy chains (Fab portion) [23]. Antibodies bind to target molecules with high affinity and specificity. The antigen-binding region is highly specific, and varies among the antibodies. Thousands of millions of different antibodies can be generated, each one with a distinct specificity [29].

\subsection{Engineered Antibody Structures}

A chimeric antibody is a combination of sequences from different species; the most common ones are those with a fully human sequence except for the variable regions, which are of murine origin. A chimeric antibody is an artificial molecule where the constant portions of the heavy and light chains are from a human $\mathrm{IgG}$, and the variable regions, $\mathrm{VH}$ and $\mathrm{VL}$, are obtained from a mouse or rat MAb. The aim of this construction is to reduce the immunogenicity of the mouse or rat antibodies, without affecting the specificity of the original antibody [29]. Efforts to reduce the immunogenicity of chimeric antibodies led to the creation, between 1988 and 1991, of "humanized" antibodies. These antibodies are less immunogenic, more effective and have a longer half-life than chimeric antibodies (4-15 days) [30, 31]. In humanized antibodies, only some small regions of the variable domains (called hypervariable regions or CDRs) belong to the original species, and the remainder has human sequences. The use of fully human MAbs reduces the possibility of an immune response. Human immunoglobulins interact better with human effector systems than antibodies of murine origin; there are differences associated to the distinct patterns of glycosylation among different species, which can affect the effectiveness of the antibody as a therapeutic agent; and the half-life of these antibodies is longer (11-24 days) [29].

Antibodies can also be engineered to obtain compact and multivalent structures as single-chain $\mathrm{Fv}$ antibody fragments $(\mathrm{scFv})$, diabodies, triabodies, bispecifics, minibodies [32] (Fig. 2b). Antibody fragments offer some advantages over intact antibodies in therapy. For instance, the speed of penetration by fragments is smaller than an intact antibody [9]. scFv incorporate a polypeptide chain to link VH and VL. This linker, of around 15 amino acids, has the necessary length and flexibility to permit an adequate spatial orientation of the $\mathrm{VH}$ and $\mathrm{VL}$ domains, generating a functional $\mathrm{Fv}$ of around $25 \mathrm{kD}$. Changing the linker length between V-domains creates new types of Fv modules [33]. If the linker is 512 residues long, a scFv molecule is constrained to associate with a second $\mathrm{scFv}$ to form a dimer [34]; and the $\mathrm{VH}$ and $\mathrm{VL}$ domains have the same specificity, the product obtained is a bivalent homodimer known as a diabody [35]. Using the same technique, it is possible to produce recombinant molecules with two different specificities, called bispecific antibodies [25]. If the linker length is below 3 residues, three scFvs are forced to associate into a trivalent dimer (triabody) or a tetramer, depending on linker length, composition and V domain orientation [36] (Fig. 2b). Minibodies are minimized antibody-like $\beta$-proteins that recognize target molecules with high specificity and affinity. This polypeptide has a length of 61 amino acid residues and adopts a conformation that has an antigen-binding ability, and appears to show excellent pharmacokinetic properties in tumours [37]. The phage display of minibodies has allowed the discovery of inhibitors to important biomolecules [38-40]. It has also been shown that scFvs selected from phage display can be improved into analogous minibody structures [41].

Today, over 200 delivery systems based on antibodies or their fragments are in preclinical or clinical trials [11, 42]. Some have already undergone clinical development and have been successful translated into the clinical environment. The first therapeutic antibody approved by FDA was rituximab $\left(\right.$ Rituxan $\left.^{\circledR}\right)$, which binds to CD20 for treating B-cell lymphoma, in 1977. However, the fact that some patients do not respond to the initial treatment or exhibit relapses over time has pushed this monotherapy towards a combination with chemotherapeutic agents. The conjugation of chemotherapeutic agents onto MAbs using a reversible linker is limited to less than ten drug molecules. So, in attempt to increase drug loading capacity and to provide some protection to these drugs, drugs can be encapsulated into NPs and the particle surface functionalized with MAbs to maintain targeting efficacy. While being therapeutic agents in their own right, these antibodies also have the ability to serve as recognizing units when attached to drug delivery systems for even more effective therapies. The feasibility of antibody based tissue targeting has been clinically demonstrated over the past two decades and was reviewed by Mehren and Weiner [43], and Weiner and Adams [43, 44].

Trastuzumab or Herceptin ${ }^{\circledR}$, which binds to HER-2, approved by FDA in 1998 for treating breast cancer, and rituximab have been conjugated to poly(lactic acid) (PLA) NPs, and the resulting conjugates exhibit a six-fold increase in the rate of particles uptake when compared with NPs without the MAb targeting molecule [45, 46].

\section{ANTIBODY FUNCTIONALIZED NANOPARTICLES}

Effective antibody-conjugated NPs must have the desirable properties capable to overcome the successive physiological barriers/conditions they will encounter in their way to reach the target, the ability to recognize and actively bind to target cells through specific antibody-receptor interactions, and being internalized when an intracellular delivery is intended. Antibodyconjugated NPs for therapeutic applications include among others PNP, L, and PM [29]. 


\subsection{Polymeric Micelles}

PM are super-molecular assemblies of amphiphilic copolymers that spontaneously associate in an aqueous phase. Their diameter does not exceed $100 \mathrm{~nm}$ and possess a core-shell structure. The core is composed of hydrophobic polymer blocks that can accommodate hydrophobic drugs, and the shell is a hydrophilic brush-like corona that makes the micelle water soluble, thereby allowing the delivery of the poorly soluble content. The attractive force leading to micellization is based on an interaction between the hydrophobic and electrostatically neutral parts of copolymers. Self-assembly starts when the copolymer concentration reaches the critical micelle concentration which is usually very low, increasing the likelihood of preserving the micellar structure after extreme dilution following intravenous administration to patients [47]. The hydrophobic blocks generally used are polyesters such as PLA, poly( $\varepsilon$-caprolactone) (PCL); poly(L-amino acid) such as poly(aspartic acid) and poly(glutamic acid); and, phospholipids such as phosphatidylethanolamine. The hydrophilic blocks commonly used are poly(ethylene glycol) (PEG) and poly(vinylpyrrolidone).

PM have several advantages over other drug delivery systems, including increased drug solubility, prolonged circulation half-life, and lower toxicity. However, at the present time this technology lacks the ability to control the release of the entrapped agents.

Currently, SP1049C [a formulation of doxorubicin (DOX)encapsulated pluronic micelles], NK911 [DOX-encapsulated micelles from a copolymer of PEG-DOX-conjugated poly(aspartic acid)], and Genexol-PM (a paclitaxel-encapsulated PEG-PLA micelle formulation) have been approved for clinical use [48].

\subsection{Liposomes}

$\mathrm{L}$ are vesicles composed of one (unilamellar) or several (multilamellar) phospholipid bilayers surrounding an internal aqueous compartment. They can incorporate both hydrophilic and hydrophobic substances in the internal aqueous phase and in the lipid bilayer, respectively. They are widely used because of their size, amphiphatic character, and tissue biocompatibility. The techniques of preparation have often been described in literature. Briefly, lipids are dissolved in an organic solvent. After evaporation of the solvent, a dry lipid film is obtained and is then dispersed in an aqueous phase. The different preparation procedures differ according to the method used to disperse the lipids (thin lipid film hydration, mechanical methods such as sonication, extrusion, etc.). Lipids generally used are cholesterol and phosphatidylcholine. The in vivo use of conventional L, however, is hampered by their rapid clearance from the circulation by the reticuloendothelial system (RES) [49] but extended circulation time can be achieved by grafting highly hydrophilic chains (e.g., PEG) to the surface of the L. Moreover, some L components inhibit the improvement of Pglycoprotein $(\mathrm{P}-\mathrm{gp})$ and consequently allow to reach a higher drug concentration inside the cells and show permeability across the BBB [50].

A Stealth ${ }^{\circledR}$ liposomal formulation of the anticancer drug DOX (Doxil $^{\mathbb{R}} /$ Caelyx $^{\circledR}$ ) was the first L delivery system to gain FDA approval in 1995 [51, 52] for the treatment of Kaposi's cancer and ovarian cancer. Other examples include DaunoXome ${ }^{\circledR}$ (daunorubicin L), DepotDur ${ }^{(}$(morphine L), and Ambisome $\left.{ }^{(}\right)$(amphotericine B L) [53]. Although no antibody-conjugated L [immunoliposomes (IL)] are yet in clinical use, extensive preclinical research activity is taking place in this area. However, some potential drawbacks like batch-to-batch variation in manufacturing, low drug loading efficiency, and poor stability can limit their market.

\subsection{Polymeric Nanoparticles}

PNP can be fabricated from a variety of biocompatible polymeric materials and hold sufficient strength and durability, which are a very important properties for many modes of targeting. PNP can encapsulate drugs or a combination of drugs, and release them in a controlled manner via diffusion of the drug through the polymer matrix, particle surface or bulk erosion, swelling followed by diffusion or in response to the local environment. Drug release mechanisms depend on the type/properties of the carrier and the type of interactions established between the drug and the polymeric matrix, and were extensively reviewed by Arifin et al. [54]. Consequently, it is possible to control the release rate and design these drug delivery systems by changing the NP properties. The release of the active agent may be constant over a long period, or may be triggered by the environment or other external events. In general, these systems can provide drug levels at an optimum range over a long period of time than other drug delivery methods, thus increasing the efficacy of the drug and maximizing patient compliance [55]. Polymers have a wide range of molecular weight and varying chemical composition which contribute to their versatility in structure and properties. Co-polymers and polymer blends can be adjusted to design the drug delivery vehicle for a specific application. Polymer blends also allow the production of particles containing two layers, commonly known as double walled particles, with advantages for clinical applications as they have the ability to deliver more than one drug or other active agent in a sequential manner and show a lower initial burst release [56-58].

Both natural (albumin, chitosan, heparin, etc.) as synthetic [PLA, poly (lactic-co-glycolic acid) (PLGA), poly(L-glutamate), PEG) biodegradable polymers are being exploited in drug delivery systems. Polymers or co-polymers comprising PLA, poly(glycolic acid), PLGA, PCL, PEG and poly(methyl methacrylate) have shown good histocompatibility and biodegradability, and are approved by the Food and Drug Administration (FDA) [59]. PLA, PGA, and their copolymer PLGA are the most commonly used biocompatible polymers for controlled release of drugs and have been extensively reviewed in the past [60-62].

Stimuli responsive polymers - smart polymers - can also be used to get target site delivery where drug release or cell internalization can be triggered by the environment or other external events. Stimuli may occur internally such as a change in $\mathrm{pH}$ in certain tissues or diseased states, a change in temperature or the presence of specific enzymes [63]. In tumour tissues, the $\mathrm{pH}$ can decrease to approximately 6.6 when compared to physiologic $\mathrm{pH}$ (7.4) therefore triggering the drug release. Micelles of PLA- $b$-PEG$b$-poly(L-histidine) triblock copolymer with a pKa of 7.0 have shown to release the drug at the slightly acidic tumour extracellular matrix [64]. NPs of glycol chitosan containing camptothecin have shown an accumulation 2 to 3 times higher at the tumour site than at the other organs and exhibited significant tumour effects [65-67]. Moreover, after cellular uptake, the drug can be released from the polymeric carrier under the acidic lysosomal $\mathrm{pH}$ (4.5 to 5.0) [68]. The most common $\mathrm{pH}$ sensitive polymers studied include poly(methacrylic acid), poly(acrylic acid), and poly(acrylamide) $[69,70]$. Also, temperature sensitive polymers can be used to produce drug carriers that will release the incorporated drug at temperatures higher than the critical solution temperature at which their physical state changes. An interesting application of thermoresponsive carriers is in hyperthermia treatment of cancer which is usually performed at $42{ }^{\circ} \mathrm{C}[71,72]$, and in the treatment of inflammatory tissues. Thus, thermo-responsive drug carriers should have their critical solution temperature above the $37{ }^{\circ} \mathrm{C}$ of the healthy body, and as close to $42{ }^{\circ} \mathrm{C}$ as possible. Examples of temperature-responsive polymers are poly( $N$-isopropylacrylamide), and poly( $N-(1)-1$-hydroxymethylpropylmethacrylamide) $[63,73]$.

Methods of preparation of NPs can be divided in two major classes, one dealing with monomers polymerization whereas the other involves dispersion of polymers such as salting out, solvent emulsification/diffusion, and nanoprecipitation [74], all involving chemical engineering techniques [17]. Higher entrapment efficiency 
can be achieved by incorporation of the drug during the process fabrication rather than adsorption on prepared NPs. PNP are mainly prepared using the emulsion/solvent evaporation technique or the precipitation solvent diffusion technique. In the first method, polymers are dissolved in an organic solvent immiscible to water (such as dicloromethane, chloroform, ethyl acetate) and emulsified in an aqueous phase generally containing an emulsifying agent [mainly poly(vinyl alcohol) (PVA) and sodium cholate] by high speed homogeneization or sonication to make an oil-in-water emulsion. Hydrophobic compounds (drug or else) to be incorporated are dissolved in the organic phase. For water soluble drugs, the technique is slightly modified to form a water-in-oil-inwater emulsion [75]. The emulsion is then stirred to completely extract/evaporate the organic solvent and harden the particles that are collected by centrifugation or filtration. The formed particles can be freeze-dried to form dry powders for storage. In this method, the polymer type and molecular weight, the co-polymer blend ratio, the type of organic solvent, the drug amount, the type and concentration of stabilizer, the mechanical strength of mixing, and the organic/aqueous volume ratio used are key parameters, and determine the drug loading, size, and superficial charge of the produced NPs, crucial properties for NP fate in vivo. The most common emulsifier used is PVA. More efficient emulsifiers such as gelatine, poloxamers, polysorbates, etc. have also been reported in literature. Feng and co-workers have studied the effect of several type and concentrations of emulsifiers on particle properties, and show that saturated phospholipids are 40 -fold more efficient than PVA and that vitamin E TPGS can result in a drug encapsulation efficiency as high as $100 \%[76,77]$. In the nanoprecipitation method, polymers are dissolved in an organic solvent miscible with water (such as acetone or ethanol) and dispersed in an aqueous phase generally containing a colloid stabilizer. The almost instantaneous diffusion of the organic solvent into the aqueous phase results in polymer precipitation as NPs [78, 79]. Finally, the solvent is evaporated off or extracted by dialysis against water. In principle, only compounds soluble in the organic solvent can be incorporated using the second method. In order to avoid using toxic organic solvents supercritical fluid technology has also been applied [80-83].

NPs can aggregate during storage and subsequent dispersion. NPs with the absolute value of the zeta potential above $30 \mathrm{mV}$ have been shown to be stable in suspension, as a larger amount of charge will enhance the repellent interaction among the particles, thereby stabilizing the NPs dispersed in the buffer [84].

\subsection{Nanoparticle Properties}

An important consideration in the development of nanocarrier systems is the biological behaviour of the nanocarrier constituents and the potential for toxicity, especially upon chronic administration. NP biodistribution is largely determined by their physical and chemical properties such as particle size and surface characteristics which makes the production of NP with the appropriate properties a main issue. The effect of NP size distribution is non-linear and varies from organ to organ, underscoring the importance of tuning NP size for each distinct in vivo application. After administration, NP will usually be taken up by the liver, spleen, and other parts of the RES depending on their size and surface characteristics [9]. The size of NP should be large enough $(>10 \mathrm{~nm})$ to prevent elimination by the glomerular excretion of kidneys [85] and their rapid leakage into blood capillaries, but small enough to escape capture by RES macrophages. Ideally, the size of an engineered-long circulatory particle should not exceed $200 \mathrm{~nm}$ to bypass the human splenic filtration process [86]. If greater than $200 \mathrm{~nm}$ and not deformable, particles may act as splenotropic agents [86].

Apart from the size of NP, their surface hydrophobic character and electrical charge are key factors for the in vivo fate of carriers
[87]. Particles with hydrophobic surfaces are easily recognized by the body immune system, and are then cleared by phagocytes from the circulation. Once in the blood, the size of NP can increase significantly, as a result of particle aggregation and adsorption of blood components mainly proteins (opsonins) capable of interacting with specific plasma membrane receptors on monocytes and various subsets of tissue macrophages, thus promoting particle recognition by these cells [9] and accumulation in the organs of the mononuclear phagocyte system (MPS) (liver, spleen, lungs, and bone marrow) [18]. Particles of different surface charge, size, and morphology will attract different types of opsonins and other blood proteins which may determine the recognition process and therefore account for the different rate and sites of particle clearance. The interaction with proteins can also interfere with other biological processes such as the blood-clotting cascade because of complement activation [88]. Neutral L (100 nm or below), show a longer circulation time in rats (half-lives up to $20 \mathrm{~h}$ ) than their anionic counterparts (half-lives less than $1 \mathrm{~h}$ ) which may be due to a non-efficient coating with the opsonizing complement proteins resulting in a poor recognition by Küpffer cells [89]. However, in the case of larger neutral or anionic Ls, clearance rates increased progressively with increasing size [90]. Therefore, if the organs of the MPS and hepatocytes are not the intended site of action than NP should be in the range of 120 to $200 \mathrm{~nm}$ in diameter [9], and have a hydrophilic surface in order to increase the likelihood of the success to reach the targeted cell/tissue [91]. Surface modification of NPs can be achieved by coating the NP surface with hydrophilic surfactants such as PEG, poloxamines, poloxamers, poly(vinyl pyrrolidone), and polysaccharides which not only improve the biocompatibility but also the resistance to protein adsorption increasing blood circulation time and target cell efficiency $[9,92$, 93]. This can be performed by adsorption, incorporation during NP production, or by covalent attachment to the surface. Alternatively, NPs can be formed from block copolymers with hydrophilic and hydrophobic domains such as PEG-co-polymers. Stealth micelle formulations have stabilizing PEG coronas to minimize opsonization of the micelles and maximize serum half-life. In humans, a 200 -fold decrease of the systemic plasma clearance was observed for PEGylated Ls in comparison to conventional Ls [94]. Also, the half-life of gelatine NPs increased from 3 to $15 \mathrm{~h}$ when they were PEGylated [95]. Long-circulating NPs of PCL containing tamoxifen and surface-modified with poly(ethylene oxide) chains have shown an enhanced blood circulation time and tumour targeting after intravenous injection in mice bearing MDA-MB-231 xenografts, a human breast cancer cell line [96]. Adjusting the ratio of polymer groups/types and using different surfactants and stabilizers, NPs with the desirable properties can be developed to carry the drug to target cells. Studies with tracking of single NP are providing new insights into the interactions and processes involved in the transport of drug carriers in vivo using fluorescence nanocrystals (quantum dots) [97].

\subsection{Nanoparticle Functionalization with Antibodies}

The selection of the antibody as the target recognizing ligand to attach onto NP surface is crucial for the optimal design of targeted NPs. It should have a high affinity and specificity towards the appropriate target surface marker. To maximize specificity, the surface marker (antigen or receptor) should be ideally unique and homogeneously expressed or overexpressed on target cells relative to normal cells [11]. For example in a breast cancer model, a receptor density of $10^{5}$ copies of HER-2 receptors per cell was necessary to improve the therapeutic efficacy of anti-HER-2targeted liposomal DOX relative to its non-targeted counter part [98]. In vitro and in vivo comparisons have shown that the intracellular concentration of drug is much higher when the drug is released from NPs in the cytoplasm after internalization $[6,99]$ as P-gp cannot remove NPs that have entered the cells via endocytosis 
$[100,101]$. The selection of the targeting ligands should be based on its propensity to be internalized via receptor-mediated endocytosis (RME) [11, 100, 102, 103] (Fig. 1B), in this way increasing the therapeutic effect and overcoming the possibility of being extruded by the multi-drug resistance (MDR)-encoded P-gp [101]. The fact that some antibodies can provide NPs with the ability to be internalized makes the MAb-NP active targeting an alternative route for overcoming MDR. Direct experimental proof has been obtained by Sapra et al. [99] for liposomal drugs targeted against internalizing epitopes (e.g., CD19) compared with those targeted against non-internalizing epitopes (e.g., CD20). Administration of single intravenous doses into human Blymphoma (Namalwa) cells of DOX-loaded anti-CD19-targeted Ls resulted in a survival time of 45.6 days against 34.3 and 28.6 days obtained for the DOX-loaded anti-CD20-targeted L and the nontargeted L formulations, respectively. This observation was attributed to the rapidly internalization of anti-CD19-targeted Ls, which allow delivering higher concentrations of drugs into the cell interior due to the breakdown of the drug-L package by lysosomal and endosomal enzymes, whereas those targeted with anti-CD20 were not internalized [104].

The antibody or the antibody fragment can be conjugated to NPs by adsorption, by direct covalent linkage between the surface of the NP and the antibody, or by using adapter molecules such as streptavidin and biotin. The coupling method must be efficient, produce a stable association, allow control of the amount of antibody that is immobilized, and assure that the activity of the antibody is preserved. Covalent coupling presents a clear advantage compared to physical adsorption as the linkage prevents the competitive displacement of the adsorbed antibodies by blood components. The covalent attachment of the antibody would involve the $\mathrm{Fc}$ region, leaving the antigen-binding site Fab region oriented to the medium to preserve its full function. For direct coupling of antibodies on NP surface, amines and carboxylic acids, the most common groups present on NP surface, can be used for reaction with ligands. Various strategies to couple antibodies to NPs are represented on Fig. (3). Common conjugation methods are based on the reaction among carboxylic groups in the particle and primary amine groups in the antibody or antibody fragment in the presence of 1-ethyl-3 (3-dimethylaminopropyl) carbodiimide (EDC) and $N$-hydroxysuccinimide (NHS) to yield a stable amide bound [105]. Alternatively, amine groups on the surface of particles can be linked to sulfhydryl groups located at known sites away from the antigen binding sites in antibodies to create a stable thioether linkage after being modified through maleimide chemistry [106]. This method is preferred as in the first method the lack of specificity in the site of conjugation may affect antibody activity [107]. Moreover, during conjugation, the NHS-based reagents converted positively charged lysines into neutral groups, leading to a probable loss of recognizing activity[108].

Linkage strategy using avidin/streptavidin (SA)-biotin technology can also be used. It involves binding between avidin and biotin with a non-covalent nature however with an extremely high affinity and dissociation halftime [109]. SA or avidin must be introduced into the ligand structure after activation with $\mathrm{N}$ maleimidobenzoyl-NHS and reaction with sulfhydryl groups in the antibody, leading to the formation of a thioether bond [110]. In parallel, biotinylated nanocarriers must be prepared to react with SA/avidin-conjugated ligands. Another approach concern ligand biotinylation using NHS-PEG-biotin to insert biotin molecules on protein-bearing primary amine groups [111]. Gelatine and human serum albumin (HSA) NPs have been surface modified by the
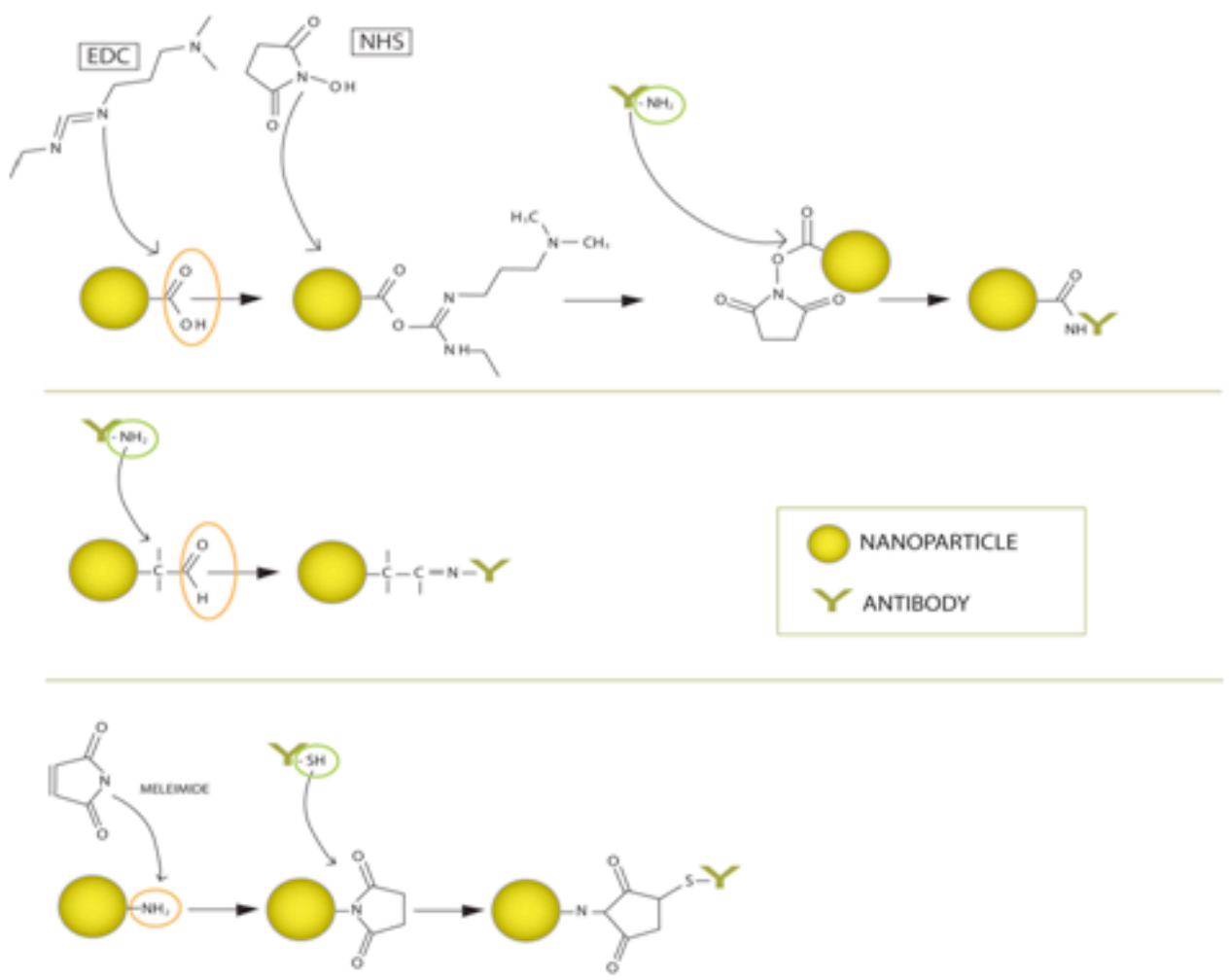

Fig. (3). Strategies of coupling antibodies to NPs: reaction among carboxylic groups on the surface of particles and primary amine groups in the antibody in the presence of EDC and NHS to yield a stable amide bound (up); reaction among aldehyde groups on the surface of particles and primary amine groups in the antibody (middle); reaction among amine groups on the surface of particles and sulfhydryl groups in the antibody to create a stable thioether linkage after being modified through maleimide chemistry (bottom). 
covalent attachment of the biotin-binding protein NeutrAvidin ${ }^{\mathrm{TM}}$ enabling the binding of biotinylated anti-HER-2 antibodies, showing intracellular specific cell targeting [112]. This group also described the selective targeting of the same NPs conjugated to antibodies specific for the CD3 antigen on CD3-positive human Tcell leukaemia cells and primary T-lymphocytes [113]. It may be advantageous to attach an antibody to the distal tip of a PEG molecule rather than conjugate the antibody to the surface of a NP therefore avoiding steric hindrances for antibody-target interaction that PEG-coating NPs can create as observed in a PEG-conjugated L $[114,115]$. Thus the PEG-molecule can be used as a spacer allowing the antibody to extend away from the NP surface. This approach has been used in vivo to target Ls to cells in tissue culture [116-118], and to lung [119] or brain [120]. Furthermore, functional groups on NP surface allow chemical conjugation to multiple diagnostic (i.e., optical, radioisotopic, or magnetic) and therapeutic agents, thus making possible to design and develop multifunctional NPs (Fig. 1a) that could be used to simultaneously imaging and treatment. Recent advances have led to bioaffinity NP probes for molecular and cellular imaging, targeted nanoparticulate drugs for cancer therapy, and integrated nanodevices for early cancer detection and screening [121]. These developments raise exciting opportunities.

\section{THERAPEUTIC APPLICATIONS OF ANTIBODY-CONJ- UGATED NANOPARTICLES}

Some examples of the major MAb-based active targeting strategies for NP systems in therapy are reported below organized in: cancer treatment, brain targeting, inflammatory diseases, infectious diseases, and other applications such as thrombosis. Examples of antibody conjugated NP-based therapeutics in in vivo studies and in clinical trials are listed in Table $\mathbf{1 .}$

\subsection{Tumour Therapy}

Cancer is a leading cause of death worldwide and accounted for 7.6 million deaths (around $13 \%$ of all deaths) in 2008. Deaths from cancer in the world are projected to continue rising, with an estimated 9 million people dying in 2015 and 11.4 million dying in 2030 according to the World Health Organization [156]. Chemotherapeutic agents have widely been used in oncology for the past 25 years but they generally exhibit a short plasma half-life due to a rapid clearance and rapid biodegradation, which allied to a poor specificity determine the use of highly toxic doses that cause severe toxic effects. In addition, cancer is often diagnosed and treated too late, when the cancer cells have already invaded and metastasized into other parts of the body. More than $60 \%$ of patients with breast, lung, colon, prostate, and ovarian cancer have hidden or overt metastatic colonies [121]. Therefore, the development of nanoscale delivery vehicles for targeted delivery of anticancer drugs to tumour cells/tissues can improve the therapeutic index of drugs and is likely one of the most exciting and clinically important application of cancer nanotechnology. Cell or tissue specific receptor/antigens can provide a useful target for cancer treatment [157]. Scientific investigations have identified cancer cell specific markers with unique phenotypes that can be exploited to target tumours. Primary tumours as well as metastatic tumours generally overexpress certain antigens on their surfaces [like HER2 in breast cancer, endothelial growth factor receptor (EGFR) in lymphoma cancer, etc.]. The ideal antigen should be expressed on all tumour cells but not expressed on critical host cells [158], should have no mutation or variation, and should be required for a critical cellular function [159]. Therefore, MAbs specific to particular tumour antigens can provide a good platform for conjugated NP targeting with high affinity and specificity as long as the particular antigens can be identified with confidence and are not expressed in significant quantities anywhere else in the body.
Active tumour targeting is typically achieved by both local and systemic administration of MAb conjugated NPs. In the case of local delivery, particularly useful for primary tumours that have not yet metastasized, the cytotoxic drug encapsulated in the NP can be delivered directly to cancer cells while minimizing harmful toxicity to non-cancerous cells adjacent. For some tumours, such as lung cancers, that are difficult to access and for metastatic cancers, the location, abundance, and size of tumour metastasis within the body limits its visualization or accessibility thus requiring a systemic administration [55].

Antibody-based therapy of human cancers has led to several remarkable outcomes, particularly in the therapy of breast cancer and lymphoma. Many solid tumours have proven less responsive, due in part to difficulties in the tumour-selective delivery of antibodies and potential cytolytic efectors. Moreover, NPs have the ability to accumulate in cells without being recognized by the P-gp, one of the main mediators of MDR, resulting in an increase in the intracellular concentration of drugs. Several studies concerning the development of antibody-conjugated NPs for cancer therapy have been performed and are reported in literature including in several reviews $[2,5,6,47,102,107,121,158,160-169]$. However, at present, there is only one formulation under clinical trial, MCC465, an IL-encapsulated DOX fabricated by Mitsubishi Pharma Corporation (Osaka, Japan) and no commercial formulation. In this formulation, the L is tagged with PEG and the F $\left(a b^{\prime}\right) 2$ fragment of $\mathrm{HuMAb}$ goat anti-human GAH, which positively reacts to $>90 \%$ of cancerous stomach tissues but negatively to all normal tissues. In preclinical studies, the antitumour efficacy of MCC-465 was compared with those of free DOX or DOX-incorporated PEG Ls with an MKN-45 human gastric cancer xenograft model. A tumour weight of $8 \mathrm{mg}, 18 \mathrm{mg}$, and $22 \mathrm{mg}$ was obtained after three intravenous injections with $3.0 \mathrm{mg} / \mathrm{Kg}$ in terms of DOX, into nude mice for DOX-IL, DOX-L, and DOX, respectively. The result showed that DOX-IL activity was significantly greater than that of DOX or DOX-L [133, 134].

In this review, the current MAb-conjugated NPs under study for cancer targeting have been organized according to particular characteristics found in tumour development (neovasculature of angiogenesis and uncontrolled cell growth) and cell/organ tumour targeting. There is a large overlap between these divisions as the targeting of cell/organ tumours involves targets specific to the type of cancer but also many of the targets found in angiogenesis and uncontrolled cell proliferation.

\subsubsection{Targeting Through Angiogenesis and Uncontrolled Cell Proliferation}

\subsubsection{Tumour Development}

Cancer is characterized by an uncontrolled growth of a group of cells that demands a higher amount of nutrients than healthy cells. Tumours cannot grow beyond a certain size, generally 1-2 $\mathrm{mm}^{3}$ $[158,170,171]$ due to a lack of oxygen and other essential nutrients. To growth beyond this size the formation of blood vessels is required to provide the necessary nutrients. The exact molecular mechanisms that initiate angiogenesis at a tumour site are not known and have been the subject of intense research. The rapid vascularization necessary to provide fast-growing cancers can create a defective vascular architecture which, coupled with a dysfunctional lymphatic drainage, causes an enhanced permeation relative to normal tissue and a fluid retention effect in the tumour interstitial space (EPR effect) $[158,172,173]$ which can facilitate an extravasation of NPs out of tumour microvasculature (passive targeting) leading to an accumulation into the tumour interstitium [174]. The concentration of PNP and macromolecular assemblies found in tumour tissues can be up to 100 -fold or greater than those in normal tissue $[175,176]$.

Since the development of new blood vessels is essential for tumour grow, an attractive antitumour strategy is to exploit the 
Table 1. Antibody-Conjugated Nanoparticles-Based Therapeutics in In Vivo Studies and in Clinical Trials

\begin{tabular}{|c|c|c|c|c|c|}
\hline Composition & Monoclonal Antibody & Target Marker & Indication & Status & Ref. \\
\hline \multicolumn{6}{|l|}{ Liposomes } \\
\hline PEG-L-DOX & $\begin{array}{l}\text { Fab' fragments of antibody } \\
\text { against MT1-MMP }\end{array}$ & $\begin{array}{l}\text { HT1080 cells, overexpressing } \\
\text { MT1-MMP }\end{array}$ & Tumour angiogenic vessels & In vivo & {$[122]$} \\
\hline L-DOX & MAb anti-HER2 & HER2 & Breast cancer & In vivo & {$[98,123]$} \\
\hline L-DOX & anti- $\beta 1 \mathrm{Fab}$ & $\begin{array}{c}\beta 1 \text { integrin-positive lung tumour } \\
\text { cells }\end{array}$ & Lung carcer & In vivo & {$[124]$} \\
\hline PEG-L-DOX & $\mathrm{MAb} 2 \mathrm{C} 5$ & $\begin{array}{l}\text { Tumour cell surface-bound } \\
\text { nucleosomes) }\end{array}$ & $\begin{array}{l}\text { Lewis lung carcinoma; colon cancer; breast } \\
\text { adenocarcinoma; prostate cancer }\end{array}$ & In vivo & $\begin{array}{l}{[125,} \\
126]\end{array}$ \\
\hline L-anti-HER-2-siRNA & scFv fragment anti-TfR & TfR & Pancreas cancer & In vivo & [127] \\
\hline PEG-L-DOX & $\mathrm{MAb} 2 \mathrm{C} 5$ & Tumour surface & Prostate cancer & In vivo & {$[126]$} \\
\hline $\begin{array}{l}\text { L-DOX; posome- } \\
\text { vincristine }\end{array}$ & MAb anti-CD19 & B-cell lymphoma & B-cell lymphoma & In vivo & [128] \\
\hline L-DOX & MAb anti-CD19 & B-cell receptor & B-cell lymphoma (blood cancer) & In vivo & $\begin{array}{l}{[99,104} \\
129,130]\end{array}$ \\
\hline L-DOX & MAb HD37 & CD19-expressing Raji cells & B-cell malignancies & In vivo & [131] \\
\hline PEG-L-DOX & $\begin{array}{l}\text { MAb HB22.7 } \\
(\text { anti-CD22) }\end{array}$ & CD22-expressing Raji cells & Non- Hodgkin's lymphoma & In vivo & {$[132]$} \\
\hline $\begin{array}{l}\text { PEG-L-DOX } \\
\text { MCC465 }\end{array}$ & Human MAb GAH & B37 cells & Stomach cancer; colorectal cancer & Phase 1 & $\begin{array}{r}{[133,} \\
134]\end{array}$ \\
\hline L-ferentinide & Anti-GD2 & $\begin{array}{l}\text { Disialoganglioside }(\mathrm{GD}(2)) \text { at the } \\
\text { cell surface }\end{array}$ & Neuroblastoma and melanoma & In vivo & {$[135]$} \\
\hline L-DOX & Anti-GD2 & $\begin{array}{c}\text { Disialoganglioside }(\mathrm{GD}(2)) \text { at the } \\
\text { cell surface }\end{array}$ & Neuroblastoma & In vivo & {$[136]$} \\
\hline PEG-L-DOX & $\mathrm{MAb} 2 \mathrm{C} 5$ & U-87 MG tumour cells & Brain tumours & In vivo & [137] \\
\hline L-daunomycin & MAb OX26 & $\begin{array}{l}\text { RBE4 brain capillary endothelial } \\
\text { cells }\end{array}$ & Brain targeting & In vivo & [138] \\
\hline L-boron compounds & Cetuximab & EGFR & $\begin{array}{l}\text { Glioma cells } \\
\text { brain targeting }\end{array}$ & In vivo & [139] \\
\hline L-boron compounds & MAb anti-EGFR & EGFR & $\begin{array}{l}\text { Glioma cells } \\
\text { brain targeting }\end{array}$ & In vivo & [140] \\
\hline L- dexamethasone & Anti-E-selectin & E-selectin & $\begin{array}{l}\text { Skin inflammation } \\
\text { glomerular renal Inflammation }\end{array}$ & In vivo & $\begin{array}{r}{[141} \\
142]\end{array}$ \\
\hline L-indinavir & Anti-HLA-DR & Lymphoid cells & $\begin{array}{l}\text { Lymph nodes } \\
\text { HIV }\end{array}$ & In vivo & [143] \\
\hline PEG-L & Anti-HLA-DR Fab’ fragment & HLA-DR & $\begin{array}{l}\text { Lymphoid organs: deep cortex of lymph } \\
\text { nodes; white pulp of the spleen } \\
\text { (HIV) }\end{array}$ & In vivo & {$[144]$} \\
\hline L-chloroquine & MAb F10 & Erythrocytes & $\begin{array}{c}\text { Infected erythrocytes: } \\
\text { malaria }\end{array}$ & In vivo & {$[145]$} \\
\hline L-chloroquine & Anti-erythrocyte F(ab')2 & Erythrocytes & $\begin{array}{l}\text { Infected erythrocytes: } \\
\text { malaria }\end{array}$ & In vivo & $\begin{array}{c}{[146,} \\
147]\end{array}$ \\
\hline \multicolumn{6}{|l|}{ Polymeric Nanoparticles } \\
\hline PLGA-PE38KDEL & Anti-HER2 & HER-2 & Breast cancer & In vivo & {$[148]$} \\
\hline PLGA & Anti-ICAM & ICAM & Lung cancer & In vivo & [149] \\
\hline $\begin{array}{c}\text { poly(lactic acid-co-l- } \\
\text { lysine) }\end{array}$ & EGFR MAb & EGFR positive cancer cells & $\mathrm{HCC}$ & In vivo & {$[150]$} \\
\hline $\begin{array}{c}\text { PLA- paclitaxel } \\
\text { PEG-PLA- paclitaxel }\end{array}$ & Anti-HER2 & HER-2 & Prostate cancer & In vivo & {$[151]$} \\
\hline $\begin{array}{l}\text { Dextran-coated } \\
\text { polymerized L }\end{array}$ & Anti-Flk-1 MAb & VEGFR-2 (Flk-1) & Melanoma & In vivo & {$[152]$} \\
\hline $\begin{array}{l}\text { Chitosan-PEG-caspase } \\
\text { inhibitor }\end{array}$ & MAb OX26 & TfR & Brain cancer & In vivo & [153] \\
\hline PEG-PLGA & $\begin{array}{l}\text { Anti-ICAM-1; anti-VCAM-1; } \\
\text { anti-E-selectin; anti-P-selectin }\end{array}$ & $\begin{array}{l}\text { ICAM-1; VCAM-1; E-selectin; P- } \\
\text { selectin }\end{array}$ & Inflamed endothelium & In vivo & {$[154]$} \\
\hline \multicolumn{6}{|l|}{ Polymeric Micelles } \\
\hline PLGA-PEG-DOX & HAb18 F(ab')2 & Hepatocellular carcinoma & Liver cancer & In vivo & {$[155]$} \\
\hline
\end{tabular}

biochemical differences between the vasculature of the tumour and the normal tissues, and aim at the tumour vasculature for therapeutic treatment with MAb-bearing long-circulating particles. Targeting the tumour vasculature provides an approach to 
circumvent the mechanical barriers that impede homogeneous distribution of drugs within the tumour tissue. Other advantages of targeting the tumour vasculature rather than the tumour cells themselves include a potentiating effect, because one blood vessel nourishes hundreds of tumour cells, and a reduced probability that drug resistance will develop, because endothelial cells have a lower mutation rate than cancer cells [177]. As more information is known about the molecular mechanisms of angiogenesis new therapeutic targets can emerge. Molecules involved in proliferation and invasion are generally overexpressed on the surface of tumour cells and include proteins involved in cell-cell or cell-matrix interactions [e.g., E-selectin, vascular cell adhesion molecule-1 (VCAM-1), and the $\alpha_{\mathrm{v}} \beta_{3}$ integrin complex] and growth factor receptors [EGFR, vascular endothelial growth factor receptor (VEGFR), and folate receptor] [9] which means that they are exposed at the cell surface, can be recognized by specific carriers, and can internalize them making these molecules potential pharmacological targets for anti-angiogenic therapy.

\subsubsection{Targeting Through Angiogenesis}

The most established angiogenic targets used by nanoparticulate systems for therapeutic benefit include the VEGFRs, $\alpha_{\mathrm{v}} \beta_{3}$ integrin, VCAM-1, and matrix metalloproteinase (MMPs) [162].

\subsection{Vascular Endothelial Growth Factor Receptor (VEGFR)}

In situ hybridization studies demonstrate VEGF mRNA expression in many human tumours. These include lung, breast, gastrointestinal tract, renal, and ovarian carcinomas. However, the expression of VEGF appears to be variable, not only among different tumour types but also within the same tumour [178].

VEGFR is considered the most relevant inducer of tumour angiogenesis for its induction of the VEGF receptor signalling cascade. The VEGF receptor of interest for most active targeting systems is VEGFR-2 as it is associated with the binding of VEGF, initiating the signalling cascade for angiogenesis [179], and is highly expressed on endothelial cells in tumour neovasculature. Apart from angiogenesis, a small number of melanoma and leukaemia cell lines express VEGFR-2 in non-endothelial cells [180, 181]. Both VEGF and VEGFR-2 are seen as promising targets for NP systems with the goal to interfere with neoangiogenesis by: 1) targeting VEGFR-2 to decrease VEGF binding; and, 2) targeting VEGF to inhibit ligand binding to VEGFR-2 [152, 182].

Anti-VEGFR-2 MAb-labeled polymeric Ls radiolabeled with ${ }^{90} \mathrm{Y}$ (anti-VEGFR-2 MAb-L- ${ }^{90} \mathrm{Y}$ ) were produced by Li et al. [152] to target VEGFR-2 in a mouse melanoma model. A significant tumour growth delay was obtained using anti-VEGFR-2 MAb-L${ }^{90} \mathrm{Y}$ treatment compared to untreated tumours as well as tumours treated with anti-VEGFR-2 MAbs alone or with ${ }^{90}$ Y-labeled antiVEGFR-2 MAb. The treatment with anti-VEGFR-2 MAb-L- ${ }^{90} \mathrm{Y}$ also showed a marked decrease in vessel density which was associated with a high level of apoptotic death in these tumours. A method to target VEGF used anti-VEGF MAb PLA NPs loaded with 5-fluorouracil that show an increase in the tumour inhibitory rate of the drug. These particles show to induce apoptosis by inhibiting tumour angiogenesis with fewer side effects, and therefore enhanced therapeutic effect in human gastric carcinoma xenografts of nude mice [183]. Bevacizumab (Avastin ${ }^{\circledR}$ ), approved in 2004, is a recombinant humanized MAb that binds to VEGF. Clinical trials of bevacizumab have been carried out for the past few years without evidence of significant clinical activity as a single agent. However, more recent studies have suggested that combining bevacizumab with chemotherapy can be effective in patients with non small cell lung cancer, advanced breast cancer, and colon cancer.

\section{$\underline{5.1 \cdot 1.2 .2 . \alpha_{\underline{v}}} \beta_{3} \underline{\text { Integrins }}$}

Integrins are cell adhesion receptors that bind to the extracellular matrix (ECM) proteins harboring the RGD (arginineglycine-aspartic acid) sequence and cell surface ligands. Their role is to transmit and detect changes from the extracellular matrix to intracellular signalling and thus regulate tumour growth, angiogenesis, proliferation, apoptosis, or metastasis [184]. Most tissues and cell types are characterized by low $\alpha_{v} \beta_{3}$ integrin levels or absence of $\alpha_{\mathrm{v}} \beta_{3}$ integrin expression. However, it is overexpressed on neovascular endothelial cells and is important in the calciumdependent signalling pathway leading to endothelial cell migration [185]. Furthermore, in some cancers such as breast cancer or melanoma, $\alpha_{v} \beta_{3}$ expression appears to correlate with the aggressiveness of the disease [186, 187]. Therefore, selective targeting of $\alpha_{\mathrm{v}} \beta_{3}$ integrin is a novel antiangiogenesis strategy for the treatment of solid tumours. Antibodies and peptides that block the function of $\alpha_{v} \beta_{3}$ and $\alpha_{v} \beta_{5}$ integrins have been shown to inhibit neovascularization in several in vivo models of pathological angiogenesis in mice $[186,188]$. HSA NPs containing DOX were conjugated with a MAb directed against $\alpha_{\mathrm{v}}$ integrins (DI17E6) using a heterobifunctional NHS-PEG-maleimid linker after MAb thiolation [189]. The produced NPs have shown the ability to specific target $\alpha_{\mathrm{v}} \beta_{3}$ integrin positive melanoma cells and an increased cytotoxic activity in $\alpha_{\mathrm{v}} \beta_{3}$ positive melanoma cells than the free drug. The half maximal inhibitory concentration $\left(\mathrm{IC}_{50}\right)$ obtained for NP-DOX-DI17E6 was $8.0 \mathrm{ng} / \mathrm{mL}$, while for NP-DOX and free DOX was $30.8 \mathrm{ng} / \mathrm{mL}$ and $57.5 \mathrm{ng} / \mathrm{mL}$, respectively.

\subsection{Vascular Cell Adhesion Molecule (VCAM)}

VCAM-1, an immunoglobulin like transmembrane glycoprotein, that is expressed on the surface of endothelial cells during inflammation and cancer and promotes cell-to-cell adhesion [190], is an optimal target as it is absent in normal human vasculature but readily inducible by angiogenesis. In cancer, increased VCAM-1 expression is linked to leukaemias and lymphomas, such as Hodgkin's disease and B-cell lymphocytic leukaemia, lung and breast cancer, melanomas, renal cell carcinoma, gastric cancer, and nephroblastoma [177]. The possibility of using antibodies to target VCAM-1 was checked using magnetooptical NPs conjugated to anti-VCAM-1 to specifically target murine heart endothelial cells expressing high levels of VCAM-1[191].

The first morphological evidence for selective in vivo targeting of tumour vessels using ILs were performed by Gosk et al. [192] that used PEG-modified ILs directed against VCAM-1. In vitro, anti-VCAM-1 Ls displayed specific binding to activated endothelial cells under static conditions, as well as under simulated blood flow conditions. The in vivo targeting of ILs was analyzed in mice bearing human Colon 677 tumour xenografts $30 \mathrm{~min}$ and $24 \mathrm{~h}$ post intravenous injection. Fluorescence microscopy studies revealed that VCAM-1 targeted ILs accumulated in tumour vessels with increasing intensities from $30 \mathrm{~min}$ to $24 \mathrm{~h}$, while control ILs accumulated in the tumour tissue by passive diffusion [192].

\subsection{Matrix Metalloproteinases (MMP)}

The main MMP target for NP systems has been the membrane type 1-matrix metalloproteinase (MT1-MMP). MT1-MMP is a membrane-anchored endopeptidase that is involved in the degradation of various extracellular matrix components, endothelial cell invasion and migration, and formation of capillary tubes [193]. It is located on angiogenic endothelium but not on the endothelial cells of pre-existing blood vessels [194]. MT1-MMP plays an important role in angiogenesis and is expressed on angiogenic endothelium cells as well on certain types of tumour cells, including malignancies of lung, gastric, colon, breast, cervical carcinomas, gliomas [122], and melanomas [122, 195, 196].

In a study performed by Hatakeyama et al., modification of PEG-Ls containing DOX with Fab fragments of anti-human MT1- 
MMP MAb significantly enhanced cellular uptake into the HT1080 cells, which highly express MT1-MMP, compared with the nontargeted Ls suggesting that MT1-MMP antibody (Fab's) is a potent targeting ligand for the MT1-MMP expressed cells. In vivo systemic administration of targeted-Ls into the tumour-bearing mice showed significant suppression of tumour growth compared to the non-targeted Ls. When DOX-Ls was administered, tumour volume was decreased in only 1 out of 6 mice at 12 and three of six mice died up to 12 day. In contrast, in the case of DOX-ILanti-MT1-MMP(Fab's), tumour volume decreased efficiently in half of mice at 12 days and no mouse died. Tumour accumulation for targeted and non-targeted Ls were comparable, suggesting that the enhanced antitumour activity of the targeted formulation resulted from acceleration of cellular uptake of Ls owing to the incorporated antibody after extravasation from capillaries in tumour [122].

\subsubsection{Targeting Through Uncontrolled Cell Proliferation}

The main cell proliferation targets explored by NP systems for therapeutic benefit include the human epidermal receptors (HER), transferrin receptors (TfR) and folate receptors, which are often overexpressed on tumour cells. The conjugation of antibodies against folate receptors has been suggested in literature but there is no published work concerning this thematic. The most common way to target folate receptors has been the conjugation of folate to NPs but is outside the scope of this article.

\subsection{Human Epidermal Receptor (HER)}

The HER family offers two highly upregulated targets on tumour cell surfaces known to mediate a cell signalling pathway for growth and proliferation in response to the binding of the growth factor ligand: the EGFR and the human epidermal receptor-2 (HER2). As a result, EGFR and HER-2 are the most heavily researched for cancer therapeutic applications. The EGFR is expressed in a wide variety of solid tumours. It has been demonstrated that the EGFR-associated signalling pathway plays an important role in carcinogenesis and cancer progression. Clinical studies using MAb blockade and EGFR tyrosine kinase inhibitors have suggested that EGFR blockade is a well-tolerated and effective treatment strategy [197].

A current cancer treatment is the MAb Cetuximab, approved in 2004 by FDA, which targets EGFR and is usually administered in a combinatory therapy in head and neck cancers. ILs with conjugated Fab' fragments of Cetuximab MAb were synthesized for targeted delivery of boron compounds to EGFR-positive glioma cells (F98 $\left.8_{\mathrm{EGFR}}\right)$ for neutron capture therapy. Much greater (8-fold) cellular uptake of boron was obtained using cetuximab-ILs in EGFR-positive cells compared with non-targeted human IgG-ILs [139]. Poly(lactic acid-co-L-lysine) NPs conjugated to a EGFR $\mathrm{MAb}$ have shown to bind to and be uptaken by hepatocellular carcinoma cells effectively. They also show an effective tumour targeting in vivo in a xenograft mouse model [150].

HER-2 also plays a significant role in the pathogenesis of many different types of cancers, and offers an attractive target for MAbbased therapeutic strategies. The use of Trastuzumab [198] as a targeting moiety offers an attractive strategy for MAb conjugated NPs. Several studies demonstrated that PNP functionalized with anti-HER-2 MAb can specifically bind and deliver drugs or toxins to breast carcinoma cells and prostate cancer cells which overexpress HER [199-203]. PLGA/montmorillonite NPs containing paclitaxel have been decorated with the HER-2 Trastuzumab antibody for targeted breast cancer chemotherapy. In vitro studies in Caco-2 colon adenocarcinoma cells and in SK-BR-3 breast cancer cells show that the antibody-conjugated NPs achieved significantly higher cellular uptake than the pure colloid. Moreover, in vitro cytotoxicity on SK-BR-3 cells showed that the anticancer action of the drug formulated in the conjugated NPs was 12.7 times higher than that of the bare NPs, and 13.1 times higher than free Taxol $^{\circledR}[204]$.

Liu et al. has performed a study on the quantitative control of targeting effect of docetaxel-loaded NPs of a PLGA-PEG/PLGA copolymer blend conjugated to HER-2. Comparing with a preconjugation strategy, the post-conjugation strategy in which the ligand is conjugated onto the DOX containing PLGA-PEG NPs already prepared provides more efficient use of the ligand and protects its bioactivity in the NP preparation process, thus resulting in much better performance in drug targeting, which was assessed in vitro with SK-BR-3 breast cancer cells of HER-2 receptor overexpression and MCF7 breast cancer cells of HER-2 receptors moderate expression. He also found a linear relation between the copolymer blend ratio of the NP matrix and the ligand density and that the amount of PNP endocytosed by SK-BR-3 cells was almost proportionally increased to the surface density of the ligand. This shows indeed an experimental evidence for the proposed copolymer blend strategy for precision engineering of the NPs [205].

The biodistribution and intracellular distribution of longcirculating ILs targeted to HER-2 prepared by conjugation of antiHER-2 MAb fragments (Fab' or single chain Fv) to PEGylated Ls was studied by Kirpotin et al. [123]. They found that MAb fragment conjugation did not affect the biodistribution or longcirculating properties of intravenously administered Ls nor increase the tumour localization of ILs, as both targeted and non-targeted Ls achieved similarly high levels (7-8 \% injected dose/g tumour tissue) of tumour tissue accumulation in HER-2-overexpressing breast cancer xenografts (BT-474). However, studies using colloidal goldlabelled Ls showed the accumulation of anti-HER-2 ILs within cancer cells, whereas matched non-targeted Ls were located predominantly in extracellular stroma or within macrophages. A similar pattern of stromal accumulation without cancer cell internalization was observed for anti-HER-2 ILs in non-HER-2 overexpressing breast cancer xenografts (MCF-7). Flow cytometry of disaggregated tumours post treatment with either Ls or ILs showed up to 6-fold greater intracellular uptake in cancer cells due to targeting. The results demonstrated that, in contrast to nontargeted Ls, anti-HER-2 ILs achieved intracellular drug delivery via MAb-mediated endocytosis, and this, rather than increased uptake in tumour tissue, was correlated with superior antitumour activity.

A very interesting study of the tracking of NP labelled with the $\mathrm{MAb}$ anti-HER-2 after injection into mice with HER-2overexpressing breast cancer was reported by Tada et al. using quantum dots [97]. They successfully identified six processes of delivery: initially in the circulation within a blood vessel, during extravasation, in the extracelullar region, binding to HER-2 on the cell membrane, moving from the cell membrane to the perinuclear region, and in the perinuclear region. The six processes were quantitatively analyzed to understand the rate-limiting constraints on quantum dot-antibody delivery. They found that the movement of the complexes at each stage was "stop-and-go".

\subsection{Transferrin}

Transferrin (Tf) is an iron-binding blood plasma glycoprotein that is involved in the transport of iron to proliferating cells. After binding to TfRs, it is endocytosed into acidic compartments where the iron dissociates. Due to the increased requirement of iron during cell proliferation, an increase number of TfRs is present on metastatic cells compared to normal healthy cells which make them of particular interest to act as targets for cancer therapeutics [206]. The conjugation of $\mathrm{Tf}$ to NPs is the most common way to target TfRs however is outside the scope of this article.

Single-chain antibody Fv fragment ( $\mathrm{scFv}$ ) against TfR has been conjugated to a cationic L-DNA complex to target tumour cells [207]. This scFv-IL can deliver the complexed gene systemically to 
tumours in vivo, where it is efficiently expressed. Barth et al. [208] describes the design and synthesis of fluorescent calcium phosphosilicate nanocomposite particles (CPNP) bioconjugated to anti-CD71 antibody (an anti-TfR antibody) via an avidin-biotin coupling strategy and their targeting ability to TfRs, which are highly expressed on breast cancer cells, in an in vivo model of breast cancer. The study shows that, $96 \mathrm{~h}$ following tail vein injection, anti-CD71-avidin-CPNP was more effective at targeting the tumour than the passively accumulating untargeted-CPNP and transferrin-conjugated CPNP based on the relative fluorescence intensity. This behaviour was attributed to the saturation of TfRs with $\mathrm{Tf}$ which turns them unable to bind to the Tf-CPNP and explained the success of the anti-CD71-avidin-CPNP, which recognize an epitope separate from the ligand-binding site on the TfR. However, the effective targeting was not limited to the tumours, but also to the spleen, which is rich in diversity of hematopoietic cells and to the stomach. Overall, these findings showed that the anti-CD71-avidin-CPNP were effective and selective in an in vivo model of breast cancer and have the potential to perform as a theranostic modality, simultaneously enhancing drug delivery, targeting, and imaging of breast cancer tumours.

\subsubsection{Tumour Cell Targeting}

According to the American Cancer Society cancer statistics for 2011, cancers of the lung and bronchus, prostate, and colorectum in men, and cancers of the lung and bronchus, breast, and colorectum in women continue to be the most common causes of cancer death [209]. These 4 cancers account for almost half of the total cancer deaths among men and women. Tumour cell targeting involves many of the targets mentioned in the previous section: targeting through angiogenesis and uncontrolled cell proliferation. However, there are other targets that are specific to the type of cancer that are included in this Section as well as antibody-conjugated NP systems that have shown specific targeting upon in vivo administration.

\subsubsection{Breast Cancer}

At present, breast cancer is the most frequently diagnosed cancer and the leading cause of cancer death among females, accounting for $23 \%$ of the total cancer cases and $14 \%$ of the cancer deaths [209]. One of the most used strategies for targeted delivery to breast cancers uses the HER-2, a growth factor receptor found to be overexpressed in $20-30 \%$ of human breast cancers [210], already mentioned in Section 5.1.1.

Trastuzumab has been used as recognizing unit attached to NPs for breast cancer therapeutics. PLGA NP containing a model protein toxin (PE38KDEL) were covalently conjugated with Fab' fragments of a humanized anti-HER-2 MAb by a two-step carbodiimide method to get PE38KDEL-loaded NP-anti-Fab' bioconjugates (PE-PNP-anti-HER) [203]. The administration of PEPNP-anti-HER in mice previously inoculated with BT-474 cells showed that compared with PE-anti-HER, the antitumour activity of PE-PNP-anti-HER was markedly improved: the final mean tumour load was $36 \pm 8 \mathrm{~mm}^{3}(0.3 \mathrm{mg} / \mathrm{Kg})$ and $6 \pm 2 \mathrm{~mm}^{3}(0.9 \mathrm{mg} / \mathrm{Kg})$, respectively. In addition, they were well tolerated in mice with a much higher MTD (maximally tolerated dose) than PE-anti-HER $(2.92 \mathrm{mg} / \mathrm{Kg} v s .0 .92 \mathrm{mg} / \mathrm{Kg})$, indicating that the systemic toxicity of PE38KDEL was dramatically reduced by PLGA encapsulation. Park et al. [98] produced DOX-loaded anti-HER-2 ILs that show marked therapeutic results in four different HER-2 overexpressing tumour xenograft models including growth inhibition, regression, and cures, and that were significantly superior to all other treatment conditions tested, including free DOX, non-targeted liposomal DOX, recombinant anti-HER-2 MAb trastuzumab, and combinations of these other agents. An enhanced accumulation in tumours and an in vivo therapeutic activity was observed by Elbayoumi and Torchilin [126] after coupling the anticancer MAb 2C5 with nucleosome-restricted activity that can recognize the surface of various tumours but not normal cells to long-circulating Ls containing DOX. These results are presented in Fig. (4) for all the produced liposomal preparations showing the biodistribution (Fig 4a), the whole body imaging of subcutaneous 4T1 tumour-bearing mice $4 \mathrm{~h}$ after the injection (Fig. 4c), and the therapeutic activity achieved expressed as tumour volumes (Fig. 4b) [126]. The final average tumour weight in animals with murine breast adenocarcinoma treated with MAb 2C5-DOX-Ls was only $0.3 \mathrm{~g}$ compared with $1 \mathrm{~g}$ in animals treated with non-specific UPC10modified DOX or original DOX, and $2 \mathrm{~g}$ in animals receiving only the buffer injections.

\subsubsection{Lung Cancer}

According to the Globocan programme from the World Health Organization, lung cancer accounted for 1.45 million of deaths and 1.7 million new cancer cases in 2010 [211]. Bevacizumab $\left(\right.$ Avastin $\left.^{\circledR}\right)$, a humanized MAb that binds to VEGF was approved in 2004 for treating non-small cell lung cancer, metastatic colorectal cancer, and metastatic breast cancer [178]. Present research in targeted therapeutics for lung cancer involves inhalable and injectable systems. Several studies performed show that the major obstacle, after intravenous injection, is to overcome the massive liver uptake therefore making difficult to achieve NP accumulation in the lungs [212]. The lack of ligands specific to lung cancer cells has limited lung targeting using NPs. Antibody-targeted therapies are beginning to offer a realistic alternative to palliative chemotherapy for many patients with advanced non-small cell lung cancer (NSCLC). Woodward et al. have studied the biodistribution of NPs linked to either a MAb to mouse lung thrombomodulin (MAb 201B) or a control antibody (MAb 33) and injected into groups of female mice using radioactive cadmium telluride/zinc sulfide $(\mathrm{CdTe} / \mathrm{Zn})$ systems for in vivo imaging. $1 \mathrm{~h}$ post-injection, the maximum lung accumulation for the group that received the MAb 201B-NPs was $437 \pm 26 \% \mathrm{ID} / \mathrm{g}$ tissue (a whole murine lung weighs $\approx 0.1 \mathrm{~g}) v s .4 \pm 0.9 \% \mathrm{ID} / \mathrm{g}$ for the group that received the MAb 33-NPs. At $1 \mathrm{~h}$, this represented a 100-fold increase in targeting efficacy vs. control [213]. Although toxicity reasons are likely to prevent $\mathrm{CdTe} / \mathrm{Zn}$ systems from being used clinically, this system serves as a useful surrogate for answering questions about targeting efficacy. Debotton et al. has designed PLA NPs conjugated to a MAb (AMB8LK) that specifically recognizes $\mathrm{H}-$ ferritin to target tumours overexpressing $\mathrm{H}$-ferritin $[151,214]$. AMB8LK has been shown to exhibit marked affinity for specific tumour organs such as pancreatic and lung (NSCLC) cancers. The AMB8LK immunoPNP showed significantly increased binding properties and increased uptake on human $\mathrm{H}$-ferritin overexpressing cell lines (CAPAN-1 and A-549) compared to non-conjugated PNP. The immunoNPs containing paclitaxel palimitate also show an increased cytotoxicity presenting a $65 \%$ cell survival when compared to $90 \%$ obtained with a paclitaxel palimitate solution and blank paclitaxel palimitate PNP. The immunoNP were more effective than both controls, probably as a result of the extensive cell uptake of the immunoNP.

Sugano et al. [124] produced DOX-loaded anti-b1 Fab' ILs that show to be 30 -fold more cytotoxic to $\beta 1$ integrin-positive lung tumour cells than drug-loaded Ls without antibody, nonspecific Fab' control ILs with drug or ILs without drug. The therapeutic efficacy of DOX-loaded ILs was also evaluated in a metastatic human lung tumour xenograft/severe combined immunodeficient mouse model. Treatment resulted in a significant suppression of tumour growth, prevented the metastatic spread of the tumour to the liver and adrenal glands and increased the median survival time of the tumour-bearing mice compared to mice treated with control formulations. Muzykantov and colleagues have shown that lung delivery can be significantly enhanced by immunotargeting the pulmonary endothelium with MAbs directed against intercellular adhesion molecule 1 (ICAM-1) [149, 215]. Although this immunoglobulin-like transmembrane endothelial adhesion molecule is constitutively expressed in the tissues of every organ, 

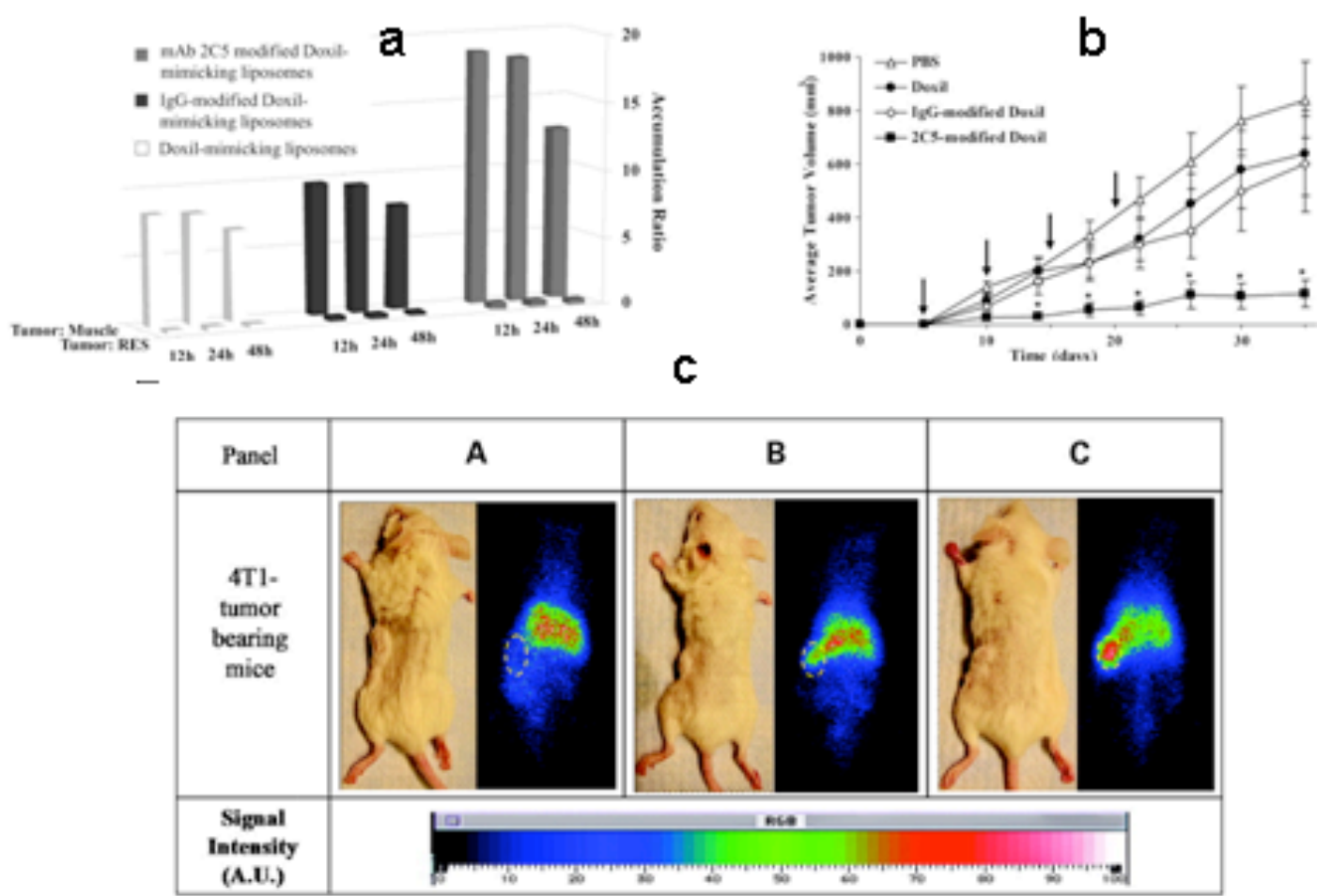

Fig. (4). (a) Tumour accumulation of the liposomal preparation. (b) Therapeutic activity, expressed as tumour volumes, of 2C5-Doxil ${ }^{\circledR}$ against control preparations in 4T1-mice. Arrows, treatment schedule, $2 \mathrm{mg} / \mathrm{Kg}$ every $5 \mathrm{~d}(n=8-10)$. (c) Whole body $\gamma$-imaging of subcutaneous $4 \mathrm{~T} 1$ tumour-bearing mice 4 $\mathrm{h}$ after the injection of ${ }^{111}$ In-labeled Ls: control Doxil ${ }^{\mathbb{B}}$-mimicking Ls (A), non-specific UPC10-Doxil ${ }^{\mathbb{B}}$-mimicking Ls (B), and MAb 2C5-Doxil ${ }^{\mathbb{B}}$-mimicking Ls (C). Circles show tumor locations. Adapted with permission from Ref. [126]. Copyright AACR (2009).

favorable pharmacokinetics (a result of the high-flow, highcapacity, and low-resistance nature of the pulmonary vasculature) ensure relatively high lung extraction of materials coupled to antiICAM antibodies [216]. NP targeting ICAM-1 hold promise as a mean of delivering therapeutics to the pulmonary endothelium. (see examples in Section 5.4.).

\subsubsection{Liver Cancer}

Hepatocellular carcinoma (HCC) is the sixth most common tumour worldwide, but due to its poor prognosis, it ranks as the third most common cause of death from cancer [156]. The global incidence of HCC is greater than a million cases a year. General chemotherapy and radiotherapy offer somewhat unsatisfactory responsiveness, making new therapeutic strategies an immediate need to combat HCC. Targeted cancer therapy is promising to minimize the non-specific toxicity and to improve therapeutic efficiency compared to conventional chemotherapy.

Kou et al. produced paclitaxel-loaded PLGA NPs coated with cationic SM5-1 single-chain antibody (SM5-1 scFv) which binds to a membrane protein specifically expressed on melanoma, HCC, and breast cancer cells [217]. The produced NPs were tested for their binding affinity and cytotoxicity in SM5-1 binding protein positive Ch-hep-3 cells, which is a human HCC cell line, and have significantly enhanced in vitro cytotoxicity as compared with nontargeted paclitaxel-loaded PLGA NPs. Jin et al. reported on the development of targeted DOX-PLGA-PEG micelle decorated with a half-antibody (HAb) HAb18 F(ab')2 (anti-HCC specific) for HCC chemotherapy [155]. The distribution profiles of targeted micelles in nude mice bearing HepG2 xenograft $2 \mathrm{~h}$ after intravenous administration showed that micelles were mainly distributed into the tumour and that a lower or invisible accumulation was observed in brain, heart, lung, liver, spleen, and kidney. Three days after the final administration, the inhibition rates of tumour (\%) were 39.8 ,
50.2 , and $63.9 \%$ for free DOX, non-targeted, and targeted micelles, respectively. The significantly lower accumulation detected in the heart indicated that the cardiac toxicity of DOX might be substantially reduced by the formulation of micelles. This result is encouraging because the cardiac toxicity is one of the most significant side effects of DOX chemotherapies.

\subsubsection{Pancreas Cancer}

Pancreatic cancer has the worst mortality rate and the lowest overall survival in all cancers. Only about $10 \%$ of patients are presented with resectable disease and are suitable for potentially curative surgery [218]. Chemotherapy is still the only option in metastatic pancreatic cancer treatment although current regimens are met with little success as poor tumour vascularization significantly limits the delivery of oncological drugs. At most of the times, chemotherapy is purely palliative with minimal impact on survival. Therefore, developing novel, specific, tumour-targeted drug delivery systems is urgently needed for this terrible disease. Immunotherapy, especially antibody therapy, has shown great promise in pancreatic cancer treatment. Many studies suggest that EGF and VEGF pathways are activated in a large amount of human pancreatic cancers. EGFR and VEGF expressions are associated with the prognosis of pancreatic cancer [219]. It has been shown that anti-EGFR MAbs including cetuximab and matuzumab inhibit the tumour growth and angiogenesis, and when combined with chemotherapeutics such as gemcitabine led to significant increase in tumour growth inhibition. Also bevacizumab has demonstrated the benefit of being used in combination with previously failed chemotherapy for pancreatic cancer [220]. Mesothelin is a tumour differentiation antigen that is highly expressed in human malignant tumours including pancreatic cancer [221]. Therefore, the use of anti-mesothelin antibodies as targeting moieties attached to NPs can play a critical role in anticancer therapy [222]. Other candidate 
genes have been indicated as potential targets for the specific delivery in pancreatic cancer including urokinase plasminogen activator receptor, Tf, HER-2, CA125 (a cell surface associated glycosylated mucin protein, also known as MUC16), and stem cell markers such as the epithelial cell adhesion molecule (EpCAM), CD44, and CD133 highly expressed in more than $50 \%$ of pancreatic cancers. Studies performed have shown that targeting of these receptors using specific antibodies inhibits pancreatic cancer growth [219]. ILs composed of siRNA encapsulated by a cationic Ls, the surface of which is decorated with an anti-TfR single-chain antibody fragment, have been developed to deliver anti-HER-2 siRNA preferentially to tumour cells and show that can sensitize human tumour cells to chemotherapeutics, silence the target gene and affect its downstream pathway components in vivo, and significantly inhibit tumour growth in a pancreatic cancer model [127]. The inclusion of a $\mathrm{pH}$ sensitive histidine-lysine peptide (HoKC) in the complex (scL-HoKC) enhances endosomal release resulting in increased effect. The advantage of using these immunoNPs is that it not only benefits pancreatic cancer treatment but also can apply to other cancer with HER-2/neu overexpression. Thus, this complex has the potential to help translate the potent effects of siRNA into a clinically viable anticancer therapeutic.

$\mathrm{Hu}$ et al. used an anti-carcinoembryonic antigen half antibody (HAb), because the carcinoembryonic antigen (CEA) is overexpressed in $90 \%$ of pancreatic tumours [223], to synthesize $\mathrm{HAb}$ conjugated lipid-polymer hybrid NPs (HAb-NPs) and characterize their ligand conjugation yields, physicochemical properties, and targeting ability against pancreatic cancer cells. In addition, using paclitaxel as a model chemotherapy drug, they showed superior cytotoxicity of the targeted NPs against a human pancreatic cell line BxPC-3 in comparison with their non-targeted counterparts. The $\mathrm{IC}_{50}$ values of $251 \mathrm{nM}$ and $526 \mathrm{nM}$ were obtained for the HAb-NPs and non-targeted NPs, respectively, which translated to a more than 2-fold increase in therapeutic efficacy due to the anti-CEA HAb targeting [224]. At present, there are very few clinical trials using targeted drug delivery (using virus vector and magnetic beads) to treat pancreatic cancer and none using antibodies as targeting unit.

\subsubsection{Prostate Cancer}

Prostate cancer is the second most frequently diagnosed cancer and the sixth leading cause of cancer death in males, accounting for almost 100000 of the total new cancer cases [211]. In vivo inoculation of paclitaxel palmitate-loaded anti-HER-2 PEGylated PNP in mice elicited a significant antitumour activity in a metastatic prostate cancer model that overexpressed the HER-2 receptor as compared to the paclitaxel palmitate solution and nontargeted PNP [151]. Both non-targeted PNP and immunoPNP showed significantly increased plasma concentrations and plasma half-life values as compared to the values of paclitaxel palmitate solution in mice, although no significant difference between them. They also found that the immunoPNP concentrated much less in the liver and spleen than PNP. An enhanced accumulation in tumour and in vivo therapeutic activity was observed with MAb2C5-DOXLs when tested against human prostate cancer in nude mice [126]. The final average tumour weight in animals treated with MAb2C5DOX-Ls was only $0.7 \mathrm{~g}$ compared with $1.7 \mathrm{~g}$ in animals treated with non-specific UPC10-modified DOX or plain DOX, and $3.3 \mathrm{~g}$ in animals receiving only the buffer injections.

\subsubsection{Colon Cancer}

Colorectal cancer is the third most malignant disorder, with over 1.2 million new cancer cases and 641000 deaths estimated to have occurred in 2010 [211]. Some examples of antibody-based targeted therapies for colorectal cancer already approved by the FDA include bevacizumab, cetuximab, and panitumumab (Amgen), a human antibody against EGFR produced in transgenic mice, approved in 2006 for the treatment of EGFR positive colorectal cancer that has seen disease progression despite prior treatment. These approvals signal the potential of antibody-targeted nanocarriers on colorectal cancer therapy simultaneously binding and inhibiting cancer pathways while delivering therapeutic payloads. Conjugates of DOX with linear and star-like hydroxypropyl methacrylamide polymers were functionalized with two different types of MAbs specific to the TfRs which are expressed in colorectal cancer cells [225], and showed significantly better therapeutic efficacy in vivo. Remarkably, star-like targeted conjugates delayed tumour growth significantly longer than linear targeted conjugates, stressing the importance of carrier design on the final results. An enhanced accumulation in tumour and in vivo therapeutic activity was observed with MAb2C5-DOX-Ls when tested against primary murine colon tumour in nude mice [126]. The final average tumour weight in animals treated with MAb2C5DOX-Ls was only $0.43 \mathrm{~g}$ compared with $1.7 \mathrm{~g}$ in animals treated with nonspecific UPC10-modified DOX or plain DOX, and $4.5 \mathrm{~g}$ in animals receiving only the buffer injections. PLGA PNP coated with conatumumab (AMG 655) death receptor 5 (DR5)-specific antibodies have shown to preferentially target DR5-expressing cells and to induce apoptosis via DR5, unlike free AMG 655 or nontargeted control PNP in colorectal HCT116 cancer cells [226]. Also, DR5-targeted PNP encapsulating camptothecin are effectively targeted to the tumour cells, thereby producing enhanced cytotoxic effects through simultaneous drug delivery and apoptosis induction.

\subsubsection{Leukaemia}

Advances in chemotherapy, targeted therapy, and stem cell transplantation have all contributed to improved leukaemia survival. NPs also offer benefits in the treatment of leukaemia by providing sustained drug levels in the bloodstream without being dependent on leaky blood vessels to access the neoplastic cells as in solid tumours.

The potential clinical utility of VEGF inhibition in oncology is not limited to solid tumours. There is growing evidence that VEGF and VEGFRs are expressed by a variety of leukaemias and other hematologic malignancies, suggesting that inhibition of VEGF or VEGFR signalling may have a role in the treatment of such conditions [227]. Several clinical trials are currently testing these hypotheses. Cancer cell-specific receptors/antigens that have been applied as targets for leukaemia therapy include CD33 (a surface antigen expressed on over $80 \%$ of leukaemia blasts from acute myeloid leukaemia suffering patients but not on healthy cells) [228], CD45, CD20 (a surface antigen expressed only in normal Bcells and B-cell lymphoma while absent on $\mathrm{T}$ lymphocytes and bone marrow), and $\mathrm{CD} 13$. The chimeric anti-CD20 MAb (rituximab) is used to treat B-cell lymphoma. Its efficacy was also demonstrated in the treatment of rheumatoid arthritis and inflammatory myositis. The humanized p67.6 anti-CD33 is currently used in the clinic conjugated with calicheamicin through an acid-labile linkage (gemtuzumab ozogamicin, Mylotarg ${ }^{\circledR}$ ) for the treatment of relapsed acute myeloid leukaemia patients who are not candidates for conventional chemotherapy.

Studies have shown that a successful targeting of leukaemia cells can be achieved using antibody-conjugated PNP [45, 99, 104, $113,129,130,229]$. Biodegradable PLA PNP coupled to anti-CD20 produced by Nobs et al. have shown to specifically bound and remained at the cellular surface of Daudi lymphoma cells (overexpressing CD20), and not on SKOV-3 human ovarian cancer cells (CD20 negative) [45]. The fact that the conjugated NPs were not internalized by Daudi cells was attributed to the fact that CD20 is a tetraspan cell surface molecule, which is not internalized in response to antibody binding. The proposed mechanism of interaction between Daudi and anti-CD20 NPs is a cell surface clustering. Sapar and Allen have demonstrated the therapeutic advantage of targeting internalizing epitopos (e.g., CD19) vs. noninternalizing epitopes (e.g., CD20). Anti-CD19-Ls were rapidly 
internalized into human B-lymphoma (Namalwa) cells, whereas those targeted with anti-CD20 were not internalized. Administration of single intravenous doses, to severe combined immunodeficient mice inoculated intravenously with Namalwa cells, of DOX-loaded anti-CD19-Ls resulted in significantly greater survival times than either DOX-loaded anti-CD20-Ls or nontargeted Ls [99, 104, 128, 130]. The toxicity and therapeutic activity of anti-CD19 Ls have shown to be related with the drug release rate obtained from different liposomal formulations. Ls with the slowest drug release rates showed no toxicity and a superior therapeutic activity than other formulations when targeted with anti-CD19 [129]. Biotinylated antibodies specific for the CD3 antigen on lymphocytic cells were conjugated onto gelatine NPs by a neutravidin-biotin-complex formation, and tested for cell typespecific targeting into CD3-positive human T-cell leukaemia cells and primary $\mathrm{T}$ lymphocytes. Uptake rates of about $84 \%$ into T-cell leukaemia cells were observed through a selective receptormediated endocytotic process [113]. PEGylated Ls containing DOX (PL-DOX) were conjugated with HB22.7, an anti-CD22 MAb that mediates internalization when bound to CD22, and tested in nonHodgkin's lymphoma xenograft-bearing mice. The DOX-loaded PEGylated ILs exhibited greater cytotoxicity (3.1- to 5.4-fold decrease in $\mathrm{IC}_{50}$ ) vs. PL-DOX in CD22-expressing cell lines, whereas the cytotoxicity was the same in CD22-negative cell lines. Comparison of the biodistribution of PL-DOX vs. DOX-loaded PEGylated ILs at $24 \mathrm{~h}$ post-treatment shows that the greatest DOX accumulation occurs in the tumour and that accumulation is 1.8fold greater for the ILs compared with PL-DOX treated mice. The spleen also showed more DOX accumulation with the IL treatment compared with the PL-DOX treatment (1.6-fold increase). Also, the ILs were more effective at reducing tumour volume than was PLDOX at all dose levels with a 1.8- to 2-fold decrease in tumour volume between corresponding single-dose treatment groups. A highly significant reduction in tumour volume was seen in the group treated with three doses of $8 \mathrm{mg} / \mathrm{Kg}$ DOX-loaded PEGylated ILs: 45-fold greater reduction in tumour volume when compared with PL-DOX, and 60-fold reduction when compared with control mice [132]. An alternative, where a specific orientation of the antibody is not necessary, is the direct attachment of Fab's to the NP surface. In an effort to develop a clinically acceptable DOX formulation, stealth ${ }^{\circledR}$ ILs were targeted against the B-cell antigen CD19, via a whole HD37 MAb, vs. its HD37 Fab's fragment or an HD37-c-myc-cys-His5 single chain Fv fragment (scFv, HD37$\mathrm{CCH})$ directed against the same epitope [131]. Compared to the untargeted Ls, stealth ${ }^{\circledR}$ ILs showed increased binding in vitro to CD19-expressing Raji cells, and when loaded with DOX, increased cytotoxicity against Raji (CD19+), but not Molt4 (CD19-) cells. Biodistribution studies in naïve and Raji-bearing mice showed that the DOX-loaded and the HD37 Fab's surface decorated stealth ${ }^{\circledR}$ ILs exhibited the longest circulation half-life of the conjugated Ls tested, and the same long circulation half-life as DOX-loaded stealth ${ }^{\circledR}$ Ls while the DOX-loaded stealth ${ }^{\circledR}$ ILs targeted via HD37 $\mathrm{MAb}$ or HD37-CCH were cleared faster due to increased liver uptake. All the formulations of DOX-loaded stealth ${ }^{\circledR}$ ILs extended the mean survival time of Raji bearing mice compared to DOXloaded stealth ${ }^{\circledR}$ ILs or the free DOX. DOX-loaded and the HD37 Fab's surface decorated stealth ${ }^{\circledR}$ ILs, which had the longest circulation half-life, appeared to be slightly more effective in prolonging survival times than DOX-loaded stealth ${ }^{\circledR}$ ILs targeted via either HD37-CCH or HD37 MAb.

\subsection{Brain Targeting}

Many neurotherapeutics are unsuccessful in treating central nervous system disorders due to their inability to reach the brain parenchyma when intravenously administered. Two physiological barriers separate the brain from its blood supply and control the transport of compounds: the BBB and the blood cerebrospinal fluid barrier. BBB is a specialized system of capillary endothelial cells that supplies the brain with the required nutrients for proper function while protecting the brain from substances which are neurotoxic in physiological concentrations [230]. BBB is composed of an inner endothelial cell monolayer which forms the wall of the capillary associated with perycites and astrocytes. This physical barrier is characterized by tight intracellular junctions and by the absence of fenestrations that restricts the entry of therapeutic agents to the brain from the periphery [231]. The blood cerebrospinal fluid barrier forms a second barrier separating the blood from the cerebrospinal fluid. It is sited at the choroid plexus epithelium and secretes the cerebrospinal fluid. It functions together with the BBB to control the internal environment of the brain [232]. The choroid epithelial cells form tight junctions but present fenestrations therefore showing a low resistance in comparison with the endothelial cells of the BBB and allowing the diffusion of small molecules [233]. Besides the higher permeability, the blood cerebrospinal fluid barrier not significantly increase the penetration of drugs into the brain due to its 1000 fold smaller surface compared with the surface area of the BBB [234].

BBB not only functions as a physical barrier but also as a biochemical barrier containing enzymes like peptidases along with several cytosolic enzymes and a particularly active efflux P-gp system that helps pumping drugs from the brain back into the bloodstream [235]. Therefore, the BBB is often the rate-limiting step in the permeation of drugs into the brain. It has been investigated that $100 \%$ of large molecule drugs do not cross the $\mathrm{BBB}$ and only small molecule drugs with a molecular mass under $400 \mathrm{Da}$ and high lipid solubility are able to cross the BBB in significant amounts [236]. Consequently, very few molecules may be transported efficiently into the brain which may compromise the efficient treatment of neurological and psychiatric disorders and makes brain drug targeting more difficult for the pharmaceutical industries. Several invasive strategies have been developed to improve the penetration of drugs into the brain such as interstitial drug delivery through direct injection into the cerebral parenchyma and implantation of drug-loaded polymeric matrices [237-239]. These strategies rely on drugs diffusion which is very slow in the cerebral parenchyma and can cause infections and cerebral edemas [240], not to mention the discomfort they pose to the patient. Nonsurgical strategies such as the modification of drugs to produce lipophilic analogs and prodrugs [241], and the generation of a transient disruption of the $\mathrm{BBB}$ through the intracarotid administration of agents such as mannitol, leukotrienes, and vasoactive peptides have also been investigated [242, 243].

Active targeting of the BBB using long-circulating NPs represents a promising non-invasive strategy for improving drug delivery to brain and at the same time prevent the access of the drug to other body parts [47, 244-246]. By suitable tailoring the size and surface properties, NPs can be made to achieve ability to cross the BBB. Gao and Jiang tested NPs with different size ranges and found that although there was no significant difference on the function of overcoming BBB among NPs whose average diameter was from 100 to $400 \mathrm{~nm}$, significant difference was observed when NP size was below $100 \mathrm{~nm}$ [247]. NPs overcoated with surface active agents (polysorbate 80 , poloxamer 188) have shown the ability to deliver many drugs across the BBB [248-251]. The mechanism of delivery appears to be associated with a receptormediated uptake process by the brain capillary endothelial cells after adsorption of apolipoprotein E or A-1 after injection into the blood stream [252]. Antibodies able to recognize the various influx transport systems expressed within the cerebral endothelial, including carrier-mediated transports (CMT), RME, and adsorptivemediated endocytosis (AME) systems can be used as targeting moieties. These transport systems have an essential physiological role in the delivery of vital substances to the brain. CMT systems mediate the passage of nutrients of low molecular weight through 
specific membrane protein carriers highly expressed on the cerebral capillaries of the BBB. Over 20 carriers have been identified, including the carriers for D-glucose, monocarboxylates, amino acids, small peptides, etc. $[253,254]$. RME provides a mean for selective uptake of high molecular weight molecules by specific type receptors. The specific receptors of the brain capillary endothelium were identified for low density lipoproteins (LDL): insulin, insulin-like growth factors, interleukin-1, folic acid, tranferrin, leptin, and Fc fragment of $\operatorname{IgG}[236,255]$. However, receptor-mediated transcytosis (RMT) was only illustrated for insulin and TfRs [256, 257]. AME system is based on electrostatic interactions established between a positively-charged ligand and the negatively-charged membrane of the BBB. It has a lower affinity and higher capacity than RME [255]. Cationized albumin and cationized immunoglobulins have shown a significantly transport improvement when compared to native proteins [258, 259]. Antibody-conjugated NPs can therefore bind specifically to the brain capillary endothelium cells, inducing an internalization mechanism depending on the antibody. NPs can be either exocytosed and hence reach the cerebral parenchyma or degraded within lysosomes leading to drug release into the brain tissue [47]. All these influx transport systems also play a key role in the growth of cancerous cells and consequently, they are usually overexpressed on tumours and therefore can also be used as targets in brain tumour therapies. For example, TfR is overexpressed on the brain capillary endothelium [260] and at the surface of proliferating cells such as brain tumour cells, especially glioblastoma multiforme [261] while, in contrast, a low level of TfR is observed on other healthy tissue. The ability of ILs to deliver genes within tumoural brain cells through TfR was studied by Zhang et al. [262]. ILs decorated with both 8D3 MAb, an antibody for TfR (to allow the crossing of the BBB by a RMT mechanism), and 83-14 MAb, an antibody for the human insulin receptor (to induce RME) [263], carrying a plasmid DNA encoding the EGFR antisense $m$ RNA, were intravenously injected in mice bearing U87 brain tumours. A $100 \%$ increase in the survival rate was observed for the group treated by the plasmid $m$ RNA-loaded-ILs in comparison to the saline control and the luciferase gene therapy group, therefore demonstrating the ability of these ILs to treat brain tumours. The MAb known as OX26 recognizes an extracellular domain on the TfR distinct from the Tf binding site and thus does not interfere with endogenous Tf binding. Experiments showed specific targeting of OX26 on the brain capillary endothelial cells in rats and its ability to reach the cerebral parenchyma [264, 265], therefore allowing the development of drug delivery systems to the brain using OX26 MAb. OX26- biotinylated-ILs loaded with daunomycin, prepared by a non-covalent (biotin-streptavidin) coupling procedure, revealed a two-fold higher accumulation in brain tissue as well as brain permeability as compared to IgG-ILs 1 hour after intravenous administration [138]. None of several other tissues analyzed such as spleen, liver, heart, skeletal muscle, and kidney (and in sharp contrast to the brain) have shown a superior targeting of OX26-ILs as compared to IgG-ILs. The authors demonstrated that such biotinylated ILs are internalized by RME in vitro by cells expressing the rat TfR [266] and by-pass P-gp in MDR RBE4 brain capillary endothelial cells, and thereby achieved 2- to 3-fold higher intracellular accumulation of liposomal daunomycin as compared to free drug [138].

EGFR is an attractive molecular target for the specific delivery of therapeutic agents to high-grade gliomas as it is frequently overexpressed in glioblastoma multiforme and anaplastic astrocytomas, but it is undetectable or weakly expressed in the normal brain [267]. ILs conjugated to anti-EGFR antibody have been proposed for boron neutron capture therapy. Cetuximab ILs were synthesized using a maleimido-PEG-cholesterol as an anchor for surface conjugation to targeted delivery of boron compounds to EGFR $(+)$ glioma cells for neutron capture therapy [139]. Much greater (8-fold) cellular uptake of boron was obtained using
cetuximab-ILs in EGFR(+) F98 $8_{\text {EGFR }}$ cells compared with nontargeted human IgG-ILs. Also, ILs composed of nickel lipid were synthesized using the antibody affinity motif of protein A (ZZ) as an adaptor for surface conjugation of anti-EGFR antibodies to targeted delivery of boron compounds to EGFR-overexpressing glioma cells. Immunohistochemical analysis revealed that the boron compound was delivered effectively into the cells but not into EGFR-deficient glioma or primary astrocytes. Moreover, studies in animal models of brain tumours confirmed that both the Ls and the boron compound were only observed in the tumour with an effective delivery into glioma cells [140]. The treatment of intracranial U-87 MG brain tumours in nude mice with DOXencapsulated long-circulating $\mathrm{Ls}$ conjugated to the MAb 2C5 provides a significant therapeutic benefit over control formulations, substantially reducing the tumour size and almost doubling the survival time [137].

Because ILs are not able for sustained release of transported compounds, they require frequent administrations to sustain a pharmacological effect [268]. ImmunoPNP with sustained release properties may offer an interesting alternative. PNP conjugated to OX26 MAb were synthesized using chitosan-PEG and chitosanPEG-biotin copolymers to carry a specific caspase inhibitor (ZDEVD-FMK), which significantly reduces vulnerability to the neuronal cell death but is unable to cross the BBB and to diffuse into the brain tissue [153]. Fluorescently-labelled NPs were administered systemically to mice and the brain uptake was observed by both fluorescent and electronic microscopy. A great number of OX26-immunoNPs could penetrate into the brain whereas the OX26-free NPs could not, suggesting the crossing of the BBB by RMT. These NPs combine the cationic character to interact with the negative charges of the brain endothelium and the affinity of OX26 for the TfR to trigger receptor-mediated transport across the BBB. Antibody-conjugated HSA NPs were prepared to deliver loperamide, an analgesic drug that normally does not cross the BBB in the brain [269]. OX26 and a transferrin receptor MAb (R17217) were covalently coupled to NPs using the NHS-PEGmaleimide-5000 crosslinker. Significant anti-analgesic effects in the tail-flick test were observed compared to the control loperamideloaded HSA NPs with IgG2a antibodies therefore demonstrating that the loperamide-MAb-coupled HSA NPs were able to transport this drug and possibly other drugs across the BBB. Tsutsui et al. synthesized hybrid bionanocapsules (BNCs), which are hollow NPs that are composed of $\mathrm{L}$ protein (the hepatitis B virus surface antigen), conjugated with anti-human EGFR antibody recognizing EGFRvIII, a constitutively active genomic sequence deletion variant of EGFR overexpressed in human glioblastoma [270]. The hybrid BNCs were efficiently delivered to glioma cells but not normal glial cells. Moreover, they confirmed the specific delivery of the hybrid BNCs to brain tumours in an in vivo brain tumour model.

A long way of optimization and evaluation is still, however, needed before potential clinical application. Providing NPs with stealth properties is a complex issue that involves the optimization of combined parameters, such as the NP size and the surfactant molecular weight and amount. Stealth properties and BBB transportation of immunoNPs, as well as effective drug release in the brain parenchyma, remain to be investigated [268].

\subsection{Inflammatory and Infectious Diseases}

One of the foremost areas of promise for targeting drug delivery by NPs that has so far been relatively unexploited is the treatment of inflammatory and infectious diseases. Large doses of the most common and potent drugs used are necessary to induce a satisfactory effect and often cause unwanted side effects when applied in their free form [271]. Inflammatory as well as infectious diseases are known to activate the immune system. Macrophages 
are among potential cellular targets by drug-loaded NPs as they play a central role in the initiation and maintenance of the inflammatory process and act as reservoirs for microorganisms involved in infected diseases. Although targeting to those immunerelated cells appears rather easy due to their capacity to recognize and phagocytize hydrophobic particles, selective targeting to organs different from liver and spleen is challenging being, however, essential for the success of these therapies. From the therapeutic point of view, phagocytosis of NP-encapsulated drugs could lead to phagocyte apoptosis (as in the case of inflammatory diseases) or efficient microbial destruction, as macrophages may serve as sites of proliferation of microbes during some or all of the infection process [86]. Also, structural changes associated with the inflammatory process (e.g., rheumatoid arthritis, infarction, infections), such as the perturbation of the endothelial barrier integrity [272], can provide an accumulation of nanocarriers in the desired area (passive targeting). There is evidence in support of increased capillary permeability to Ls and polymeric nanospheres in the size range of 50-200 $\mathrm{nm}$ during inflammation based on observations in experimental animals and in humans [273-277]. Also, the overexpression of particular cell adhesion molecules (CAM) involved in leukocyte recruitment at inflammatory loci offers opportunities to achieve selective delivery to disease tissues [278] using MAb against these adhesion molecules. The induction of E-selectin, involved in the arrest of monocytes, neutrophils, and subsets of T-lymphocytes within the circulation, on endothelial cells is clearly associated with inflammatory and immune processes [279]. Therefore, antibody-conjugated NPs can present significant implications for the improved treatment of inflammatory diseases such as rheumatoid arthritis, inflammatory bowel disease, atherosclerosis, and multiple sclerosis, as well as bacterial and viral diseases such as tuberculosis, malaria, and acquired immunodeficiency syndrome (AIDS).

\subsubsection{Inflammatory Diseases}

Inflammation is a naturally occurring defence mechanism upon exposure to specific antigens, chemicals, infections, and physical stress. It is characterized by different events taking place at or near the injured area, including vascular endothelium cell (VEC) activation and immune-related cells like macrophage accumulation.

Due to their critical role in the initiation and maintenance of inflammation that leads to tissue destruction, the direct targeting of macrophages by NPs can find an application in the treatment of diseases such as atherosclerosis where monocytes/macrophages are attracted to the vessel wall promoting atherosclerotic lesions and plaque vulnerability, restenosis and rheumatoid arthritis where macrophages are activated and proliferate in an abnormal way leading to the production of pro-inflammatory cytokines and MMP at the joint synovium [280], and multiple sclerosis (an inflammatory disease of the central nervous system) where after their activation, they secrete an increased amount of nitric oxide (NO) which has neurotoxic effects and affects the permeability of the BBB [281, 282]. Also, due to their capacity to reach the central nervous system, circulating macrophages can act as carriers for drug-loaded NPs representing a powerful way to treat neuroinflammatory diseases.

CAMs are known to play a role in leukocyte recruitment. The expression of particular cell CAMs, such as ICAM-1, E-selectin, Pselectin, and/or VCAM-1, is locally induced or enhanced at sites of pathological inflammation [279] in acute and chronic disorders including rheumatoid arthritis [283], organ ischemia-reperfusion injury [284], inflammatory bowel diseases [285], asthma [286], atherosclerosis. The overexpression of these CAMs at inflammatory loci offers opportunities for the development of drug delivery strategies to achieve selective delivery to disease tissues [271, 278]. MAbs against adhesion molecules have been used to inhibit leukocyte recruitment into areas of dermal, synovial, and lung inflammation [287-290]. Examples of such molecules in clinical development are CDP870 for the treatment of rheumatoid arthritis and Crohn's disease, and CDP860 for the acute treatment of coronary restenosis. This has provided the platform for further research and development, as an approach for antibody-based therapy of chronic disease [105]. A promising opportunity for therapeutic intervention is to couple these MAbs to NPs, allowing the transfer of large numbers of drug molecules to an individual target site.

Studies on production of PNP that have been shown to accumulate in vascular lesions for the prevention of restenosis [291, 292] and for imaging and therapy of arthritis [273, 293, 294], and of Ls for the treatment of encephalomyelitis [295-299] and multiple sclerosis [300], have been until now based on passive targeting and targeting using peptides or glycol groups. Despite the studies concerning antibody-conjugated NPs are at the very beginning, promising initial outcomes have already been achieved. ICAM-1 targeting offers the possibility of intracellular drug delivery, given that endothelial cells internalize multimeric anti-ICAM conjugates, within 15 to $30 \mathrm{~min}$ [301], and anti-ICAM nanocarriers via a unique, newly defined pathway, CAM-mediated endocytosis [302]. In addition to acting as delivery vehicles, antibody blocking of ICAM-1 suppresses leukocyte adhesion to endothelial cells, providing an anti-inflammatory benefit to the effects of drugs. Also, anti-E-selectin ILs loaded with dexamethasone have been tested in vivo and display binding and internalization in a mouse model of skin inflammation [141]. Dexamethasone-loaded Ls conjugated with anti-E-selectin antibodies were shown to be internalized by activated endothelial cells in vitro through E-selectin-mediated endocytosis in an injury model characterized by glomerular renal inflammation $[142,303]$. These ILs not only show an accumulation in the inflamed kidney 3.6 times higher than non-targeted $\operatorname{IgG~Ls}$, but also reduce inflammatory gene expression without affecting blood glucose levels, a severe side effect of administration of free dexamethasone. The targeting approaches on the basis of endothelial cell adhesion molecules offer a possibility of selectively targeting the inflamed endothelium, and are an alternative approach in colitis therapy. Based on mechanisms of leukocyte recruitment to sites of inflammation, leukocyte-inspired biodegradable PEGylated PLGA particles conjugated with antibodies such as anti-human ICAM-1, anti-human VCAM-1, anti-human E-selectin, and antihuman P-selectin that exhibit highly selective accumulation on inflamed endothelium in vitro and in vivo were designed by Sakhalkar et al. [154]. The particles exhibited: $i$ ) in vitro attachment efficiencies to inflamed endothelium on par with that of leukocytes; ii) up to 15 -fold selective adhesion to inflamed endothelium under physiologically relevant in vitro flow conditions; iii) a 6-fold selective adhesion for cytokine inflamed endothelium, relative to non-cytokine treated endothelium, in vivo; and, iv) up to 10 -fold enhancement in adhesion to trauma-induced inflamed endothelium in vivo due to the addition of the targeting ligand.

\subsubsection{Infectious Diseases}

Infectious diseases like AIDS, malaria, and tuberculosis continue to be one of the greatest health challenges in the world. The main drawbacks of conventional chemotherapy are the high drug doses required due to their unspecificity and subsequent toxicity, and the development of MDR. Macrophages act as host cells to many bacteria, parasites, and virus allowing the development of many deadly diseases. Therefore, targeting NPs to macrophages is particularly attractive because it allows the increase of drug concentration at specific sites where macrophages are abundant thus decreasing the systemic toxicity.

\subsubsection{Viral Infectious Disease: Acquired Immunodeficiency} Syndrome (AIDS)

In AIDS, macrophages represent a cell population of the RES that plays an important role in the immunopathogenesis of the 
disease. Encouraging results of the improved delivery of antiviral agents to the MPS have been obtained using NPs [304]. An increased antiviral activity in a dose-dependent manner, as determined by a reduction of the human immunodeficiency virus (HIV) type 1 antigen production, was observed in vitro using poly(hexylcyanoacrylate) (PHCA) PNP loaded with the protease inhibitor saquinavir or the nucleoside analogue zalcitabine in infected primary human monocytes/macrophages when compared with the free drug [305]. The composition and size of PNP have shown a great influence on the capacity of HIV-infected macrophages to phagocytyze azidothymidine-loaded PNP. PHCA and HSA PNP with a diameter of $200 \mathrm{~nm}$ have delivered the antiviral drug more successfully [251]. Considering the high viral load observed in the lymphoid tissues and the fact that the viral replication in lymph nodes is 10-100-fold higher than that in peripheral blood mononuclear cells [306], the attachment of antibodies to NPs represents an attractive strategy to obtain an efficient delivery of therapeutic drugs to lymphoid tissues [144], therefore decreasing their viral stores. HLA-DR (human leukocyte antigens) is a major histocompatibility complex class II (MHC-II) cell surface receptor that is expressed in substantial levels by cells involved in the HIV infection development process such as follicular dendritic cells (FDC), B lymphocytes, activated CD4+ Tcells, and antigen presenting cells like macrophages. Additionally, HLA-DR determinant is physically present on the virion surface and constitutes one of the most abundant host-derived molecules carried by HIV-1 [307]. Therefore, NPs bearing surface-attached anti-HLA-DR antibodies constitute an interesting approach to target specifically HIV-1 reservoirs, as well as free HIV-1 particles trapped in the FDC network.

The ability of Ls bearing anti-HLA-DR Fab' fragments at the end termini of PEG chains to target HLA-DR expressing cells and increase their accumulation in secondary lymphoid organs has been evaluated and compared to that of conventional Ls, sterically stabilized Ls, and conventional ILs [144]. Fluorescence microscopy studies demonstrated that sterically stabilized Ls accumulated only in macrophage-rich areas such as the subcapsular region of lymph nodes, and in the red pulp and marginal zone of the spleen. In contrast, sterically stabilized ILs highly accumulated in the deep cortex of lymph nodes which contains aggregates of B-cells and FDCs constituting the follicles, therefore representing a convenient strategy to deliver drugs in this area of the nodes inhibiting more efficiently HIV-1 replication. Moreover, the injection of sterically stabilized ILs resulted in an intense fluorescence signal in the white pulp of the spleen, suggesting a selective targeting of B-cells in the follicles, and of macrophages present in the marginal zone surrounding the lymphoid follicle. The use of sterically stabilized ILs could represent a convenient strategy to concentrate anti-HIV-1 drugs at sites of infection, more particularly within lymphoid organs, therefore reducing the dissemination of HIV-1 and preserving the FDC microenvironment that will likely protect the infected host from developing the characteristic immunodefficient state. Bergeron et al. [143] also show that immunoliposomal indinavir is as efficient as the free agent to inhibit HIV-1 replication in cultured cells. On a tissue distribution study, they found that sterically stabilized anti-HLA-DR-ILs were very efficient in delivering high concentrations of indinavir to lymphoid tissues for at least 15 days post- a single subcutaneous injection to $\mathrm{C} 3 \mathrm{H}$ mice, increasing by up to 126 times the drug accumulation in lymph nodes while free indinavir resulted in low drug levels in lymphoid organs. No toxicity and immunogenicity signals were observed in rodents after repeated administrations of liposomal formulations [143].

The improved pharmacology of immunoliposomal drugs could reduce the dose and frequency of administration of antivirals used in conventional therapy, facilitating drug compliance and limiting the occurrence of drug resistance. These results are very important as in 2009, 2.6 million people contracted the virus and there were 1.8 million HIV/AIDS-related deaths. More than 5 million people in low- and middle-income countries were receiving antiretroviral therapy by the end of 2009 , but that left more than 9 million untreated HIV-positive people in these countries [156].

\subsubsection{Malaria}

Malaria, the most prevalent parasitic disease in the world, is a serious public health problem which affected 225 million people and accounted for 781000 deaths, mostly of children under five years old, in 2009 [156]. The disease, caused by Plasmodium species transmitted to humans by the bites of a female mosquito, is being controlled by using antimalarial drugs, like chloroquine (CQ) and more recently tafenoquine, to which the malarial parasites are rapidly developing resistance by enhancing the drug efflux from the infected cells [308]. In order to effectively control this disease, it is essential the development of newer strategies for treating drugresistant malaria with existing drugs. The most important property of a nanocarrier in the context of malaria is the ability to remain in the blood stream for a long period of time in order to improve the interaction with infected red blood cells and parasite membranes [309].

Studies have shown that the covalent attachment of antibodies to Ls specifically enhanced their binding to rat erythrocytes in vivo and reduced their uptake by the liver and therefore can be used to target antimalarials to erythrocytes $[146,310,311]$. MAb F10bearing Ls containing CQ were produced and its efficacy was evaluated in mice infected with CQ-susceptible or CQ-resistant $P$. berghei [145]. CQ-loaded MAb F10-Ls were able to control not only the CQ-susceptibility but also the CQ-resistant P. berghei infections. Intravenous injection of CQ-loaded MAb F10-Ls at a dose of $5 \mathrm{mg} / \mathrm{Kg}$ of body weight per day on days 4 and 6 postinfection completely cured the mice (75\% and $90 \%$, respectively) infected with CQ-resistant P. berghei. The high therapeutic efficacy was attributed to the high degree of specificity of MAb F10-Ls to the malaria-infected erythrocytes and their efficient internalization, and to the possible specific binding of MAb F10-Ls to free parasites. These characteristics conjugated with the ability of Ls to deliver several drug molecules at the same time to the target cells, provided a high concentration of the drug in infected cells sufficient to kill the intracellular parasite. Also CQ-encapsulated Ls covalently attached to anti-erythrocyte $\mathrm{F}\left(\mathrm{ab}^{\prime}\right) 2$ fragments showed to be effective in suppression of the CQ susceptible and resistant $P$. berghei infections, both in terms of reduction in parasitaemia and prolongation in the survival times [146, 147].

Although some promising results have already been obtained, antibody-conjugated NP technology applied to malaria therapy is a domain that it is still in the very beginning.

\subsubsection{Tuberculosis}

Approximately 2 billion people are currently infected with Mycobacterium tuberculosis worldwide, representing about $30 \%$ of the global population. M. tuberculosis invades and begins its replication within alveolar macrophages before the bacterium spreads out. Therefore, tuberculosis can be seen as a disease involving macrophages which makes the targeting of macrophages by antibody-conjugated NPs a promising alternative in tuberculosis treatment. The same approaches mentioned in the previous sections for viral infectious diseases can be taken for the targeting of macrophages and treatment of tuberculosis. However, at present no studies have yet been developed in this area.

\subsection{Pulmonary Diseases}

Lung diseases, such as acute lung injury, cystic fibrosis, chronic obstructive lung disease, pulmonary hypertension, and others, could all benefit from targeted drug delivery systems. The lungs are 
unique among the various body organs in that drugs, including NPs carrying drugs, may be delivered to them via the airways or intravenously. Inhalation is gaining more attention in recent years, due to the large alveolar surface for drug absorption, the low thickness of the epithelial barrier, an extensive vascularization, a rather low proteolytic activity in the alveolar space compared to other administration routes, and the absence of the first passmetabolism [212]. However, especially for lung diseases in which dysregulated endothelial function is an important component of pathogenesis, intravenous administration will often be the preferred route for NP delivery. The endothelium represents an important therapeutic target for controlling oxidative stress, thrombosis, and inflammation involved in pulmonary diseases therefore constitutive CAM (e.g., ICAM-1 and PECAM-1) can be ideal candidates for lung targeting [212]. Moreover, while monomeric immunocarriers exhibited avid binding to target CAMs but poor internalization in EC both in vitro and in vivo, multimeric nanoscale conjugates (< $500 \mathrm{~nm}$ ) obtained by coating beads with anti-ICAM antibodies were rapidly internalized in ECs via an unique endocytic process induced by ICAM clustering [302, 312]. It seems that utilizing NPs conjugated anti-CAM can be a promising delivery concept to endothelial cells and especially useful to treat pulmonary diseases. Studies performed by Wiewrodt et al. and Muro et al. showed that the endothelial cells internalize NPs conjugated with multiple copies of either ICAM-1 or PECAM-1 antibodies [302, 313]. Conjugates with diameter from 100 to $300 \mathrm{~nm}$ can enter endothelial cells, whereas conjugates of larger size $(500 \mathrm{~nm}$ to $1 \mu \mathrm{m}$ in diameter) remain attached to the cell surface. Therefore, by modulating the size of anti-CAM conjugate carriers, the drugs can be targeted to the surface of endothelial cells or to their interior. Anti-ICAM-conjugated PLGA PNP were tested in vitro and in vivo by Muro et al. to measure their targeting ability to the lung [149]. The anti-ICAM PNP rapidly and specifically bound to tumour necrosis factor-activated ECs in a dose-dependent manner at both static and physiological shear stress conditions, and bound to ECs and accumulated in the pulmonary vasculature after intravenous injection in mice. Anti-ICAM PNP displayed markedly higher EC affinity $v s$. naked anti-ICAM $(K \mathrm{~d} \approx 80 \mathrm{pM} v s . \approx 8 \mathrm{nM})$ in cell culture and, probably because of this factor, higher value and selectivity of pulmonary targeting. Maruyama et al. have produced long-circulating ILs which can effectively bind to the lung in vivo by conjugation of $34 \mathrm{MAb}$, highly specific MAb to pulmonary endothelial cells, directly to the PEG terminal [119]. They found that the efficiency of IL binding to the target depended on the antibody density. The final number of antibody per $\mathrm{L}$ varied from 0 to 74, but the average size of the ILs stayed approximately the same (90 - $130 \mathrm{~nm}$ in diameter). The results show that lung binding reached a plateau at about $30 \mathrm{MAb}$ per $\mathrm{L}$ with a further increase in antibody content resulting in an increase in liver uptake.

\subsection{Other Therapeutic Applications}

Thrombosis is the formation of a blood clot inside a blood vessel, obstructing the flow of blood through the circulatory system. When a blood vessel is injured, the body uses platelets and fibrin to form a blood clot and prevent blood loss. In people admitted to hospital, thrombosis is a major cause for complications, and can often lead to loss of capacity and occasionally death. The main function of tissue plasminogen activator (tPA) is the proteolytic activation of plasminogen into plasmin, the form capable of breaking down blood clots. Currently, tPA is administered intravenously after myocardial infarction and stroke to ensure blood-clot dissolution. One problem associated with such treatment is the systemic toxicity of tPA, which can act upon plasminogen both in circulation and at the clot site, generating systemic plasmin and rendering the patient highly vulnerable to haemorrhaging. By conjugation of a fibrin-specific antibody to NPs it is possible to directly deliver tPA to the clot site. Yurko et al. covalently attached
tPA and antifibrin antibody to polystyrene NPs, and an in vitro fibrinolysis assay showed that the tPA-antibody-NP conjugate were only slightly less potent than free tPA [314]. Moreover, tPA activity in the absence of clots was more than 3-fold less than that of the free enzyme. This system could therefore become a promising agent for thrombolytic treatment because the NPs can be expected to dissolve clots at approximately the same rate as free tPA, while simultaneously cleaving much less plasminogen in the circulation, thus lowering the risk of haemorrhage.

\section{CONCLUSIONS, CHALLENGES AND PERSPECTIVES}

Antibody-conjugated NPs are a rapidly evolving research field with tremendous clinical perspectives. Despite the vast efforts devoted to their development and some success already achieved, MAbs-conjugated NPs still encounter many challenges and limitations. For clinical success, it is essential to continue the research in interdisciplinary areas of molecular and cellular immunology, proteomics, intracellular trafficking, material science, biology, mechanical, and chemical engineering.

Further investigations are necessary to find other target cells and cell molecules and increase the knowledge on specific and disease-related adhesion mechanisms. A great contribution is the new technologies used in antibody production that can be engineered to bind to their target with high affinity and improved cell penetration. New tracking studies currently being performed provide insights into particle behaviour in complex biological environments. However, a better understanding of these processes, including their transport in the blood circulation, cellular recognition, translocation into the cytoplasm, and final fate in the target cell is needed to rational improve the particle design to increase the therapeutic index of the targeting nanocarriers. Controlling and tailoring the physicochemical properties of NPs and their behaviours in various conditions is also a key to success. The materials used for NP fabrication have to be chosen carefully to ensure the safety of the system. Moreover, the long-term effects of various nanoparticulate systems are not well known and have to be well assessed before moving further in their development and applications. Another issue that must be addressed and requires further investigation on the already known NP production methods as well as the development of new techniques is the difficulty, costs, and safety of scaling-up.

Although studies in murine models are important, problems when attempting to translate potential therapies to humans are expected to occur due to the differences in biology of murine and humans including the mechanisms of NP clearance. Nevertheless, it is tempting to hope that, in the near future, targeted drug delivery using antibody-conjugated NPs translates from initial successes reported in laboratory animals to medical practice.

\section{CONFLICT OF INTEREST}

None declared.

\section{AKNOWLEDGEMENTS}

Inês Peça is grateful for financial support from Fundação para a Ciência e a Tecnologia through contract SFRH/BD/48773/2008. This work has been supported by Fundação para a Ciência e a Tecnologia through grant no. PEst-C/EQB/LA0006/2011.

\section{ABBREVIATIONS}

$\begin{array}{ll}\mathrm{AME} & =\text { adsorptive-mediated endocytosis } \\ \mathrm{BBB} & =\text { blood brain barrier } \\ \mathrm{BNCs} & =\text { bionanocapsules }\end{array}$




\begin{tabular}{|c|c|c|c|c|c|}
\hline BSA & $=$ & bovin serum albumin & SA & $=$ & streptavidin \\
\hline CAM & $=$ & cell adhesion molecule & $\mathrm{scFv}$ & $=$ & single-chain antibody Fv fragment \\
\hline CDR & $=$ & complementary determining regions & $\mathrm{Tf}$ & $=$ & transferrin \\
\hline CEA & $=$ & carcinoembryonic antigen & TfR & $=$ & human transferrin receptor \\
\hline CMT & $=$ & carrier-mediated transport & TfR & $=$ & transferrin receptor \\
\hline CPNP & $=$ & calcium phosphosilicate nanocomposite particles & tPA & $=$ & tissue plasminogen activator \\
\hline CQ & $=$ & chloroquine & VCAM-1 & $=$ & vascular cell adhesion molecule-1 \\
\hline DOX & $=$ & doxorubicin & VEC & $=$ & vascular endothelium cell \\
\hline DR5 & $=$ & death receptor 5 & VEGFR & $=$ & vascular endothelial growth factor receptor \\
\hline
\end{tabular}

$\mathrm{ECM}=$ extracellular matrix proteins

EDC = 1-ethyl-3-(3-dimethylaminopropyl) carbodiimide

\section{REFERENCES}

EGFR $=$ epidermal growth factor receptor

FDC $=$ follicular dendritic cells

$\mathrm{HAb}=$ half antibody

[1] Kreuter, J. In: Nanoparticles; Marcel Dekker: New York, 1994

[2] Gu, F.; Karnik, R.; Wang, A.; Alexis, F.; Levy-Nissenbaum, E.; Hong, S.; Langer, R.; Farokhzad, O. Targeted nanoparticles for cancer therapy. Nano Today, 2007, 2(3), 14-21.

[3] Merisko-Liversidge, E.; Liversidge, G.G.; Cooper, E.R. Nanosizing: a formulation approach for poorly-water-soluble compounds. Eur. J. Pharm. Sci., 2003, 18(2), 113-120.

HAMA $=$ human anti-mouse antibody

$\mathrm{HCC}=$ hepatocellular carcinoma

[4] Nijhara, R.; Balakrishnan, K. Bringing nanomedicines to market: regulatory challenges, opportunities, and uncertainties. Nanomedicine, 2006, 2(2), 127136.

HER = human epidermal receptor

HER-2 = human epidermal receptor-2

[5] Cho, K.J.; Wang, X.; Nie, S.M.; Chen, Z.; Shin, D.M. Therapeutic nanoparticles for drug delivery in cancer. Clin. Cancer Res., 2008, 14(5), 1310-1316.

HIV = human immunodeficiency virus

HLA-DR = human leukocyte antigen complex

HuMAbs = human monoclonal antibodies

[6] Wang, X.; Yang, L.L.; Chen, Z.; Shin, D.M. Application of nanotechnology in cancer therapy and imaging. CA Cancer J. Clin., 2008, 58(2), 97-110.

[7] Zhang, L.; Gu, F.X.; Chan, J.M.; Wang, A.Z.; Langer, R.S.; Farokhzad, O.C. Nanoparticles in medicine: therapeutic applications and developments. Clin. Pharmacol. Ther, 2008, 83(5), 761-769.

$\mathrm{IC}_{50}=$ half maximal inhibitory concentration

[8] Singh, R.; Lillard, J.W. Nanoparticle-based targeted drug delivery. Exp. Mol. Pathol., 2009, 86(3), 215-223.

ICAM-1 = intercellular adhesion molecule 1

IL $=$ immunoliposome

$\mathrm{L}=$ liposome

MAbs = monoclonal antibodies

MDR = multi-drug resistance

[9] Moghimi, S.M.; Hunter, A.C.; Murray, J.C. Long-circulating and targetspecific nanoparticles: theory to practice. Pharmacol. Rev., 2001, 53(2), 283318.

[10] Gupta, P.K. Drug targeting in cancer-chemotherapy - a clinical perspective. J. Pharm. Sci., 1990, 79(11), 949-962.

[11] Allen, T.M. Ligand-targeted therapeutics in anticancer therapy. Nat. Rev Cancer, 2002, 2(10), 750-763.

[12] Langer, R. Drug delivery and targeting. Nature, 1998, 392(6679), 5-10.

MHC-II = major histocompatibility complex class II

[13] Kumar, M. Nano and microparticles as controlled drug delivery devices. $J$. Pharm. Pharm. Sci., 2000, 3(2), 234-258.

MMP = matrix metalloproteinase

MPS = mononuclear phagocyte system

[14] Lawrence, M. J.; Rees, G. D. Microemulsion-based media as novel drug delivery systems. Adv. Drug Deliv. Rev., 2000, 45(1), 89-121.

MT1-MMP = membrane type 1-matrix metalloproteinase

[15] Lambert, G.; Fattal, E. Couvreur, P. Nanoparticulate systems for the delivery of antisense oligonucleotides. Adv. Drug Deliv. Rev., 2001, 47(1), 99-112.

MuMAbs $=$ murine monoclonal antibodies

[16] Brannonpeppas, L. Recent advances on the use of biodegradable microparticles and nanoparticles in controlled drug-delivery. Int. J. Pharm. 1995, 116(1), 1-9.

NHS $=N$-hydroxysuccinimide

NPs $\quad=$ nanoparticles

[17] Soppimath, K.S.; Aminabhavi, T.M.; Kulkarni, A.R.; Rudzinski, W.E. Biodegradable polymeric nanoparticles as drug delivery devices. J. Control. Release, 2001, 70(1-2), 1-20.

NSCLC = advanced non-small cell lung cancer

PCAM = platelet endothelial call adhesion molecule

[18] Brigger, I.; Dubernet, C.; Couvreur, P. Nanoparticles in cancer therapy and diagnosis. Adv. Drug Deliv. Rev., 2002, 54(5), 631-651.

[19] Feng, S.S.; Chien, S. Chemotherapeutic engineering: application and further development of chemical engineering principles for chemotherapy of cancer and other diseases. Chem. Eng. Sci., 2003, 58(18), 4087-4114.

[20] Sanz, L.; Blanco, B.; Alvarez-Vallina, L. Antibodies and gene therapy: teaching old 'magic bullets' new tricks. Trends Immunol., 2004, 25(2), 85-91.

[21] van Dijk, M.A.; van de Winkel, J.G.J. Human antibodies as next generation therapeutics. Curr. Opin. Chem. Biol., 2001, 5(4), 368-374.

[22] Kohler, G.; Milstein, C. Continuous cultures of fused cells secreting antibody of predefined specificity. Nature, 1975, 256(5517), 495-497.

[23] Roque, A.C.A.; Lowe, C.R.; Taipa, M.A. Antibodies and genetically engineered related molecules: production and purification. Biotechnol. Prog., 2004, 20(3), 639-654

[24] Sa'adu, A.; Zumla, A. Human monoclonal antibodies: production, use, problems. Postgraduate Medical Science; Monoclonal antibodies: Production, engineering and clinical application, 1995, 85-120.

[25] Francisco, J.; Campbell, R.; Iverson, B.; Georgiou, G. Production and fluorescence-activated cell sorting of escherichia-coli expressing a funtional antibody fragment on the external surface. Proceedings of the National Academy of Sciences of the United States of America, 1993, 90(22), 1044410448.

[26] Schaffitzel, C.; Hanes, J.; Jermutus, L.; Pluckthun, A. Ribosome display: an in vitro method for selection and evolution of antibodies from libraries. $J$. Immunol. Methods, 1999, 231(1-2), 119-135. 
Winter, G.; Milstein, C., Man-Made antibodies. Nature, 1991, 349(6307), 293-299.

[28] Rees, A.; Staunton, D.; Webster, D.; Searle, S.; Henry, A.; Pedersen, J. Antibody designe - beyond the natural limits. Trends Biotechnol., 1994, 12(5), 199-206.

[29] Arruebo, M.; Valladares, M.; Gonzalez-Fernandez, A. Antibody-conjugated nanoparticles for biomedical applications. J. Nanomater., 2009, 439389, 24 pp.

[30] Jain, R.K. Transport od molecules across tumor vasculature. Cancer Metastasis Rev., 1987, 6(4), 559-593.

[31] Weiner, L. Monoclonal antibody therapy of cancer. Semin. Oncol., 1999, 26(5), 43-51.

[32] Adams, G.; Schier, R. Generating improved single-chain Fv molecules for tumor targeting. J. Immunol. Methods, 1999, 23I(1-2), 249-260.

[33] Hudson, P.; Kortt, A. High avidity scFv multimers; diabodies and triabodies. J. Immunol. Methods, 1999, 231(1-2), 177-189.

[34] Arndt, K.; Muller, K.; Pluckthun, A. Factors influencing the dimer to monomer transition of an antibody single-chain Fv fragment. Biochemistry, 1998, 37(37), 12918-12926.

[35] Holliger, P.; Winter, G. Diabodies: small bispecific antibody fragments. Cancer Immunol. Immunother., 1997, 45(3-4), 128-130.

[36] Kortt, A.; Dolezal, O.; Power, B.; Hudson, P. Dimeric and trimeric antibodies: high avidity scFvs for cancer targeting. Biomol. Eng., 2001, 18(3), 95-108.

[37] Hu, S.; Shivery, L.; Raubitschek, A.; Sherman, M.; Williams, L.; Wong, J.; Shively, J.; Wu, A. Minibody: a novel engineered anti-carcinoembryonic antigen antibody fragment (single-chain $\mathrm{Fv}-\mathrm{C}(\mathrm{H}) 3$ ) which exhibits rapid, high-level targeting of xenografts. Cancer Res., 1996, 56(13), 3055-3061.

[38] Martin, F.; Toniatti, C.; Salvati, A.; Venturini, S.; Ciliberto, G.; Cortese, R.; Sollazzo, M. The affinity-selection of a minibody polypeptide inhibitor of human interleukin-6. Embo Journal, 1994, 13(22), 5303-5309.

[39] Dimasi, N.; Martin, F.; Volpari, C.; Brunetti, M.; Biasiol, G.; Altamura, S.; Cortese, R.; DeFrancesco, R.; Steinkuhler, C.; Sollazzo, M. Characterization of engineered hepatitis $\mathrm{C}$ virus NS3 protease inhibitors affinity selected from human pancreatic secretory trypsin inhibitor and minibody repertoires. $J$. Virol., 1997, 71(10), 7461-7469.

[40] Martin, F.; Steinkuhler, C.; Brunetti, M.; Pessi, A.; Cortese, R.; De Francesco, R.; Sollazzo, M. A loop-mimetic inhibitor of the HCV-NS3 protease derived from a minibody. Protein Eng., 1999, 12(11), 1005-1011.

[41] Schmidt, A.; Muller, D.; Mersmann, M.; Wuest, T.; Gerlach, E.; GarinChesa, P.; Rettig, W.J.; Pfizenmaier, K.; Moosmayer, D. Generation of human high-affinity antibodies specific for the fibroblast activation protein by guided selection. Eur. J. Biochem., 2001, 268(6), 1730-1738.

[42] Carter, P. Improving the efficacy of antibody-based cancer therapies. Nat. Rev. Cancer, 2001, I(2), 118-129.

[43] Von Mehren, M.; Adams, G.P.; Weiner, L.M. Monoclonal antibody therapy for cancer. Annual Review of Medicine-Selected Topics in the Clinical Sciences, 2003, 54, 343-369.

[44] Weiner, L.M.; Adams, G.P. New approaches to antibody therapy. Oncogene, 2000, 19(53), 6144-6151.

[45] Nobs, L.; Buchegger, F.; Gurny, R.; Allemann, E. Biodegradable nanoparticles for direct or two-step tumor immunotargeting. Bioconjug. Chem., 2006, 17(1), 139-145.

[46] Nobs, L.; Buchegger, F.; Gurny, R.; Allemann, E. Poly(lactic acid) nanoparticles labeled with biologically active neutravidin (TM) for active targeting. Eur. J. Pharm. Biopharma., 2004, 58(3), 483-490.

[47] Beduneau, A.; Saulnier, P.; Benoit, J.P. Active targeting of brain tumors using nanocarriers. Biomaterials, 2007, 28(33), 4947-4967.

[48] Sutton, D.; Nasongkla, N.; Blanco, E.; Gao, J. Functionalized micellar systems for cancer targeted drug delivery. Pharm. Res., 2007, 24(6), 10291046

[49] Juliano, R.L.; Stamp, D. Pharmacokinetics of liposome-encapsulated antitumor drugs - studies with vinblastine, actinomycin-D, Cytosine-arabinoside, and dounomycin. Biochem. Pharmacol., 1978, 27(1), 21-27.

[50] Rahman, A.; Husain, S.R.; Siddiqui, J.; Verma, M.; Agresti, M.; Center, M.; Safa, A.R.; Glazer, R.I. Liposome-mediated modulation os multidrug resistance in humam HL-60 leukaemia-cells. J. Natl. Cancer Inst., 1992, 84(24), 1909-1915.

[51] Northfelt, D.W.; Martin, F.J.; Working, P.; Volberding, P.A.; Russell, J.; Newman, M.; Aantea, M.A.; Kaplan, L.D. Doxorubicin encapsulated in liposomes containing surface-found polyethylene glycol: pharmacokinetics, tumor localization, and safety in patients with AIDS-related Kaposi's sarcoma. J. Clin. Pharmacol., 1996, 36(1), 55-63.

[52] Muggia, F.; Hamilton, A. Phase III data on Caelyx (R) in ovarian cancer. Eur. J. Cancer, 2001, 37(9), S15-S18.

[53] Farokhzad, O.C.; Langer, R. Nanomedicine: developing smarter therapeutic and diagnostic modalities. Adv. Drug Deliv. Rev., 2006, 58(14), 1456-1459.

[54] Arifin, D.Y.; Lee, L.Y.; Wang, C.H. Mathematical modeling and simulation of drug release from microspheres: implications to drug delivery systems. Adv. Drug Deliv. Rev., 2006, 58(12-13), 1274-1325.

[55] Gu, F.X.; Karnik, R.; Wang, A.Z.; Alexis, F.; Levy-Nissenbaum, E.; Hong, S.; Langer, R.S.; Farokhzad, O.C. Targeted nanoparticles for cancer therapy. Nano Today, 2007, 2(3), 14-21.

[56] Yeo, Y.; Park, K.N. Control of encapsulation efficiency and initial burst in polymeric microparticle systems. Arch. Pharm. Res., 2004, 27(1), 1-12.
[57] Bodmeier, R.; McGinity, J.W. The preparation and evaluation of drugcontaining poly(DL-lactide) microspheres formed by the solvent evaporation method. Pharm. Res., 1987, 4(6), 465-471.

[58] Pekarek, K. J.; Jacob, J. S.; Mathiowitz, E. Double-walled polymer microspheres for controlled drug-releae. Nature, 1994, 367(6460), 258-260.

[59] Food and Drug Administration. http://www.fda.gov/default.htm (accessed July 15,2011$)$

[60] Avgoustakis, K. Pegylated poly(lactide) and poly(lactide-co-glycolide) nanoparticles: preparation, properties and possible applications in drug delivery. Curr. Drug Deliv., 2004, 1(4), 321-333.

[61] Anderson, J.M.; Shive, M.S. Biodegradation and biocompatibility of PLA and PLGA microspheres. Adv. Drug Deliv. Rev., 1997, 28(1), 5-24.

[62] Astete, C.E.; Sabliov, C.M. Synthesis and characterization of PLGA nanoparticles. J. Biomater. Sci. Polym. Ed., 2006, 17(3), 247-289.

[63] Bawa, P.; Pillay, V.; Choonara, Y.E.; du Toit, L.C. Stimuli-responsive polymers and their applications in drug delivery. Biomed. Mater, 2009, 4(2), $15 \mathrm{pp}$

[64] Lee, E.S.; Oh, K.T.; Kim, D.; Youn, Y.S.; Bae, Y.H. Tumor pH-responsive flower-like micelles of poly(L-lactic acid)-b-poly (ethylene glycol)-b-poly(Lhistidine). J. Control. Release, 2007, 123(1), 19-26.

[65] Gullotti, E. Yeo, Y. Extracellularly activated nanocarriers: a new paradigm of tumor targeted drug delivery. Mo. Pharm., 2009, 6(4), 1041-1051.

[66] Min, K.H.; Park, K.; Kim, Y.S.; Bae, S.M.; Lee,S.; Jo, H.G.; Park, R.W.; Kim, I.S.; Jeong, S.Y.; Kim, K.; Kwon, I.C. Hydrophobically modified glycol chitosan nanoparticles-encapsulated camptothecin enhance the drug stability and tumor targeting in cancer therapy. J. Control. Release, 2008, 127(3), 208-218

[67] Cho, Y.W; Park, S.A.; Han, T.H.; Son, D.H.; Park, J.S.; Oh, S.J; Moon D.H.; Cho, K.J.; Ahn, C.H.; Byun, Y.; Kim, I.S.; Kwon, I.C.; Kim, S.Y. In vivo tumor targeting and radionuclide imaging with self-assembled nanoparticles: mechanisms, key factors, and their implications. Biomaterials, 2007, 28(6), 1236-1247.

[68] Stubbs, M.; McSheehy, P.M.J.; Griffiths, J.R.; Bashford, C.L. Causes and consequences of tumour acidity and implications for treatment. Mol. Med. Today, 2000, 6(1), 15-19.

[69] Lo, C.L.; Lin, K.M.; Hsiue, G.H. Preparation and characterization of intelligent core-shell nanoparticles based on poly(D,L-lactide)-g-poly $(\mathrm{N}$ isopropyl-acrylamide-co-methacrylic acid). $J$. Control. Release, $\mathbf{2 0 0 5}$, 104(3), 477-488

[70] Han, S.K.; Na, K.; Bae, Y.H. Sulfonamide based pH-sensitive polymeric micelles: physicochemical characteristics and $\mathrm{pH}$-dependent aggregation. Colloids Surfaces A Physicochem. Eng. Aspects, 2003, 214(1-3), 49-59.

[71] Hauck, M.L.; Coffin, D.O.; Dodge, R.K.; Dewhirst, M.W.; Mitchell, J.B.; Zalutsky, M.R. A local hyperthermia treatment which enhances antibody uptake in a glioma xenograft model does not affect tumour interstitial fluid pressure. Int. J. Hyperthermia, 1997, 13(3), 307-316.

[72] Kong, G.; Braun, R.D.; Dewhirst, M.W. Hyperthermia enables tumorspecific nanoparticle delivery: effect of particle size. Cancer Res., 2000 , 60(16), 4440-4445.

[73] Rapoport, N. Physical stimuli-responsive polymeric micelles for anti-cancer drug delivery. Prog. Polym. Sci., 2007, 32(8-9), 962-990.

[74] Galindo-Rodriguez, S.; Allemann, E.; Fessi, H.; Doelker, E. Physicochemical parameters associated with nanoparticle formation in the salting-out, emulsification-diffusion, and nanoprecipitation methods. Pharm. Res., 2004, 21(8), 1428-1439.

[75] Zambaux, M.F.; Bonneaux, F.; Gref, R.; Maincent, P.; Dellacherie, E.; Alonso, M.J.; Labrude, P.; Vigneron, C. Influence of experimental parameters on the characteristics of poly(lactic acid) nanoparticles prepared by a double emulsion method. J. Control. Release, 1998, 50(1-3), 31-40.

[76] Feng, S.S.; Huang, G.F. Effects of emulsifiers on the controlled release of paclitaxel (Taxol $(\mathrm{R})$ ) from nanospheres of biodegradable polymers. $J$. Control. Release, 2001, 71(1), 53-69.

[77] Mu, L.; Feng, S.S. Vitamin E TPGS used as emulsifier in the solvent evaporation/extraction technique for fabrication of polymeric nanospheres for controlled release of paclitaxel (Taxol (R)). J. Control. Release, 2002, 80(1-3), 129-144

[78] Niwa, T.; Takeuchi, H.; Hino, T.; Kunou, N.; Kawashima, Y. Preparations of biodegradable nanopheres of water-soluble and insoluble drugs with D,Llactide glycolide copolymer by a novel spontaneous emulsification solven diffusion method, and the drug release behavior. J. Control. Release, 1993 , 25(1-2), 89-98.

[79] Allemann, E.; Leroux, J.C.; Gurny, R.; Doelker, E. In-vitro extended-release properties of drug-loaded poly(DL-lactic acid) nanoparticles produced by a salting-out procedure. Pharm. Res., 1993, 10(12), 1732-1737.

[80] Tom, J.W.; Debenedetti, P.G. Particle formation with supercritical fluids - a review. J. Aerosol Sci., 1991, 22(5), 555-584.

[81] Randolph, T.W.; Randolph, A.D.; Mebes, M.; Yeung, S. Sub-micrometersized biodegradable particles of poly(l-lactic acid) via the gas antisolvent spray precipitation process. Biotechnol. Prog., 1993, 9(4), 429-435

[82] Tan, H.S.; Borsadia, S. Particle formation using supercritical fluids: pharmaceutical applications. Expert Opin. Ther. Pat., 2001, 11(5), 861-872.

[83] Costa, M.S.; Duarte, A.R.C.; Cardoso, M.M.; Duarte, C.M.M. Supercritical antisolvent precipitation of PHBV microparticles. Int. J. Pharm., 2007, 328(1), 72-77.

[84] Mohanraj, V.J.; Chen, Y. Nanoparticles - a review. Trop. J. Pharm. Res., 
2006, 5(1), 561-573.

[85] Seymour, L.W.; Duncan, R.; Strohalm, J.; Kopecek, J. Effect of molecularweight (mbarw) of n-(2-hydroxypropyl)methacrylamide copolymers on body distribution and rate of excretion after subcutaneous, intraperitoneal, and intravenous administration to rats. J. Biomed. Mater. Res., 1987, 21(11), 1341-1358.

[86] Moghimi, S.M.; Porter, C.J.H.; Muir, I.S.; Illum, L.; Davis, S.S. nonphagocytic uptake of intravenously injected microspheres in rat spleen influence of particle-size and hydrophilic coating. Biochem. Biophys. Res. Commun., 1991, 177(2), 861-866.

[87] Muller, R.H.; Souto, E.B.; Goppert, T.; Gohla, S. In: Biological and Pharmaceutical Nanomaterials; C. Kumar, Ed.; Wiley VCH: New York, 2006; pp. 287-303.

[88] Moghimi, S.M.; Patel, H.M. Serum-mediated recognition of liposomes by phagocytic cells of the reticuloendothelial system - the concept of tissue specificity. Adv. Drug Deliv. Rev., 1998, 32(1-2), 45-60.

[89] Senior, J.; Gregoriadis, G. Is half-life of curculating liposomes determined by changes in their permeability. FEBS Lett., 1982, 145(1), 109-114.

[90] Senior, J.; Crawley, J.C.W.; Gregoriadis, G. Tissue distribution of liposmies exhibiting long kalf-lives in the circulation after intravenous-injection. Biochim. Biophys. Acta, 1985, 839(1), 1-8.

[91] Storm, G.; Belliot, S.O.; Daemen, T.; Lasic, D.D. surface modification of nanoparticles to oppose uptake by the mononuclear phagocyte system. Adv. Drug Deliv. Rev., 1995, 17(1), 31-48.

[92] Gref, R.; Minamitake, Y.; Peracchia, M.T.; Trubetskoy, V.; Torchilin, V.; Langer, R. Biodegradable long-circulating polymeric nanospheres. Science, 1994, 263(5153), 1600-1603.

[93] Maitra, A. In: Handbook of Surface and Colloid; Birdi, K.S., Ed.; CRC Press: Denmark, 1997; pp. 603-611.

[94] Allen, T.M. Long-circulating (sterically stabilized) liposomes for targeted drug-delivery. Trends Pharmacol. Sci., 1994, 15(7), 215-220.

[95] Van Vlerken, L.E.; Vyas, T.K.; Amiji, M.M. Poly(ethylene glycol)-modified nanocarriers for tumor-targeted and intracellular delivery. Pharm. Res., 2007, 24(8), 1405-1414.

[96] Shenoy, D.B.; Amiji, M.A. Poly(ethylene oxide)-modified poly(epsiloncaprolactone) nanoparticles for targeted delivery of tamoxifen in breast cancer. Int. J. Pharm., 2005, 293(1-2), 261-270.

[97] Tada, H.; Higuchi, H.; Wanatabe, T.M.; Ohuchi, N. In vivo real-time tracking of single quantum dots conjugated with monoclonal anti-HER2 antibody in tumors of mice. Cancer Res., 2007, 67(3), 1138-1144.

[98] Park, J.W.; Hong, K.L.; Kirpotin, D.B.; Colbern, G.; Shalaby, R.; Baselga, J.; Shao, Y.; Nielsen, U.B.; Marks, J.D.; Moore, D.; Papahadjopoulos, D.; Benz, C.C. Anti-HER2 immunoliposomes: enhanced efficacy attributable to targeted delivery. Clin. Cancer Res., 2002, 8(4), 1172-1181.

[99] Sapra, P.; Allen, T.M. Internalizing antibodies are necessary for improved therapeutic efficacy of antibody-targeted liposomal drugs. Cancer Res., 2002, 62(24), 7190-7194.

[100] Bennis, S.; Chapey, C.; Couvreur, P.; Robert, J. Enhanced cytotoxicity of doxorubicin encapsulated in polyisohexylcyanoacrylate nanospheres against multidrug-resistant tumor-cells in culture. Eur. J. Cancer, 1994, 30A(1), 8993.

[101] Larsen, A.K.; Escargueil, A.E.; Skladanowski, A. Resistance mechanisms associated with altered intracellular distribution of anticancer agents. Pharmacol. Ther, 2000, 85(3), 217-229.

[102] Peer, D.; Karp, J.M.; Hong, S.; FaroKhzad, O.C.; Margalit, R.; Langer, R. Nanocarriers as an emerging platform for cancer therapy. Nat. Nanotechnol., 2007, 2(12), 751-760.

[103] Pastan, I.; Hassan, R.; FitzGerald, D.J.; Kreitman, R.J. Immunotoxin therapy of cancer. Nat. Rev. Cancer, 2006, 6(7), 559-565.

[104] de Menezes, D.E.L; Pilarski, L.M.; Allen, T.M. In vitro and in vivo targeting of immunoliposomal doxorubicin to human B-cell lymphoma. Cancer Res., 1998, 58(15), 3320-3330.

[105] Chapman, A.P. PEGylated antibodies and antibody fragments for improved therapy: a review. Adv. Drug Deliv. Rev., 2002, 54(4), 531-545.

[106] Cooper, M.A. Optical biosensors in drug discovery. Nat. Rev. Drug Discov, 2002, l(7), 515-528.

[107] Pietronave, S.; Iafisco, M.; Locarno, D.; Rimondini, L.; Prat, M. Functionalized nanomaterials for diagnosis and therapy of cancer. J. Appl. Biomater. Biomech., 2009, 7(2), 77-89.

[108] Melton, R.G. Preparation and purification of antibody-enzyme conjugates for therapeutic applications. Adv. Drug Deliv. Rev., 1996, 22(3), 289-301.

[109] Green, N.M. Avidin and streptavidin. Methods Enzymol., 1990, 184, 51-67.

[110] Pardridge, W.M. Vector-mediated peptide drug-delivery to the brain. $A d v$. Drug Deliv. Rev., 1995, 15(1-3), 109-146.

[111] Phillips, N.C.; Gagne, L.; Tsoukas, C.; Dahman, J. Immunoliposome targeting to murine cd4(+) leukocytes is dependent on immune status. $J$. Immunol., 1994, 152(6), 3168-3174.

[112] Wartlick, H.; Michaelis, K.; Balthasar, S.; Strebhardt, K.; Kreuter, J.; Langer, K. Highly specific HER2-mediated cellular uptake of antibody-modified nanoparticles in tumour cells. J. Drug Target., 2004, 12(7), 461-471.

[113] Dinauer, N.; Balthasar, S.; Weber, C.; Kreuter, J.; Langer, K.; Von Briesen, H. Selective targeting of antibody-conjugated nanoparticles to leukemic cells and primary T-lymphocytes. Biomaterials, 2005, 26(29), 5898-5906.

[114] Klibanov, A.L.; Maruyama, K.; Beckerleg, A.M.; Torchilin, V.P.; Huang, L. Activity of amphipathic poly(ethylene glycol)-5000 to prolong the circulation time of liposomes depends on the liposome size and is unfavorable for immunoliposome binding to target. Biochim. Biophys. Acta, 1991, $1062(2), 142-148$.

[115] Torchilin, V.P. Immunoliposomes and PEGylated immunoliposomes: possible use for targeted delivery of imaging agents. Immunomethods, 1994, 4(3), 244-58.

[116] Allen, T.M.; Brandeis, E.; Hansen, C.B.; Kao, G.Y.; Zalipsky, S. A new strategy for attachment of antibodies to sterically stabilized liposomes resulting in efficient targeting to cancer cells. Biochim. Biophys. Acta, 1995, 1237(2), 99-108.

[117] Hansen, C.B.; Kao, G.Y.; Moase, E.H.; Zalipsky, S.; Allen, T.M. Attachment of antibodies to sterically stabilized liposomes - evaluation, comparison and optimization of coupling procedures. Biochim. Biophys. Acta, 1995, 1239(2), 133-144.

[118] Shahinian, S.; Silvius, J.R. A novel strategy affords high-yield coupling of antibody fab' fragments to liposomes. Biochim. Biophys. Acta, 1995, $1239(2), 157-167$.

[119] Maruyama, K.; Takizawa, T.; Yuda, T.; Kennel, S.J.; Huang, L.; Iwatsuru, M. Targetability of novel immunoliposomes modified with amphipathic poly(ethylene glycol)s conjugated at their distal terminals to monoclonalantibodies. Biochim. Biophys. Acta, 1995, 1234(1), 74-80.

[120] Huwyler, J.; Wu, D.F.; Pardridge, W.M. Brain drug delivery of small molecules using immunoliposomes. Proceedings of the National Academy of Sciences of the United States of America, 1996, 93(24), 14164-14169.

[121] Nie, S.M.; Xing, Y.; Kim, G.J.; Simons, J.W. Nanotechnology applications in cancer. Annu. Rev. Biomed. Eng., 2007, 9, 257-288.

[122] Hatakeyama, H.; Akita, H.; Ishida, E.; Hashimoto, K.; Kobayashi, H.; Aoki, T.; Yasuda, J.; Obata, K.; Kikuchi, H.; Ishida, T.; Kiwada, H.; Harashima, H. Tumor targeting of doxorubicin by anti-MT1-MMP antibody-modified PEG liposomes. Int. J. Pharm., 2007, 342(1-2), 194-200.

[123] Kirpotin, D.B.; Drummond, D.C.; Shao, Y.; Shalaby, M.R.; Hong, K.L.; Nielsen, U.B.; Marks, J.D.; Benz, C.C.; Park, J.W. Antibody targeting of long-circulating lipidic nanoparticles does not increase tumor localization but does increase internalization in animal models. Cancer Res., 2006, 66(13), 6732-6740.

[124] Sugano, M.; Egilmez, N.K.; Yokota, S.J.; Chen, F.A.; Harding, J.; Huang, S.K.; Bankert, R.B. Antibody targeting of doxorubicin-loaded liposomes suppresses the growth and metastatic spread of established human lung tumor xenografts in severe combined immunodeficient mice. Cancer Res., 2000, 60(24), 6942-6949.

[125] ElBayoumi, T.A.; Torchilin, V.P. Tumor-specific anti-nucleosome antibody improves therapeutic efficacy of doxorubicin-loaded long-circulating liposomes against primary and metastatic tumor in mice. Mol. Pharm., 2009, 6(1), 246-254.

[126] El Bayoumil, T.; Torchilin, V.P. Tumor-targeted nanomedicines: enhanced antitumor efficacy in vivo of doxorubicin-loaded, long-circulating liposomes modified with cancer-specific monoclonal antibody. Clin. Cancer Res., 2009, 15(6), 1973-1980.

[127] Pirollo, K.F.; Rait, A.; Zhou, Q.; Hwang, S.H.; Dagata, J.A.; Zon, G.; Hogrefe, R.I.; Palchik, G.; Chang, E.H. Materializing the potential of small interfering RNA via a tumor-targeting nanodelivery system. Cancer Res., 2007, 67(7), 2938-2943.

[128] Sapra, P.; Moase, E.H.; Ma, J.; Allen, T.M., Improved therapeutic responses in a xenograft model of human B lymphoma (Namalwa) for liposomal vincristine versus liposomal doxorubicin targeted via anti-CD19 IgG2a or Fab' fragments. Clin. Cancer Res., 2004, 10(3), 1100-1111.

[129] Allen, T.M.; Mumbengegwi, D.R.; Charrois, G.J.R. Anti-CD19-targeted liposomal doxorubicin improves the therapeutic efficacy in murine B-cell lymphoma and ameliorates the toxicity of liposomes with varying drug release rates. Clin. Cancer Res., 2005, 11(9), 3567-3573.

[130] Sapra, P.; Allen, T.M. Improved outcome when B-cell lymphoma is treated with combinations of immunoliposomal anticancer drugs targeted to both the CD19 and CD20 epitopes. Clin. Cancer Res., 2004, 10(14), 4893-4893.

[131] Cheng, W.W.K.; Allen, T.M. Targeted delivery of anti-CD19 liposomal doxorubicin in B-cell lymphoma: a comparison of whole monoclonal antibody, Fab' fragments and single chain Fv. J. Control. Release, 2008, $126(1), 50-58$.

[132] Tuscano, J.M.; Martin, S.M.; Ma, Y.P.; Zamboni, W.; O'Donnell, R.T. Efficacy, biodistribution, and pharmacokinetics of CD22-targeted pegylated liposomal doxorubicin in a B-cell non-hodgkin's lymphoma xenograft mouse model. Clin. Cancer Res., 2010, 16(10), 2760-2768.

[133] Matsumura, Y.; Gotoh, M.; Muro, K.; Yamada, Y.; Shirao, K.; Shimada, Y; Okuwa, M.; Matsumoto, S.; Miyata, Y.; Ohkura, H.; Chin, K.; Baba, S.; Yama, T.; Kannami, A.; Takamatsu, Y.; Ito, K.; Takahashi, K. Phase I and pharmacokinetic study of MCC-465, a doxorubicin (DXR) encapsulated in PEG immunoliposome, in patients with metastatic stomach cancer. Annals Oncol., 2004, 15(3), 517-525.

[134] Hosokawa, S.; Tagawa, T.; Niki, H.; Hirakawa, Y.; Nohga, K.; Nagaike, K. Efficacy of immunoliposomes on cancer models in a cell-surface-antigendensity-dependent manner. British J. Cancer, 2003, 89(8), 1545-1551.

[135] Raffaghello, L.; Pagnan, G.; Pastorino, F.; Cosimo, E.; Brignole, C.; Marimpietri, D.; Bogenmann, E.; Ponzoni, M.; Montaldo, P.G. Immunoliposomal fenretinide: a novel antitumoral drug for human neuroblastoma. Cancer Lett., 2003, 197(1-2), 151-155.

[136] Pastorino, F.; Brignole, C.; Marimpietri, D.; Sapra, P.; Moase, E.H.; Allen, 
T.M. Ponzoni, M. Doxorubicin-loaded Fab' fragments of antidisialoganglioside immunoliposomes selectively inhibit the growth and dissemination of human neuroblastoma in nude mice. Cancer Res., 2003, 63(1), 86-92.

[137] Gupta, B.; Torchilin, V.P. Monoclonal antibody 2C5-modified doxorubicinloaded liposomes with significantly enhanced therapeutic activity against intracranial human brain U-87 MG tumor xenografts in nude mice. Cancer Immunol. Immunother., 2007, 56(8), 1215-1223.

[138] Schnyder, A.; Krahenbuhl, S.; Drewe, J.; Huwyler, J. Targeting of daunomycin using biotinylated immunoliposomes: Pharmacokinetics, tissue distribution and in vitro pharmacological effects. J. Drug Target., 2005, 13(5), 325-335.

[139] Pan, X.G.; Wu, G.; Yang, W.L.; Barth, R.F.; Tjarks, W.; Lee, R.J. Synthesis of cetuximab-immunoliposomes via a cholesterol-based membrane anchor for targeting of EGFR. Bioconjug. Chem., 2007, 18(1), 101-108.

[140] Feng, B.; Tomizawa, K.; Michiue, H.; Miyatake, S.; Han, X.J.; Fujimura, A.; Seno, M.; Kirihata, M.; Matsui, H. Delivery of sodium borocaptate to glioma cells using immunoliposome conjugated with anti-EGFR antibodies by ZZHis. Biomaterials, 2009, 30(9), 1746-1755.

[141] Everts, M.; Koning, G.A.; Kok, R.J.; Asgeirsdottir, S.A.; Vestweber, D.; Meijer, D.K.F.; Storm, G.; Molema, G. In vitro cellular handling and in vivo targeting of E-selectin-directed immunoconjugates and immunoliposomes used for drug delivery to inflamed endothelium. Pharm. Res., 2003, 20(1), 64-72.

[142] Van der Veen, B.S.; Asgeirsdottir, S.A.; Zwiers, P.J.; Molema, G.; Heeringa, P. Induction of CXCR2 expression and its ligands in experimental anti-MPO IgG induced glomerulonephritis. Clin. Exp. Rheumatol., 2007, 25(1), S91S91.

[143] Gagne, J.F.; Desormeaux, A.; Perron, S.; Tremblay, M.J.; Bergeron, M.G. Targeted delivery of indinavir to HIV-1 primary reservoirs with immunoliposomes. Biochim. Biophys. Acta, 2002, 1558(2), 198-210.

[144] Bestman-Smith, J.; Gourde, P.; Desormeaux, A.; Tremblay, M.J.; Bergeron, M.G. Sterically stabilized liposomes bearing anti-HLA-DR antibodies for targeting the primary cellular reservoirs of HIV-1. Biochim. Biophys. Acta, 2000, 1468(1-2), 161-174.

[145] Owais, M.; Varshney, G.; Choudhury, A.; Chandra, S.; Gupta, C. Chloroquine encapsulated in malaria-infected erythrocyte-specific antibodybearing liposomes effectively controls chloroquine-resistant plasmodiumberghei infections in mice. Antimicrob. Agents Chemother., 1995, 39(1), 180-184.

[146] Agrawal, A.; Singhal, A.; Gupta, C. Functional-drug targeting to erythrocytes invivo using antibody bearing liposomes as drug vehicles. Biochem. Biophys. Res. Commun., 1987, 148(1), 357-361.

[147] Chandra, S.; Agrawal, A.; Gupta, C. Chloroquine delivery to erythrocytes in plasmodium berghei-infected mice using antibody-bearing liposomes as drug vehicles. J. Biosci., 1991, 16(3), 137-144.

[148] Chen, H.; Gao, J.; Lu, Y.; Kou, G.; Zhang, H.; Fan, L.; Sun, Z.; Guo, Y.; Zhong, Y. Preparation and characterization of PE38KDEL-loaded anti-HER2 nanoparticles for targeted cancer therapy. J. Control. Release, 2008, 128(3), 209-216.

[149] Muro, S.; Dziubla, T.; Qiu, W.N.; Leferovich, J.; Cui, X.; Berk, E.; Muzykantov, V.R. Endothelial targeting of high-affinity multivalent polymer nanocarriers directed to intercellular adhesion molecule 1. J. Pharmacol. Exp. Ther, 2006, 317(3), 1161-1169.

[150] Liu, P.; Li, Z.; Zhu, M.; Sun, Y.; Li, Y.; Wang, H.; Duan, Y. Preparation of EGFR monoclonal antibody conjugated nanoparticles and targeting to hepatocellular carcinoma. J. Mater. Sci. Mater. Med., 2010, 21(2), 551-556.

[151] Debotton, N.; Parnes, M.; Kadouche, J.; Benita, S. Overcoming the formulation obstacles towards targeted chemotherapy: in vitro and in vivo evaluation of cytotoxic drug loaded immunonanoparticles. J. Control. Release, 2008, 127(3), 219-230

[152] Li, L.Y.; Wartchow, C.A.; Danthi, S.N.; Shen, Z.M.; Dechene, N.; Pease, J.; Choi, H.S.; Doede, T.; Chu, P.; Ning, S.C.; Lee, D.Y.; Bednarski, M.D.; Knox, S.J. A novel antiangiogenesis therapy using an integrin antagonist or anti-FLK-1 antibody coated Y-90-labeled nanoparticles. Int. J. Radiat. Oncol. Biol. Phys., 2004, 58(4), 1215-1227.

[153] Aktas, Y.; Yemisci, M.; Andrieux, K.; Gursoy, R.N.; Alonso, M.J.; Fernandez-Megia, E.; Novoa-Carballal, R.; Quinoa, E.; Riguera, R.; Sargon, M.F.; Celik, H.H.; Demir, A.S.; Hincal, A.A.; Dalkara, T.; Capan, Y.; Couvreur, P. Development and brain delivery of chitosan-PEG nanoparticles functionalized with the monoclonal antibody OX26. Bioconjug. Chem., 2005, 16(6), 1503-1511.

[154] Sakhalkar, H.S.; Dalal, M.K.; Salem, A.K.; Ansari, R.; Fu, A.; Kiani, M.F.; Kurjiaka, D.T.; Hanes, J.; Shakesheff, K.M.; Goetz, D.J. Leukocyte-inspired biodegradable particles that selectively and avidly adhere to inflamed endothelium in vitro and in vivo. Proceedings of the National Academy of Sciences of the United States of America, 2003, 100(26), 15895-15900.

[155] Jin, C.; Qian, N.S.; Zhao, W.; Yang, W.Q.; Bai, L.; Wu, H.; Wang, M.C.; Song, W.J.; Dou, K.F. Improved therapeutic effect of DOX-PLGA-PEG micelles decorated with bivalent fragment $\mathrm{HAb} 18 \mathrm{~F}\left(\mathrm{ab}^{\prime}\right)(2)$ for hepatocellular carcinoma. Biomacromolecules, 2010, 1 (9), 2422-2431.

[156] World Health Organization. http://www.who.int (accessed August 4, 2011)

[157] Ruoslahti, E.; Bhatia, S.N.; Sailor, M.J. Targeting of drugs and nanoparticles to tumors. J. Cell Biol., 2010, 188(6), 759-768.

[158] Brannon-Peppas, L.; Blanchette, J.O. Nanoparticle and targeted systems for cancer therapy. Adv. Drug Deliv. Rev., 2004, 56(11), 1649-1659.

[159] Abou-Jawde, R.; Choueiri, T.; Alemany, C.; Mekhail, T. An overview of targeted treatments in cancer. Clin. Ther., 2003, 25(8), 2121-2137.

[160] Kim, C.K.; Lim, S.J. Recent progress in drug delivery systems for anticancer agents. Arch. Pharm. Res., 2002, 25(3), 229-239.

[161] Liu, Y.Y.; Miyoshi, H.; Nakamura, M. Nanomedicine for drug delivery and imaging: a promising avenue for cancer therapy and diagnosis using targeted functional nanoparticles. Int. J. Cancer, 2007, 120(12), 2527-2537.

[162] Byrne, J.D.; Betancourt, T.; Brannon-Peppas, L. Active targeting schemes for nanoparticle systems in cancer therapeutics. Adv. Drug Deliv. Rev., 2008, 60(15), 1615-1626

[163] Park, K.; Lee, S.; Kang, E.; Kim, K.; Choi, K.; Kwon, I.C. New generation of multifunctional nanoparticles for Cancer Imaging and Therapy. $A d v$ Funct. Mater, 2009, 19(10), 1553-1566.

[164] Jain, K.K. Advances in the field of nanooncology. BMC Med., 2010, 8, 83.

[165] Arias, J.L. Drug targeting strategies in cancer treatment: an overview. Mini Rev. Med. Chem., 2011, 11(1), 1-17.

[166] Arias, J.L. Drug delivery strategies in targeting cancer: current concepts and future developments. Curr. Drug Targets, 2011, 12(8), 1094-1095.

[167] Kateb, B.; Chiu, K.; Black, K.L.; Yamamoto, V.; Khalsa, B.; Ljubimova, J.Y; Ding, H.; Patil, R.; Portilla-Arias, J.A; Modo, M.; Moore, D.F; Farahani, K.; Okun, M.S.; Prakash, N.; Neman, J.; Ahdoot, D.; Grundfest, W.; Nikzad, S.; Heiss, J.D. Nanoplatforms for constructing new approaches to cancer treatment, imaging, and drug delivery: what should be the policy? Neuroimage, 2011, 54(1), S106-S124.

[168] Mishra, B.; Patel, B.B.; Tiwari, S. Colloidal nanocarriers: a review on formulation technology, types and applications toward targeted drug delivery. Nanomedicine, 2010, 6(1), 9-24.

[169] Fay, F.; Scott, C.J. Antibody-targeted nanoparticles for cancer therapy Immunotherapy, 2011, 3(3), 381-394.

[170] Grossfeld, G.D.; Carroll, P.R.; Lindeman, N.; Meng, M.W.; Groshen, S ; Feng, A.C.; Hawes, D.; Cote, R.J. Thrombospondin-1 expression in patients with pathologic stage $\mathrm{T} 3$ prostate cancer undergoing radical prostatectomy: association with $\mathrm{p} 53$ alterations, tumor angiogenesis, and tumor progression. Urology, 2002, 59(1), 97-102.

[171] Jones, A.; Harris, A.L. New developments in angiogenesis: a major mechanism for tumor growth and target for therapy. Cancer J. Sci. Am. 1998, 4(4), 209-217.

[172] Teicher, B.A. Molecular targets and cancer therapeutics: discovery, development and clinical validation. Drug Resist. Updat., 2000, 3(2), 67-73.

[173] Maitra, A. In: Handbook of Surface and Colloid; Birdi, K.S., Ed.; CRC Press: Boca Raton, 1997; pp. 603-611.

[174] Hobbs, S.K.; Monsky, W.L.; Yuan, F.; Roberts, W.G.; Griffith, L.; Torchilin, V.P.; Jain, R.K. Regulation of transport pathways in tumor vessels: role of tumor type and microenvironment. Proceedings of the National Academy of Sciences of the United States of America, 1998, 95(8), 4607-4612.

[175] Maeda, H.; Matsumura, Y. Tumoritropic and lymphotropic principles of macromolecular drugs. Crit. Rev. Ther. Drug Carrier Syst., 1989, 6(3), 193210.

[176] Matsumura, Y.; Maeda, H. A new concept for macromolecular therapeutics in cancer-chemotherapy - mechanism of tumoritropic accumulation of proteins and the antitumor agent smancs. Cancer Res., 1986, 46(12), 63876392.

[177] Dienst, A.; Grunow, A.; Unruh, M.; Rabausch, B.; Nor, J.E.; Fries, J.W.U.; Gottstein, C. Specific occlusion of murine and human tumor vasculature by VCAM-1-targeted recombinant fusion proteins. J. Natl. Cancer Inst., 2005, 97(10), 733-747.

[178] Ferrara, N.; Hillan, K.J.; Novotny, W. Bevacizumab (Avastin), a humanized anti-VEGF monoclonal antibody for cancer therapy. Biochem. Biophys. Res. Commun., 2005, 333(2), 328-335.

[179] Veikkola, T.; Karkkainen, M.; Claesson-Welsh, L.; Alitalo, K. Regulation of angiogenesis via vascular endothelial growth factor receptors. Cancer Res., 2000, 60(2), 203-212

[180] Fiedler, W.; Graeven, U.; Ergun, S.; Verago, S.; Kilic, N.; Stockschlader, M.; Hossfeld, D.K. Vascular endothelial growth factor, a possible paracrine growth factor in human acute myeloid leukaemia. Blood, 1997, 89(6), 18701875 .

[181] Liu, B.; Earl, H.M.; Baban, D.; Shoaibi, M.; Fabra, A.; Kerr, D.J.; Seymour, L.W. Melanoma cell lines express VEGF receptor KDR and respond to exogenously added VEGF. Biochem. Biophys. Res. Commun., 1995, 217(3), 721-727.

[182] Chen, J.; Wu, H.; Han, D.Y.; Xie, C.S. Using anti-VEGF McAb and magnetic nanoparticles as double-targeting vector for the radioimmunotherapy of liver cancer. Cancer Lett., 2006, 231(2), 169-175.

[183] Huang, K.H.; Liu, J.H.; Wang, L.Y.; Zhu, Z.H.; Chen, Q.K.; Min, J.; Chen, R.F. Study of the anti-tumor effect of anti-vascular endothelial growth facto $\mathrm{McAb}$ 5-fluorouracil loaded polylactic acid nanoparticles. Zhonghua Wei Chang Wai Ke Za Zhi, 2007, 10(5), 482-485.

[184] Mousa, S.A. Anti-integrin as novel drug-discovery targets: potential therapeutic and diagnostic implications. Curr. Opin. Chem. Biol., 2002, 6(4), 534-541.

[185] Nisato, R.E.; Tille, J.-C.; Jonczyk, A.; Goodman, S.L.; Pepper, M.S. Alphavbeta3 and alphavbeta5 integrin antagonists inhibit angiogenesis in vitro. Angiogenesis, 2003, 6(2), 105-119.

[186] Brooks, P.C.; Stromblad, S.; Klemke, R.; Visscher, D.; Sarkar, F.H.; 
Cheresh, D.A. Antiintegrin alpha-v-beta-3 blocks human breast-cancer growth and angiogenesis in human skin. J. Clin. Invest., 1995, 96(4), 18151822 .

[187] Feldinghabermann, B.; Mueller, B.M.; Romerdahl, C.A.; Cheresh, D.A. Involvement of integrin alpha-v gene-expression in human-melanoma tumorigenicity. J. Clin. Invest., 1992, 89(6), 2018-2022.

[188] Brooks, P.C.; Montgomery, A.M.P.; Rosenfeld, M.; Reisfeld, R.A.; Hu, T.H.; Klier, G.; Cheresh, D.A. Integrin alpha(v)beta(3) antagonists promote tumor-regression by inducing apoptosis of angiogenic blood-vessels. Cell, 1994, 79(7), 1157-1164.

[189] Wagner, S.; Rothweiler, F.; Anhorn, M.G.; Sauer, D.; Riemann, I.; Weiss, E.C.; Katsen-Globa, A.; Michaelis, M.; Cinatl, J.; Schwartz, D.; Kreuter, J.; von Briesen, H.; Langer, K. Enhanced drug targeting by attachment of an anti alpha $\mathrm{v}$ integrin antibody to doxorubicin loaded human serum albumin nanoparticles. Biomaterials, 2010, 31(8), 2388-2398.

[190] Osborn, L.; Hession, C.; Tizard, R.; Vassallo, C.; Luhowskyj, S.; Chirosso, G.; Lobb, R. Direct expression cloning of vascular cell-adhesion molecule-1, a cytokine-induced endothelial protein that binds to lymphocytes. Cell, 1989, 59(6), 1203-1211

[191] Tsourkas, A.; Shinde-Patil, V.R.; Kelly, K.A.; Patel, P.; Wolley, A.; Allport, J.R.; Weissleder, R. In vivo imaging of activated endothelium using an antiVCAM-1 magnetooptical probe. Bioconjug. Chem., 2005, 16(3), 576-581.

[192] Gosk, S.; Moos, T.; Gottstein, C.; Bendas, G. VCAM-1 directed immunoliposomes selectively target tumor vasculature in vivo. Biochim. Biophys. Acta, 2008, 1778(4), 854-863.

[193] Genis, L.; Galvez, B.G.; Gonzalo, P.; Arroyo, A.G. MT1-MMP: universal or particular player in angiogenesis? Cancer Metastasis Rev., 2006, 25(1), 7786 .

[194] Kondo, M.; Asai, T.; Katanasaka, Y.; Sadzuka, Y.; Tsukada, H.; Ogino, K.; Taki, T.; Baba, K.; Oku, N. Anti-neovascular therapy by liposomal drug targeted to membrane type-1 matrix metalloproteinase. Int. J. Cancer, 2004, $108(2), 301-306$

[195] Sato, H.; Takino, T.; Miyamori, H. Roles of membrane-type matrix metalloproteinase-1 in tumor invasion and etastasis. Cancer Sci., 2005, 96(4), 212-217.

[196] Yana, I.; Seiki, M. MT-MMPs play pivotal roles in cancer dissemination. Clin. Exp. Metastasis, 2002, 19(3), 209-215.

[197] Laskin, J.J.; Sandier, A.B. Epidermal growth factor receptor: a promising target in solid tumours. Cancer Treat. Rev., 2004, 30(1), 1-17.

[198] Harries, M.; Smith, I. The development and clinical use of trastuzumab (Herceptin). Endocr. Relat. Cancer, 2002, 9(2), 75-85.

[199] Sun, B.; Feng, S.S. Trastuzumab-functionalized nanoparticles of biodegradable copolymers for targeted delivery of docetaxel. Nanomedicine, 2009, 4(4), 431-445.

[200] Anhorn, M.G.; Wagner, S.; Kreuter, J.; Langer, K.; Von Briesen, H. Specific targeting of HER2 overexpressing breast cancer cells with doxorubicinloaded trastuzumab-modified human serum albumin nanoparticles. Bioconjug. Chem., 2008, $19(12), 2321-2331$.

[201] Cirstoiu-Hapca, A.; Bossy-Nobs, L.; Buchegger, F.; Gurny, R.; Delie, F. Differential tumor cell targeting of anti-HER2 (Herceptin (R)) and antiCD20 (Mabthera (R)) coupled nanoparticles. Int. J. Pharm., 2007, 331(2), 190-196.

[202] Kocbek, P.; Obermajer, N.; Cegnar, M.; Kos, J.; Kristl, J. Targeting cancer cells using PLGA nanoparticles surface modified with monoclonal antibody. J. Control. Release, 2007, 120(1-2), 18-26.

[203] Chen, H.W.; Gao, J.; Lu, Y.; Kou, G.; Zhang, H.; Fan, L.; Sun, Z.G.; Guo, Y.J.; Zhong, Y.Q. Preparation and characterization of PE38KDEL-loaded anti-HER2 nanoparticles for targeted cancer therapy. J. Control. Release, 2008, 128(3), 209-216.

[204] Sun, B.; Ranganathan, B.; Feng, S.S. Multifunctional poly(D,L-lactide-coglycolide)/montmorillonite (PLGA/MMT) nanoparticles decorated by Trastuzumab for targeted chemotherapy of breast cancer. Biomaterials, 2008, 29(4), 475-486.

[205] Liu, Y.T.; Li, K.; Liu, B.; Feng, S.S. A strategy for precision engineering of nanoparticles of biodegradable copolymers for quantitative control of targeted drug delivery. Biomaterials, 2010, 31(35), 9145-9155.

[206] Singh, M. Transferrin as a targeting ligand for liposomes and anticancer drugs. Curr. Pharm. Des., 1999, 5(6), 443-451.

[207] Xu, L.; Huang, C.C.; Huang, W.Q.; Tang, W.H.; Rait, A.; Yin, Y.Z.; Cruz, I.; Xiang, L.M.; Pirollo, K.F.; Chang, E.H. Systemic tumor-targeted gene delivery by anti-transferrin receptor scFv-immunoliposomes. Mol. Cancer Ther, 2002, 1(5), 337-346.

[208] Barth, B.M.; Sharma, R.; Altinoglu, E.I.; Morgan, T.T.; Shanmugavelandy, S.S.; Kaiser, J.M.; McGovern, C.; Matters, G.L.; Smith, J.P.; Kester, M.; Adair, J.H. Bioconjugation of calcium phosphosilicate composite nanoparticles for selective targeting of human breast and pancreatic cancers in vivo. ACS Nano, 2010, 4(3), 1279-87.

[209] Siegel, R.; Ward, E.; Brawley, O.; Jemal, A.J. Cancer statistics, 2011: the impact of eliminating socioeconomic and racial disparities on premature cancer deaths. CA Cancer J. Clin., 2011, 61(4), 212-236.

[210] Slamon, D.J.; Clark, G.M.; Wong, S.G.; Levin, W.J.; Ullrich, A.; McGuire, W.L. Human-breast cancer - correlation of relapse and survival with amplification of the her-2 neu oncogene. Science, 1987, 235(4785), 177-182.

[211] World Health Organization. Globocan Programme. http://www.globocan.iarc.fr (accessed August 4, 2011).
[212] Azarmi, S.; Roa, W.H.; Loebenberg, R. Targeted delivery of nanoparticles for the treatment of lung diseases. Adv. Drug Deliv. Rev., 2008, 60(8), 863875.

[213] Woodward, J.D.; Kennel, S.J.; Mirzadeh, S.; Dai, S.; Wall, J.S.; Richey, T; Avenell, J.; Rondinone, A.J. In vivo SPECT/CT imaging and biodistribution using radioactive (CdTe)-Te-125m/ZnS nanoparticles. Nanotechnology, 2007, 18(17), 5 pp

[214] Debotton, N.; Zer, H.; Parnes, M.; Harush-Frenkel, O.; Kadouche, J.; Benita, $\mathrm{S}$. A quantitative evaluation of the molecular binding affinity between a monoclonal antibody conjugated to a nanoparticle and an antigen by surface plasmon resonance. Eur. J. Pharm. Biopharm. 2010, 74(2), 148-156.

[215] Muro, S.; Muzykantov, V. R. Targeting of antioxidant and anti-thrombotic drugs to endothelial cell adhesion molecules. Curr. Pharm. Des., 2005 , 11(18), 2383-2401.

[216] Rossin, R.; Muro, S.; Welch, M.J.; Muzykantov, V.R.; Schuster, D.P. In vivo imaging of $\mathrm{Cu}-64$-labeled polymer nanoparticles targeted to the lung endothelium. J. Nucl. Med., 2008, 49(1), 103-111.

[217] Kou, G.; Gao, J.; Wang, H.; Chen, H.W.; Li, B.H.; Zhang, D.P.; Wang, S.H; Hou, S.; Qian, W.Z.; Dai, J.X.; Zhong, Y.Q.; Guo, Y.J. Preparation and characterization of paclitaxel-loaded PLGA nanoparticles coated with cationic SM5-1 single-chain antibody. J. Biochem. Mol. Biol., 2007, 40(5), 731-739.

[218] Sultana, A.; Smith, C.T.; Cunningham, D.; Starling, N.; Tait, D.; Neoptolemos, J.P.; Ghaneh, P. Systematic review, including meta-analyses, on the management of locally advanced pancreatic cancer using radiation/combined modality therapy. Br. J. Cancer, 2007, 96(8), 1183-1190.

[219] Yu, X.J.; Zhang, Y.Q.; Chen, C.Y.; Yao, Q.Z.; Li, M. Targeted drug delivery in pancreatic cancer. Biochim. Biophys. Acta, 2010, 1805(1), 97-104.

[220] Bruckner, H.W.; Hrehorovich, V.R.; Sawhney, H.S. Bevacizumab as treatment for chemotherapy-resistant pancreatic cancer. Anticancer Res. 2005, 25(5), 3637-3639.

[2221] Li, M.; Bharadwaj, U.; Zhang, R.X.; Zhang, S.; Mu, H.; Fisher, W.E.; Brunicardi, F.C.; Chen, C.Y.; Yao, Q.Z. Mesothelin is a malignant factor and therapeutic vaccine target for pancreatic cancer. Mol. Cancer Ther., 2008, 7(2), 286-296

[222] Hassan, R.; Bullock, S.; Premkumar, A.; Kreitman, R.J.; Kindler, H.; Willingham, M.C.; Pastan, I. Phase I study of SS1P a recombinant antimesothelin immunotoxin given as a bolus IV infusion to patients with mesothelin-expressing mesothelioma, ovarian, and pancreatic cancers. Clin. Cancer Res., 2007, 13(17), 5144-5149.

[223] Ona, F.V.; Zamcheck, N.; Dhar, P.; Moore, T.; Kupchik, H.Z. Carcinoembryonic antigen (cea) in diagnosis of pancreatic cancer. Cancer, 1973, 3I(2), 324-327.

[224] Hu, C.M.J.; Kaushal, S.; Cao, H.S.T.; Aryal, S.; Sartor, M.; Esener, S.; Bouvet, M.; Zhang, L.F. Half-antibody functionalized lipid-polymer hybrid nanoparticles for targeted drug delivery to carcinoembryonic antigen presenting pancreatic cancer cells. Mol. Pharm., 2010, 7(3), 914-920.

[225] Jelinkova, M.; Strohalm, J.; Etrych, T.; Ulbrich, K.; Rihova, B. Starlike vs. classic macromolecular prodrugs: two different antibody-targeted HPMA copolymers of doxorubicin studied in vitro and in vivo as potential anticancer drugs. Pharm. Res., 2003, 20(10), 1558-1564.

[226] Fay, F.; McLaughlin, K.M.; Small, D.M.; Fennell, D.A.; Johnston, P.G.; Longley, D.B.; Scott, C.J. Conatumumab (AMG 655) coated nanoparticles for targeted pro-apoptotic drug delivery. Biomaterials, 2011, 32(33), 8645 53

[227] Gerber, H.P.; Ferrara, N. The role of VEGF in normal and neoplastic hematopoiesis. J. Mol. Med. (Berl), 2003, 81(1), 20-31.

[228] Griffin, J.D.; Linch, D.; Sabbath, K.; Larcom, P.; Schlossman, S.F. A monoclonal-antibody reactive with normal and leukemic human myeloid progenitor cells. Leuk. Res., 1984, 8(4), 521-534.

[229] Bicho, A.; Peca, I.; Roque, A.; Cardoso, M.M. Anti-CD8 conjugated nanoparticles to target mammalian cells expressing CD8. Int. J. Pharm., 2010, 399(1-2), 80-86.

[230] Gururangan, S.; Friedman, H.S. Innovations in design and delivery of chemotherapy for brain tumors. Neuroimaging Clin. N. Am., 2002, 12(4), 583-597.

[231] Pardridge, W.M. Blood-brain barrier carrier-mediated transport and brain metabolism of amino acids. Neurochem. Res., 1998, 23(5), 635-644

[232] Engelhardt, B.; Sorokin, L. The blood-brain and the blood-cerebrospinal fluid barriers: function and dysfunction. Semin. Immunopathol., 2009, 31(4), 497-511.

[233] Saito, Y.; Wright, E.M. Bicarbonate transport across the frog choroid-plexus and its control by cyclic-nucleotides. J. Physiol., 1983, 336(MAR), 635-648.

[234] Pardridge, W.M. Drug delivery to the brain. J. Cereb. Blood Flow Metab., 1997, 17(7), 713-731.

[235] Golden, P.L.; Pollack, G.M. Blood-brain barrier efflux transport. J. Pharm. Sci., 2003, 92(9), 1739-1753.

[236] Pardridge, W.M. Blood-brain barrier delivery. Drug Discov. Today, 2007, 12(1-2), 54-61.

[237] DiMeco, F.; Li, K.W.; Tyler, B.M.; Wolf, A.S.; Brem, H.; Olivi, A. Local delivery of mitoxantrone for the treatment of malignant brain tumors in rats. J. Neurosurg., 2002, 97(5), 1173-1178.

[238] Lesniak, M.S.; Upadhyay, U.; Goodwin, R.; Tyler, B; Brem, H. Loca delivery of doxorubicin for the treatment of malignant brain tumors in rats. Anticancer Res., 2005, 25(6B), 3825-3831. 
[239] Westphal, M.; Hilt, D.C.; Bortey, E.; Delavault, P.; Olivares, R.; Warnke, P.C.; Whittle, I.R.; Jaaskelainen, J.; Ram, Z. A phase 3 trial of local chemotherapy with biodegradable carmustine (BCNU) wafers (Gliadel wafers) in patients with primary malignant glioma. Neuro Oncol., 2003, 5(2), 79-88.

[240] Pardridge, W.M. Non-invasive drug delivery to the human brain using endogenous blood-brain barrier transport systems. Pharm. Sci. Technolo. Today, 1999, 2(2), 49-59.

[241] Sinkula, A.A.; Yalkowsky, S.H. Rationale for design of biologically reversible drug derivatives - prodrugs. J. Pharm. Sci., 1975, 64(2), 181-210.

[242] Cosolo, W.C.; Martinello, P.; Louis, W.J.; Christophidis, N. Blood-brainbarrier disruption using mannitol - time course and electron-microscopy studies. Am. J. Physiol., 1989, 256(2), R443-R447.

[243] Cloughesy, T.F.; Black, K.L. Pharmacological blood-brain barrier modification for selective drug delivery. J. Neurooncol., 1995, 26(2), 125132 .

[244] Agarwal, A.; Lariya, N.; Saraogi, G.; Dubey, N.; Agrawal, H.; Agrawal, G.P. Nanoparticles as novel carrier for brain delivery: a review. Curr. Pharm. Des., 2009, 15(8), 917-925.

[245] Alam, M.I.; Beg, S.; Samad, A.; Baboota, S.; Kohli, K.; Ali, J.; Ahuja, A.; Akbar, M. Strategy for effective brain drug delivery. Eur. J. Pharm. Sci., 2010, 40(5), 385-403.

[246] Misra, A.; Ganesh, S.; Shahiwala, A.; Shah, S.P. Drug delivery to the central nervous system: a review. J. Pharm. Pharm. Sci., 2003, 6(2), 252-273.

[247] Gao, X.; Chen, J.; Tao, W.; Zhu, J.; Zhang, Q.; Chen, H.; Jiang, X. UEA Ibearing nanoparticles for brain delivery following intranasal administration. Int. J. Pharm., 2007, 340(1-2), 207-215.

[248] Kreuter, J.; Ramge, P.; Petrov, V.; Hamm, S.; Gelperina, S.E.; Engelhardt, B.; Alyautdin, R.; Von Briesen, H.; Begley, D.J. Direct evidence that polysorbate-80-coated poly( butylcyanoacrylate) nanoparticles deliver drugs to the CNS via specific mechanisms requiring prior binding of drug to the nanoparticles. Pharm. Res., 2003, 20(3), 409-416.

[249] Steiniger, S.C.J.; Kreuter, J.; Khalansky, A.S.; Skidan, I.N.; Bobruskin, A.I.; Smirnova, Z.S.; Severin, S.E.; Uhl, R.; Kock, M.; Geiger, K.D.; Gelperina, S.E. Chemotherapy of glioblastoma in rats using doxorubicin-loaded nanoparticles. Int. J. Cancer, 2004, 109(5), 759-767.

[250] Petri, B.; Bootz, A.; Khalansky, A.; Hekmatara, T.; Mueller, R.; Uhl, R.; Kreuter, J.; Gelperina, S. Chemotherapy of brain turnour using doxorubicin bound to surfactant-coated poly(butyl cyanoacrylate) nanoparticles: revisiting the role of surfactants. J. Control. Release, 2007, 117, 51-58.

[251] Schafer, V.; Vonbriesen, H.; Andreesen, R.; Steffan, A.M.; Royer, C.; Troster, S.; Kreuter, J.; Rubsamenwaigmann, H. Phagocytosis of nanoparticles by human-immunodeficiency-virus (hiv)-infected macrophages - a possibility for antiviral drug targeting. Pharm. Res., 1992, 9(4), 541-546.

[252] Kreuter, J. In: Nanoparticles as Drug Carriers; Imperial College Press: London, 2006; pp. 527-547.

[253] Allen, D.D.; Geldenhuys, W.J. Molecular modeling of blood-brain barrier nutrient transporters: in silico basis for evaluation of potential drug delivery to the central nervous system. Life Sci., 2006, 78(10), 1029-1033.

[254] Nagasawa, K.; Ito, S.; Kakuda, T.; Nagai, K.; Tamai, I.; Tsuji, A.; Fujimoto, S. Transport mechanism for aluminum citrate at the blood-brain barrier: kinetic evidence implies involvement of system Xc(-) immortalized rat brain endothelial cells. Toxicol. Lett., 2005, 155(2), 289-296.

[255] Bickel, U.; Yoshikawa, T.; Pardridge, W.M. Delivery of peptides and proteins through the blood-brain barrier. Adv. Drug Deliv. Rev., 2001, 46(13), 247-279.

[256] Pardridge, W.M.; Eisenberg, J.; Yang, J. Human blood-brain-barrier insulinreceptor. J. Neurochem., 1985, 44(6), 1771-1778.

[257] Pardridge, W.M.; Eisenberg, J.; Jing, Y. Human blood-brain-barrier transferrin receptor. Metabolism, 1987, 36(9), 892-895.

[258] Triguero, D.; Buciak, J.B.; Yang, J.; Pardridge, W.M. Blood-brain-barrier transport of cationized immunoglobulin-g - enhanced delivery compared to native protein. Proceedings of the National Academy of Sciences of the United States of America, 1989, 86(12), 4761-4765.

[259] Pardridge, W.M.; Triguero, D.; Buciak, J.; Yang, J. Evaluation of cationized rat albumin as a potential blood-brain-barrier drug transport vector. $J$. Pharmacol. Exp. Ther., 1990, 255(2), 893-899.

[260] Jefferies, W.A.; Brandon, M.R.; Hunt, S.V.; Williams, A.F.; Gatter, K.C.; Mason, D.Y. transferrin receptor on endothelium of brain capillaries. Nature, 1984, 312 (5990), 162-163.

[261] Hall, W.A. Transferrin receptor on glioblastoma-multiforme. J. Neurosurg., 1991, 74(2), 313-314.

[262] Zhang, Y.; Lee, H.J.; Boado, R.J.; Pardridge, W.M. Receptor-mediated delivery of an antisense gene to human brain cancer cells. J. Gene Med., 2002, 4(2), 183-194.

[263] Podlecki, D.A.; Smith, R.M.; Kao, M.; Tsai, P.; Huecksteadt, T.; Brandenburg, D.; Lasher, R.S.; Jarett, L.; Olefsky, J.M. Nuclear translocation of the insulin-receptor - a possible mediator of insulins long-term effects. $J$. Biol. Chem., 1987, 262(7), 3362-3368.

[264] Pardridge, W.M.; Buciak, J.L.; Friden, P.M. Selective transport of an antitransferrin receptor antibody through the blood-brain-barrier invivo. $J$. Pharmacol. Exp. Ther, 1991, 259(1), 66-70.

[265] Huwyler, J.; Yang, J.; Pardridge, W.M. Receptor mediated delivery of daunomycin using immunoliposomes: pharmacokinetics and tissue distribution in the rat. J. Pharmacol. Exp. Ther., 1997, 282(3), 1541-1546.
[266] Schnyder, A.; Krahenbuhl, S.; Torok, M.; Drewe, J.; Huwyler, J. Targeting of skeletal muscle in vitro using biotinylated immunoliposomes. Biochem. J., 2004, 377(1), 61-67.

[267] Sauter, G.; Maeda, T.; Waldman, F.M.; Davis, R.L.; Feuerstein, B.G Patterns of epidermal growth factor receptor amplification in malignant gliomas. Am. J. Pathol., 1996, 148(4), 1047-1053.

[268] Olivier, J.C.; Huertas, R.; Lee, H.J.; Calon, F.; Pardridge, W.M. Synthesis of pegylated immunonanoparticles. Pharm. Res., 2002, 19(8), 1137-1143.

[269] Ulbrich, K.; Hekmatara, T.; Herbert, E.; Kreuter, J. Transferrin- and transferrin-receptor-antibody-modified nanoparticles enable drug delivery across the blood-brain barrier (BBB). Eur. J. Pharm. Biopharm., 2009, 71(2), 251-256.

[270] Tsutsui, Y.; Tomizawa, K.; Nagita, M.; Michiue, H.; Nishiki, T.; Ohmori, I.; Seno, M.; Matsui, H. Development of bionanocapsules targeting brain tumors. J. Control. Release, 2007, 122(2), 159-164.

[271] Ulbrich, W.; Lamprecht, A. Targeted drug-delivery approaches by nanoparticulate carriers in the therapy of inflammatory diseases. J. R. Soc. Interface, 2010, 7(1), S55-S66.

[272] Turner, N.C.; Wright, N.A. In: Oxford Textbook of Pathology; Oxford University Press Eds.: Oxford, 1992; pp. 351-390.

[273] Boerman, O.C.; Oyen, W.J.G.; Storm, G.; Corvo, M.L.; vanBloois, L; vanderMeer, J.W.M.; Corstens, F.H.M. Technetium-99m labelled liposomes to image experimental arthritis. Ann. Rheum. Dis., 1997, 56(6), 369-373.

[274] Boerman, O.C.; Oyen, W.J.G.; vanBloois, L.; Koenders, E.B.; vanderMeer, J.W.M.; Corstens, F.H.M.; Storm, G. Optimization of technetium-99mlabeled PEG liposomes to image focal infection: effects of particle size and circulation time. J. Nucl. Med., 1997, 38(3), 489-493.

[275] Dams, E.T.M.; Oyen, W.J.G.; Boerman, O.C.; Storm, G.; Laverman, P. Koenders, E.B.; van der Meer, J.W.M.; Corstens, F.H.M. Technetium-99mlabeled liposomes to image experimental colitis in rabbits: Comparison with technetium-99m-HMPAO-granulocytes and technetium-99m-HYNIC-IgG. $J$ Nucl. Med., 1998, 39(12), 2172-2178.

[276] Dams, E.T.M.; Becker, M.J.; Oyen, W.J.G.; Boerman, O.C.; Storm, G.; Laverman, P.; de Marie, S.; van der Meer, J.W.M.; Bakker-Woudenberg, I.; Corstens, F.H.M. Scintigraphic imaging of bacterial and fungal infection in granulocytopenic rats. J. Nucl. Med., 1999, 40(12), 2066-2072.

[277] Dams, E.T.M.; Oyen, W.J.G.; Boerman, O.C.; Storm, G.; Laverman, P.; Kok, P.J.M.; Buijs, W.; Bakker, H.; van der Meer, J.W.M.; Corstens, F.H.M. Tc-99m-PEG liposomes for the scintigraphic detection of infection and inflammation clinical evaluation. J. Nucl. Med., 2000, 41(4), 622-630.

[278] Simone, E.; Ding, B.-S.; Muzykantov, V. Targeted delivery of therapeutics to endothelium. Cell Tissue Res., 2009, 335(1), 283-300.

[279] Pober, J.S.; Cotran, R.S.The role of endothelial-cells in inflammation. Transplantation, 1990, 50(4), 537-544.

[280] Chellat, F.; Merhi, Y.; Moreau, A.; Yahia, L. Therapeutic potential of nanoparticulate systems for macrophage targeting. Biomaterials, 2005, 26(35), 7260-7275.

[281] Misko, T.P.; Trotter, J.L.; Cross, A.H. Mediation of inflammation by encephalitogenic cells - interferon-gamma induction of nitric-oxide synthase and cyclooxygenase-2. J. Neuroimmunol., 1995, 61(2), 195-204.

[282] Benveniste, E.N. Role of macrophages/microglia in multiple sclerosis and experimental allergic encephalomyelitis. J. Mol. Med. (Berl), 1997, 75(3), 165-173.

[283] Koch, A.E.; Burrows, J.C.; Haines, G.K.; Carlos, T.M.; Harlan, J.M.; Leibovich, S.J. Immunolocalization of endothelial and leukocyte adhesion molecules in human rheumatoid and osteoarthritic synovial tissues. Lab Invest., 1991, 64(3), 313-320.

[284] Jones, S.P.; Trocha, S.D.; Strange, M.B.; Granger, D.N.; Kevil, C.G.; Bullard, D.C.; Lefer, D.J. Leukocyte and endothelial cell adhesion molecules in a chronic murine model of myocardial reperfusion injury. Am. J. Physiol. Heart Circ. Physiol., 2000, 279(5), H2196-H2201.

[285] Malizia, G.; Calabrese, A.; Cottone, M.; Raimondo, M.; Treidosiewicz, L.K.; Smart, C.J.; Oliva, L.; Pagliaro, L. Expression of leukocyte adhesion molecules by mucosal mononuclear phagocytes in inflammatory boweldisease. Gastroenterology, 1991, 100(1), 150-159.

[286] Wegner, C.D.; Gundel, R.H.; Reilly, P.; Haynes, N.; Letts, L.G.; Rothlein, R. Intercellular-adhesion molecule-1 (icam-1) in the pathogenesis of asthma. Science, 1990, 247(4941), 456-459.

[287] Forrest, M.J.; Eiermann, G.J.; Meurer, R.; Walakovits, L.A.; Macintyre, D.E. The role of cd18 in il-8 induced dermal and synovial inflammation. $\mathrm{Br} . J$. Pharmacol., 1992, 106(2), 287-294.

[288] Gundel, R.H.; Wegner, C.D.; Torcellini, C.A.; Clarke, C.C.; Haynes, N.; Rothlein, R.; Smith, C.W.; Letts, L.G. Endothelial leukocyte adhesion molecule-1 mediates antigen-induced acute airway inflammation and latephase airway-obstruction in monkeys. J. Clin. Invest., 1991, 88(4), 1407 1411.

[289] Gundel, R. H.; Wegner, C.D.; Torcellini, C.A.; Letts, L.G. The role of intercellular-adhesion molecule-1 in chronic airway inflammation. Clin. Exp. Allergy, 1992, 22(5), 569-575.

[290] Weg, V.B.; Williams, T.J.; Lobb, R.R.; Nourshargh, S. A monoclonalantibody recognizing very late activation antigen-4 inhibits eosinophil accumulation invivo. J. Exp. Med., 1993, 177(2), 561-566.

[291] Uwatoku, T.; Shimokawa, H.; Abe, K.; Matsumoto, Y.; Hattori, T.; Oi, K. Matsuda, T.; Kataoka, K.; Takeshita, A. Application of nanoparticle technology for the prevention of restenosis after balloon injury in rats. Circ. 
Res., 2003, 92(7), E62-E69.

[292] Kolodgie, F.D.; John, M.; Khurana, C.; Farb, A.; Wilson, P.S.; Acampado, E.; Desai, N.; Soon-Shiong, P.; Virmani, R. Sustained reduction of in-stent neointimal growth with the use of a novel systemic nanoparticle paclitaxel. Circulation, 2002, 106(10), 1195-1198.

[293] Richards, P.J.; Williams, B.D.; Williams, A.S. Suppression of chronic streptococcal cell wall-induced arthritis in Lewis rats by liposomal clodronate. Rheumatology, 2001, 40(9), 978-987.

[294] Ishihara, T.; Kubota, T.; Choi, T.; Higaki, M. Treatment of experimental arthritis with stealth-type polymeric nanoparticles encapsulating betamethasone phosphate. J. Pharmacol. Exp. Ther, 2009, 329(2), 412-417.

[295] Huitinga, I.; Vanrooijen, N.; Degroot, C.J.A.; Uitdehaag, B.M.J.; Dijkstra, C.D. Suppression of experimental allergic encephalomyelitis in lewis rats after elimination of macrophages. J. Exp. Med., 1990, 172(4), 1025-1033.

[296] Bauer, J.; Huitinga, I.; Zhao, W.G.; Lassmann, H.; Hickey, W.F.; Dijkstra, C.D. The role of macrophages, perivascular cells, and microglial cells in the pathogenesis of experimental autoimmune encephalomyelitis. Glia, 1995, 15(4), 437-446

[297] Calvo, P.; Gouritin, B.; Villarroya, H.; Eclancher, F.; Giannavola, C.; Klein, C.; Andreux, J.P.; Couvreur, P. Quantification and localization of PEGylated polycyanoacrylate nanoparticles in brain and spinal cord during experimental allergic encephalomyelitis in the rat. Eur. J. Neurosci., 2002, 15(8), 13171326.

[298] Cavaletti, G.; Cassetti, A.; Canta, A.; Galbiati, S.; Gilardini, A.; Oggioni, N.; Rodriguez-Menendez, V.; Fasano, A.; Liuzzi, G. M.; Fattler, U.; Ries, S.; Nieland, J.; Riccio, P.; Haas, H. Cationic liposomes target sites of acute neuroinflammation in experimental autoimmune encephalomyelitis. Mol. Pharm., 2009, 6(5), 1363-1370.

[299] Linker, R.A.; Weller, C.; Luehder, F.; Mohr, A.; Schmidt, J.; Knauth, M.; Metselaar, J.M.; Gold, R. Liposomal glucocorticosteroids in treatment of chronic autoimmune demyelination: long-term protective effects and enhanced efficacy of methylprednisolone formulations. Exp. Neurol., 2008, 211(2), 397-406.

[300] Schmidt, J.; Metselaar, J.M.; Wauben, M.H.M.; Toyka, K.V.; Storm, G.; Gold, R. Drug targeting by long-circulating liposomal glucocorticosteroids increases therapeutic efficacy in a model of multiple sclerosis. Brain, 2003, 126(8), 1895-1904.

[301] Muro, S.; Gajewski, C.; Koval, M.; Muzykantov, V.R. ICAM-1 recycling in endothelial cells: a novel pathway for sustained intracellular delivery and prolonged effects of drugs. Blood, 2005, 105(2), 650-658.

[302] Muro, S.; Wiewrodt, R.; Thomas, A.; Koniaris, L.; Albelda, S.M.; Muzykantov, V.R.; Koval, M. A novel endocytic pathway induced by clustering endothelial ICAM-1 or PECAM-1. J. Cell Sci., 2003, 116(8), 1599-1609.

[303] Asgeirdottir, S.A.; Zwiers, P.J.; Morselt, H.W.; Moorlag, H.E.; Bakker, H.I.; Heeringa, P.; Kok, J.W.; Kallenberg, C.G.M.; Molema, G.; Kamps, J.A.A.M. Inhibition of proinflammatory genes in anti-GBM glomerulonephritis by targeted dexamethasone-loaded Ab(Esel) liposomes. Am. J. Physiol. Renal Physiol., 2008, 294(3), F554-F561.

[304] Bender, A.; Schafer, V.; Steffan, A.M.; Royer, C.; Kreuter, J.; Rubsamenwaigmann, H.; Vonbriesen, H. Inhibition of hiv in-vitro by antiviral drug-targeting using nanoparticles. Res. Virol., 1994, 145(3-4), 215 220.

[305] Bender, A.R.; vonBriesen, H.; Kreuter, J.; Duncan, I.B.; RubsamenWaigmann, H. Efficiency of nanoparticles as a carrier system for antiviral agents in human immunodeficiency virus-infected human monocytes/macrophages in vitro. Antimicrob. Agents Chemother, 1996, 40(6), 1467-1471.

[306] Cohen, O.J.; Pantaleo, G.; Lam, G.K.; Fauci, A.S. Studies on lymphoid tissue from HIV-infected individuals: implications for the design of therapeutic strategies. Springer Semin. Immunopathol., 1997, 18(3), 305-322.

[307] Arthur, L.O.; Bess, J.W.; Sowder, R.C.; Benveniste, R.E.; Mann, D.L.; Chermann, J.C.; Henderson, L.E. Cellular proteins bound to immunodeficiency viruses - implications for pathogenesis and vaccines. Science, 1992, 258(5090), 1935-1938.

[308] Schapira, A.; Beales, P.; Halloran, M. Malaria - living with drug-resistance. Parasitol. Today, 1993, 9(5), 168-174.

[309] Santos-Magalhaes, N.S.; Mosqueira, V.C.F. Nanotechnology applied to the treatment of malaria. Adv. Drug Deliv. Rev., 2010, 62(4-5), 560-575.

[310] Singhal, A.; Gupta, C. Antibody-mediated targeting of liposomes to red-cells in vivo. FEBS Lett., 1986, 201(2), 321-326.

[311] Agrawal, A.; Gupta, C. Tuftsin-bearing liposomes in treatment of macrophage-based infections. Adv. Drug Deliv. Rev., 2000, 4l(2), 135-146.

[312] Murciano, J.C.; Muro, S.; Koniaris, L.; Christofidou-Solomiclou, M.; Harshaw, D.W.; Albelda, S.M.; Granger, D.N.; Cines, D.B.; Muzykantov, V.R. ICAM-directed vascular immunotargeting of antithrombotic agents to the endothelial luminal surface. Blood, 2003, 101(10), 3977-3984.

[313] Wiewrodt, R.; Thomas, A.P.; Cipelletti, L.; Christofidou-Solomidou, M.; Weitz, D.A.; Feinstein, S.I.; Schaffer, D.; Albelda, S.M.; Koval, M.; Muzykantov, V.R. Size-dependent intracellular immunotargeting of therapeutic cargoes into endothelial cells. Blood, 2002, 99(3), 912-922.

[314] Yurko, Y.; Maximov, V.; Andreozzi, E.; Thompson, G.L.; Vertegel, A.A. Design of biomedical nanodevices for dissolution of blood clots. Mater. Sci. Eng. C Biomimetic Supramol. Syst., 2009, 29(3), 737-741. 